Temporary Contemporary

Creating vibrant spaces to support the conditions for creative and cultural activity 


\section{Temporary Contemporary}

\section{Creating vibrant spaces to support the conditions for creative and cultural activity}


Copyright (C) 2020 University of Huddersfield

Published by University of Huddersfield

The University of Huddersfield

Queensgate

Huddersfield HD13DH

Email enquiries university.press@hud.ac.uk

First published 2020

Except otherwise noted, this publication is (c) 2020 the Authors, under a Creative Commons Attribution licence: http://creativecommons.org/licenses/by/3.0/

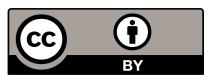

Every effort has been made to locate copyright holders of materials included and to obtain permission for their publication.

The publisher is not responsible for the continued existence and accuracy of websites referenced in the text.

A CIP catalogue record for this book is available from the British Library. ISBN: 978-86218-174-8

e-ISBN: 978-1-86218-1755

Editors: Dr Rowan Bailey, Professor Nic Clear, Professor Donal Fitzpatrick, Dr Linda Jean Pittwood and Dr Anna Powell.

Design: A.N.D. Studio, www.and-studio.co.uk

Printed by: Team Impression, Leeds, United Kingdom.

Photography: special thanks to Laura Mateescu, images reproduced courtesy of the artists. 


\section{Contents}

6-9 Preface

10-19 Introduction

20-39 Chapter One

Action Research and Place-based Making

Dr Rowan Bailey

Putting Space into Action Through Art

Action Research

Place-based making out in the field

Curatorial Action Research - rethinking place

$40-51 \quad$ Chapter Two

Mixed Cultural Ecologies

By Professor Donal Fitzpatrick

Cultural ecology

Exhibitions in the ecosystem

The cellular oganism

52-67 Chapter Three

Looking is Contingent on the Apparatus of Viewing

By Dr Anna Powell \& Dr Linda Jean Pittwood

Representation and the politics of looking

Reconstructed memories

Memorialisation and monuments

68-81 Chapter Four

Designing Curation - The Exhibition in Art, Design and Architecture

By Professor Nic Clear

The Exhibition as a Site of Privilege

The Exhibition and its Social Function

The Exhibition in Teaching and Research

The Exhibition as Case Study

Exhibitions - a conclusion

$82-91 \quad$ Conclusion

92-96 Acknowledgements 


\section{Exhibition List}

6-14

April 2018

10-29

September 2018

11-27

October 2018

7-21

December 2018

7-21

December 2018

10-26

January 2019

$10-26$

January 2019

31 January

-4 March 2019

13 March

-6 April 2019

13 March

-6 April 2019

15 April

-3 May 2019

15 April

-3 May 2019

18 May

-1 June 2019

14-21

June 2019
Place, Space, Action

Dr Rowan Bailey

Black Bag

Ryan Durrant

Showgirl Manifesto

Dr Alison J Carr

Uncanny Valley

Nick Deakin

Flood

Richard Mulhearn

A Proposal for a Monument for Carl Einstein Dr Dale Holmes

Empire of Memory

Garry Clarkson

Synthetic Spaces

Professor Nic Clear and Hyun Jun Park

Temporary Tactical Urbanism

Drloanni Delsante

What's this Dull Town to Me?

Andrew Taylor and Katrina Whitehead

Nocturne

Dr Stella Baraklianou

Making Material Memories

Charlotte Goldthorpe

Situating Practices

Claire Booth-Kurpnieks

Bigfoot in West Belfast

Dr Liam Devlin 
14 June

-21 June 2019

24 June

-13 July 2019

24 June

-13 July 2019
Photography and Lived Experience

Alex Beldea, Thomas Duffield, Tim Brown, Sam Welburn and Simon Weldon

The Laundry Pile

Dr Jade Lord, Emma Rigby and Lizzie Harrison

Quilting Together

Nicola Perren

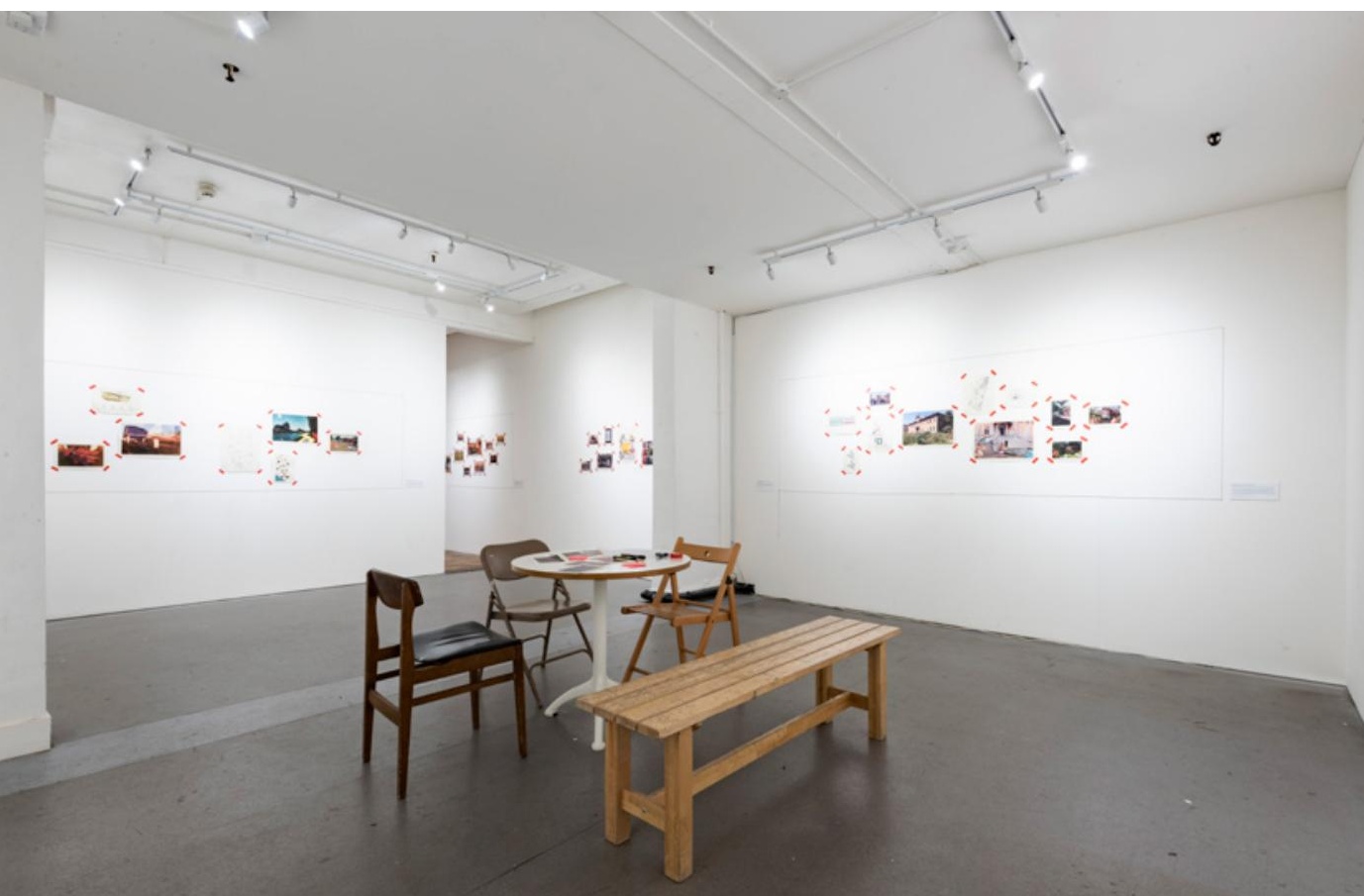

Temporary Contemporary, Huddersfield. Laura Mateescu, 2020. 


\section{Preface}


This is the first book that documents and reflects on an aspect of the Temporary Contemporary initiative. Launching in 2018, Temporary Contemporary is a collaboration between the School of Art, Design and Architecture at the University of Huddersfield and Kirklees Council. This collaboration, in the form of an action research project, has sought to reflect on the efficacy, meanings and wider contribution of cultural activity in Huddersfield town and beyond. It is one small part of a bigger project about the future cultural heart of Huddersfield.

Huddersfield is a town in Northern England with a population of around 160,000, separated from larger urban centres and neighbouring towns by encircling hills and mountains. According to the 2015 and 2019 Indices of Multiple Deprivation published by the government, it is one of the most deprived areas of the UK. The town, like much of the UK, was seeing shop closures prior to the 2020 Covid-19 pandemic, as a result of factors including austerity policies and online retail.

The title Creating Vibrant Spaces to Support the Conditions for Creative and Cultural Activity refers to the aims of Temporary Contemporary in its entirety. The initiative achieves these aims through populating former retail spaces in the town with exhibitions and events, fostering partnerships and creating networking opportunities for cultural and creative producers, repurposing fine historic buildings and making connections with rich cultural traditions in the town including music, theatre and textiles.

The contents of this book focus on a specific strand of the initiative, the first year (2018-2019) of its exhibition programme in the Market Gallery, a white cube gallery within Queensgate Indoor Market. It discusses seventeen exhibitions, curated by staff members and postgraduate students in the School of Art, Design and Architecture. However, the aim of this focus is to better contextualise and understand the collaborative nature of Temporary Contemporary as a growing cultural ecology in Huddersfield and how it has developed, in partnership with Kirklees Council, which includes working with the Creative Development Team in Queensgate Indoor Market and more recently in the Piazza Shopping Centre.

Therefore, the four chapters seek to contextualise the exhibitions in relation to the place-based making and action research we have developed through this collaboration. We have engaged with mixed cultural ecologies as an important framework for exploring the relationship between ways of working in a live environment and in collaboration with others. 
This book provides one contribution to the many discussions about the role of culture in towns and cities. The insights of our collaborative research may be of interest and use to policy makers, academics, artists, curators and anyone else with a concern about the cultural and social future of towns and cities in the UK and beyond.

\section{Dr Rowan Bailey}

School of Art, Design and Architecture, University of Huddersfield.

\section{Professor Nic Clear}

School of Art, Design and Architecture, University of Huddersfield.

\section{Chris Cotton}

Strategic Lead for Markets, Kirklees Council.

\section{Kath Davies}

Strategic Lead for Cultural Development, Kirklees Council.

\section{Professor Donal Fitzpatrick}

School of Art, Design and Architecture, University of Huddersfield. 

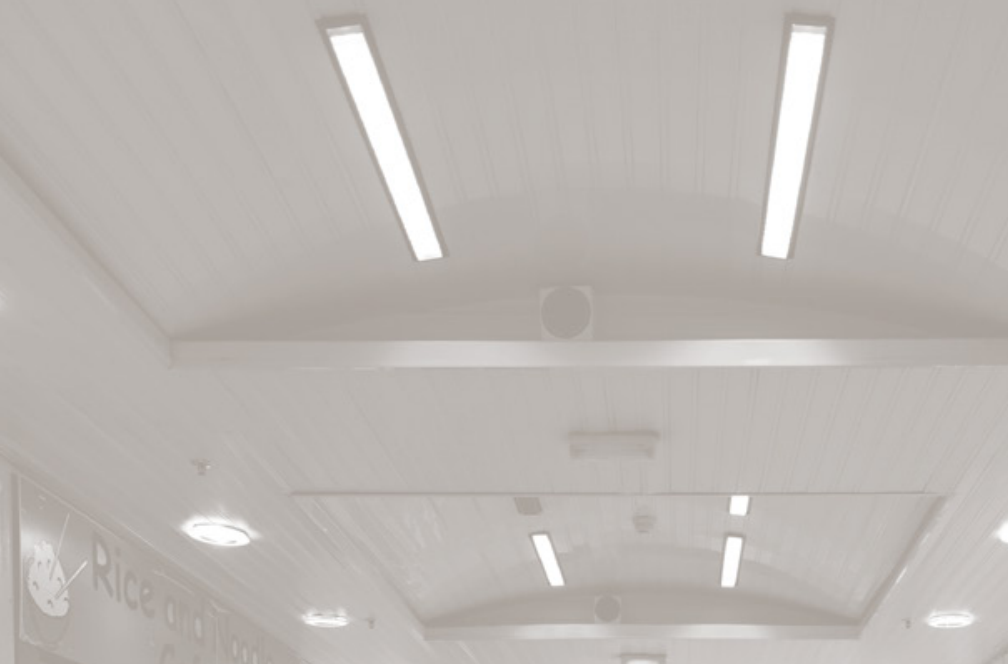

2

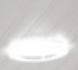

ปั่ - $15 x$
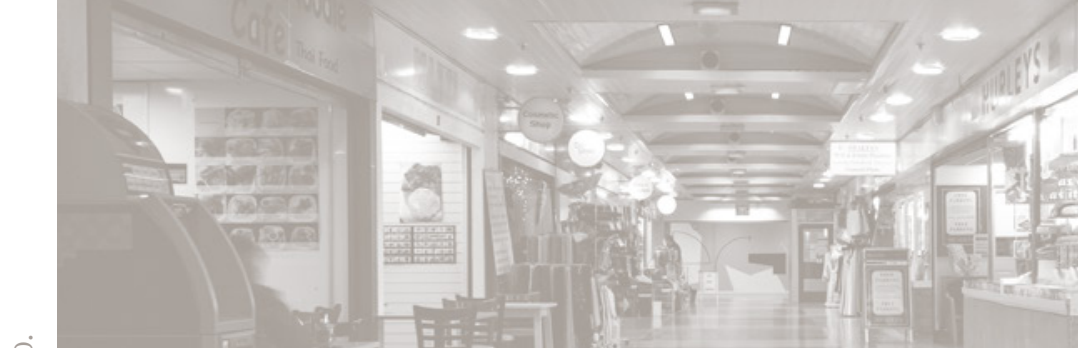

1- -1 Es
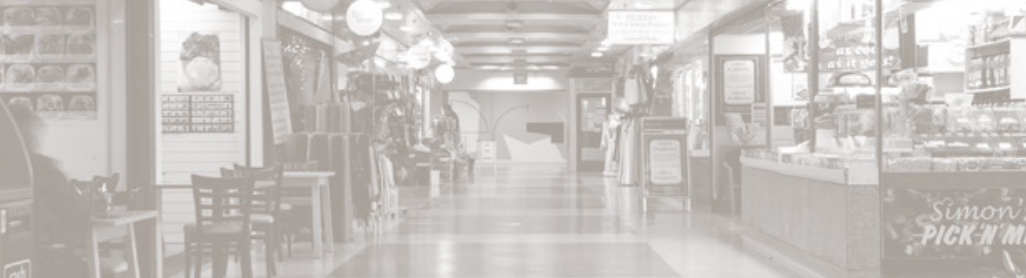

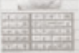

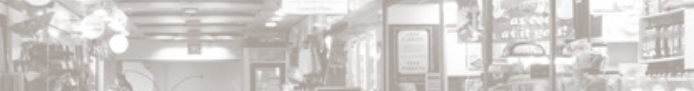

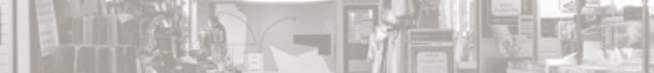

1.

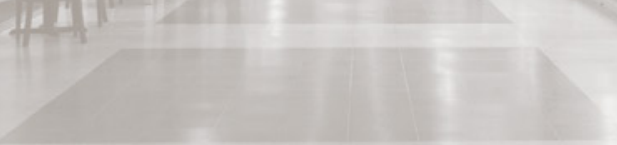




\section{Introduction}




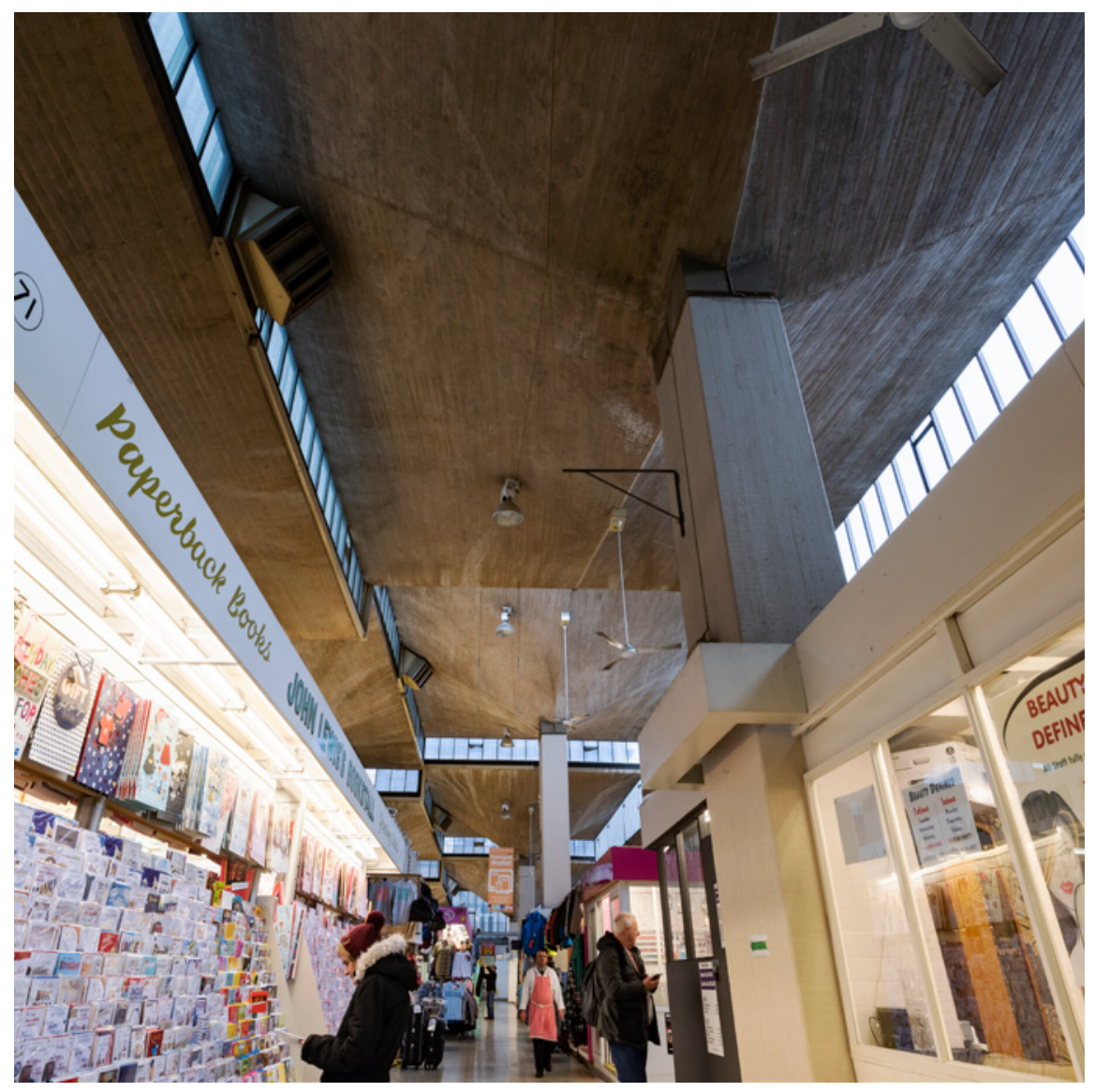

Queensgate Indoor Market, Huddersfield. Laura Mateescu, 2020.

Queensgate Indoor Market in Huddersfield, a large town in the North of England, has a roof made of asymmetric hyperbolic paraboloid shells. But this architectural term belies the charm of the 1970s modernist concrete columns, which at the top spread like umbrellas or the underside of mushrooms. Under the columns, traders sell fruit, vegetables, greetings cards, jumpers, batteries and second hand books. Increasingly, threaded between the thriving stalls are vacant spaces and empty units. Since 2018, the Temporary Contemporary initiative and the questions that underpin it have started to weave between the columns too. 
Temporary Contemporary is a partnership project of Kirklees Council and the School of Art, Design and Architecture, University of Huddersfield. Its aim is to provide a platform for original and inspirational exhibitions, performances and research. It forms cultural hubs and test-sites for creative production, collaboration and situated curatorial practices. Its principle question is: how might creative thinking and action be nurtured and lead to the growth of places? Its principle aim is to create vibrant spaces to support the conditions for creative and cultural activity.

Temporary Contemporary has its roots in ROTOR, a project that took place between 2012 and 2017 at Huddersfield Art Gallery. ROTOR was a programme of research exhibitions and public engagement developed by the School of Art, Design and Architecture at the University of Huddersfield, in partnership with the gallery and funded by Arts Council England. ${ }^{1}$

Marking the culmination of the thirteen ROTOR exhibitions within this programme, the School hosted a conference entitled Culture, Community, Creativity, held in January 2018 at the Lawrence Batley theatre in Huddersfield. Culture, Community, Creativity disseminated and celebrated ROTOR's outcomes and set the goal of exploring new challenges and possibilities for creative and cultural activity in the district. The speakers, panellists and workshop facilitators were invited from a range of backgrounds and breadth of specialisms, both in the United Kingdom and internationally. ${ }^{2}$ ROTOR was positioned as the starting point for a series of engaging discussions around the challenges and benefits of projects that produce the conditions for creative thinking and action to flourish. It was through these discussions that the mission of Temporary Contemporary began to find its form.

The first year of Temporary Contemporary took place in Queensgate Indoor Market with the development of three distinct spaces for arts and cultural activity: 'Market Gallery' (a white cube gallery space presenting research exhibitions from staff and postgraduate students at the School of Art, Design and Architecture), 'Market Hardware' (a space to showcase undergraduate student work) and 'Market Showcase' (spaces for artists working locally and cultural organisations to initiate a wide variety of activities). These spaces were created in collaboration with the Strategic Lead for Markets, Queensgate Indoor Market and the Arts \& Creative Development Team at Kirklees Council.

Some of the highlights of the Temporary Contemporary Market Showcase programme in 2018 and 2019 included 
a mural commissioned for the market by artist Kasia Breska, a long-form consultancy event by artist Jean McEwan titled 'Growing Cultures', which invited people to imagine, dream and talk about what tomorrow's culture in the Kirklees region could be and look like using seed planting, mapping and zine making, and the WOVEN in Kirklees textiles festival, which temporarily occupied several of the vacant market stalls. Shortly after its launch, Market Gallery was the site of a collaboration with Huddersfield Contemporary Music Festival (HMCF) who used the venue to showcase the work of composer in residence Christian Marclay. In October 2018, Temporary Contemporary won Innovation of the Year in the Blachere Market Awards by the National Association of British Market Authorities (NABMA).

The spaces programmed by the School of Art, Design and Architecture in collaboration with Kirklees Council are complemented and augmented by Parlour by Parley, led by independent arts professional Victoria McCorkell. Parley is an artist and audience development agency that considers the spaces and places where arts and cultural conversation, connection and learning take place. The name 'Parley' derives from the old French verb "parler" to speak, rendering explicit the role of voice and dialogue in Parley's activities. Parley has occupied a space in Queensgate Market since 2018 which remains permanently open for use by the community. The Parlour space hosts the monthly evening Temporary Contemporary happenings, where visitors are invited to come to the market after opening hours to exhibition previews, performances, music and social events. More recently, these happenings have expanded to the vacant retail units of the Piazza Shopping Centre, as part of a shared programme where creative communities collaborating with Temporary Contemporary showcase their work and practices with a range of different audiences. Temporary Contemporary has always been receptive to the idea that it is an evolving and changing live environment; an ecology of continuous change, adaptation, participation and collaboration.

This book primarily documents and reflects upon the first year of the curatorial programme for Market Gallery, which comprised seventeen exhibitions, but it is always mindful of the negotiation between the different strands of the programme and the context of the market itself. The following four chapters outline the underpinning themes of the initiative within the context of live action research. These themes are: place-based making, cultural and mixed ecologies, the apparatus of viewing, and the exhibition as research method. 


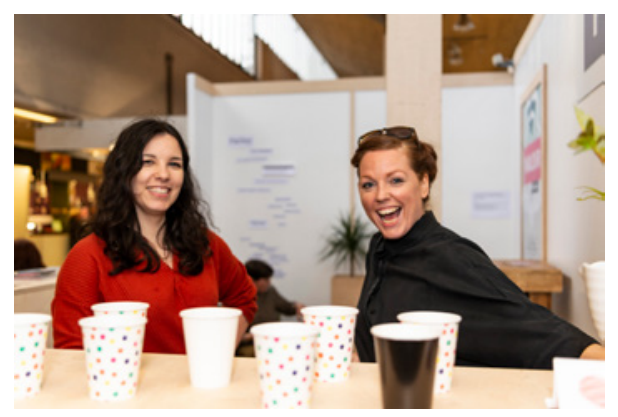

[Left \& below] Parlour by Parley space. Images courtesy of Victoria McCorkell (pictured right) and Laura Mateescu.
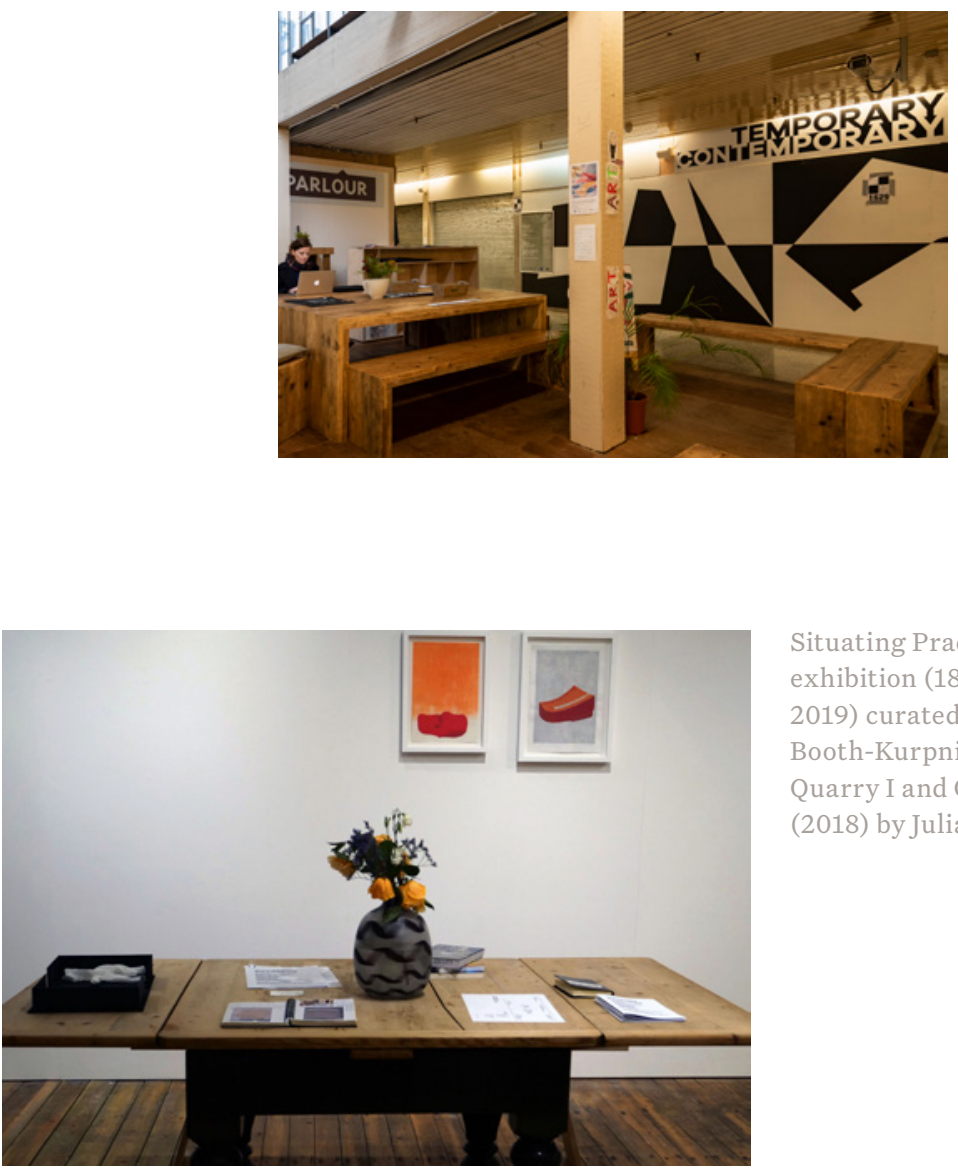

Situating Practices exhibition (18 May-1 June 2019) curated by Claire Booth-Kurpnieks featuring Quarry I and Quarry II (2018) by Julia McKinlay. 


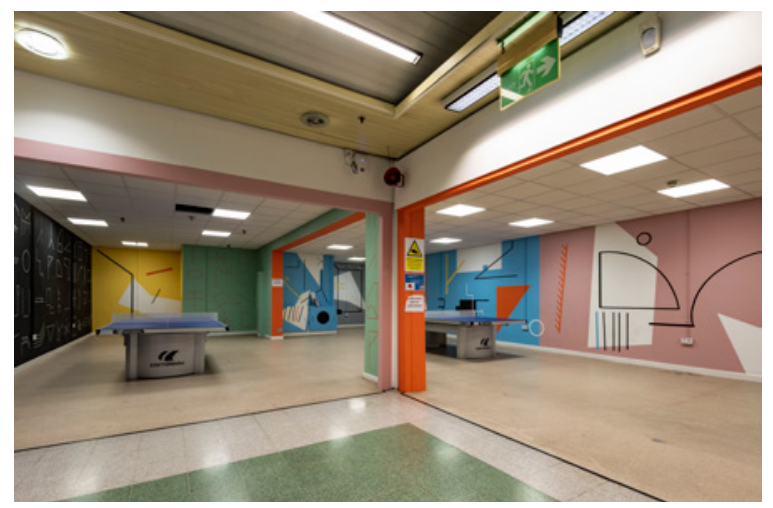

Kasia Breska, Queensgate Market Mural Project, Huddersfield, 2018.

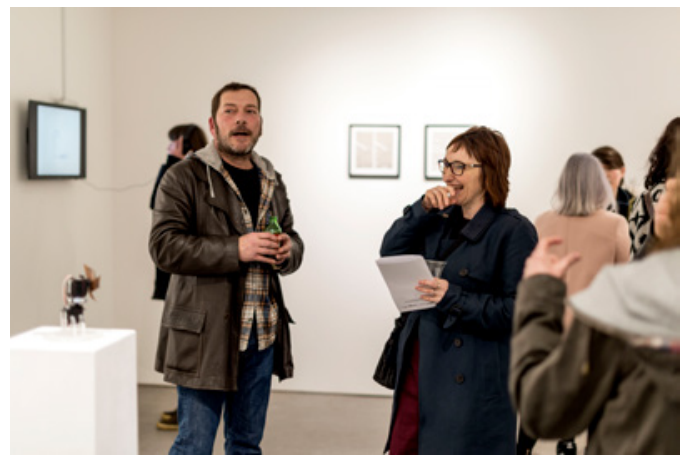

Ryan Durrant and Katy Suggit, School of Art Design and Architecture at Temporary Contemporary happening.

Exterior Queensgate Market, Huddersfield. Image courtesy Laura Mateescu.

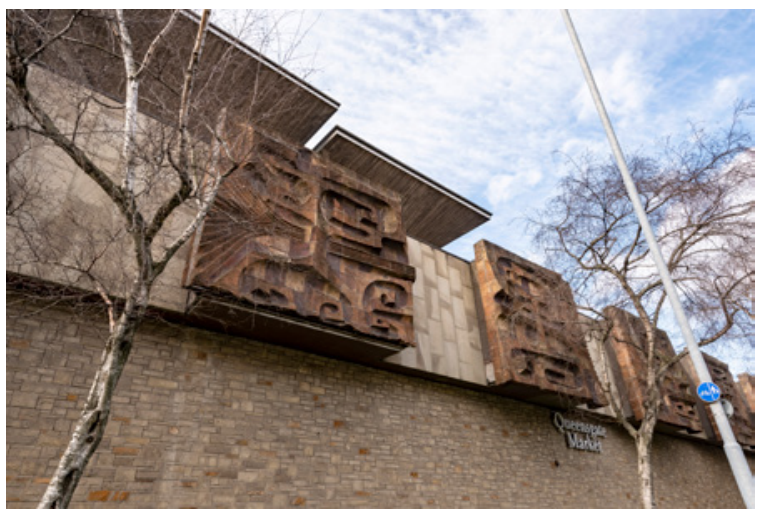


In the first chapter, Dr Rowan Bailey discusses the terms 'action research' and 'place-based making' in the context of Temporary Contemporary. As the lead coordinator of the Market Gallery programme, Bailey takes this opportunity to consider how live action research has been a means for facilitating a 'mixed cultural ecology' in Huddersfield, making reference to the insights generated out of collaborative working with a variety of stakeholders and beneficiaries. The provocation here is that grass roots initiatives from within a place create its character, which in turn renders visible a network of exchanges between cultural practices. The chapter also discusses the exhibitions that have considered 'place' in, with and through visual cultural and creative practices: Place, Space, Action (6-14 April 2018) curated by Dr Rowan Bailey, Uncanny Valley (7-21 December 2018) curated by Nick Deakin, Temporary Tactical Urbanism (13 March-6 April 2019) curated by Dr loanni Delsante, What's this dull town to me? (13 March-6 April 2019) by Andrew Taylor and Katrina Whitehead, Synthetic Spaces (31 January- 4 March 2019) by Professor Nic Clear and Hyun Jun Park and Situating Practices (18 May-1 June 2019) curated by Claire Booth-Kurpnieks.

Temporary Contemporary questions what can be done to support the cultural ecology of Huddersfield. The term 'cultural ecology', as outlined in the Arts and Humanities Research Council report 'The Ecology of Culture', ${ }^{3}$ includes everything around art and culture, including people, places, relationships, technology, food and drink. Using the metaphor of 'ecology' draws attention to the relationships formed within an ecosystem, including shared values that contribute towards collaborative exchange. As John Holden, author of the report, explains:
Particular individuals instigate work, but culture is only ever realised through the skills of many, and only becomes 'culture' once it is communicated and received. Seeing culture as a communal endeavour, involving all the elements of creation, communication and reception, embeds the artist in fact not at the centre, nor at the (equally romantic) periphery, but in a social network. ${ }^{4}$

Temporary Contemporary expands on the term 'cultural ecology' by paying attention to the role of 'mixed ecologies' and to the ways in which art and non-art practices develop and negotiate with each other. The cultural interventions of Temporary Contemporary are not intended to overwrite the original purpose of the market or other vacant spaces that it occupies, but rather to exist alongside them within the ecology, and prompt reflection on the negotiation of research, art, craft, architecture, music, 
'greening,' sport, public meeting spaces, food and drink. In Professor Donal Fitzpatrick's chapter, he reflects on the terms 'cultural ecology' and 'mixed ecology' and focuses on the exhibitions that best exemplify 'ecology' in a broad sense: Black Bag (10-29 September 2018) by Ryan Durrant, Flood (7-21 December 2018) by Richard Mulhearn, The Laundry Pile (24 June- 13 July 2019) curated by Dr Jade Lord, Emma Rigby and Lizzie Harrison, Quilting Together (24 June- 13 July 2019) by Nicola Perren and Making Material Memories (15 April-3 May 2019) by Charlotte Goldthorpe.

As well as being collaborative, Temporary Contemporary is an appeal for assessments of cultural value that are not primarily rooted in the economic. It has been concerned with aesthetic, social, educational, well-being and experiential values and what they contribute to the cultural ecology of Huddersfield. This consideration of values (in the plural) places the initiative within a constellation of projects including: In Certain Places in Lancashire, UK, ${ }^{5}$ the festivals in Johannesberg that Kim Guerney documents in The Art of Public Space: Curating and Re-imagining the Ephemeral City (2015), ${ }^{6}$ and the People Making Places project in Yorkshire during 2002-2004. ${ }^{7}$ All of these projects share a commitment to place-based making activity through creative thinking and action.

Dr Anna Powell and Dr Linda Jean Pittwood in their chapter discuss the broad notion of looking in relation to the apparatuses of viewing, including the knowledges that audiences bring to an experience of viewing, and the role of image in the construction of memory. Powell and Pittwood look closely at five exhibitions in the Market Gallery that explored representation itself, monuments and memory: Showgirl Manifesto (11-27 October 2018) by Dr Alison J Carr, Photography and Lived Experience (14-21 June 2019), Nocturne (15 April-3 May 2019) by Dr Stella Baraklianou, A proposal for a monument for Carl Einstein (10-26 January 2019) by Dr Dale Holmes, Empire of Memory (10-26 January 2019) by Garry Clarkson, and Bigfoot in West Belfast (14-21 June 2019) by Dr Liam Devlin.

As a form of 'live action research', Temporary Contemporary aims to facilitate the conditions of possibility for transformation and change through its exhibition programme which offers up social commentary, provocations for thinking, and access to diverse forms of art, design and architecture with and for a broad range of audiences. These audiences include: university lecturers, artists, local artisan producers, musicians, students and members of the general public. Reflecting on this, Professor 
Nic Clear considers on the role of exhibitions in research practice and art, design and architecture pedagogies and discusses the Market Gallery exhibition Synthetic Spaces (31 January-4 March 2019) that he curated with Hyun Jun Park.

\section{Temporary Contemporary has created much-needed} opportunities for creative practitioners to congregate and exchange ideas through regular evening events ('happenings'). These evening events have generated opportunities for local artisan retailers like Magic Rock brewery and KWAS wine shop and bar to support these activities and share audiences and customers. Moreover, in a relatively short period of time, the Temporary Contemporary programme has moved on to populate other vacant retail units in the town and has become central to the thinking of Kirklees Council in its approach to culture and regeneration for Huddersfield.

The collaborators involved in Temporary Contemporary include: Kath Davies, Strategic Lead for Cultural Development for Kirklees Council and Chris Cotton, Strategic Lead for Markets for Kirklees Council, alongside staff from the School of Art, Design and Architecture. To ensure the quality, sustainability and value of Temporary Contemporary, the project is overseen by a board of advisors comprising Dr Helen Pheby, Senior Curator at Yorkshire Sculpture Park, Dr Derek Horton, Artist, Writer, Curator and Consultant, the Directors of HATCH, Natalie Walton and Alison McIntyre, and Natalie Rudd, Senior Curator Arts Council Collection. More stakeholders and participants are listed in the acknowledgements section at the back of this book.

The conclusion of this book argues that although dealing with a specific place, the Temporary Contemporary research has provided new insights into the futures of art and culture in towns like Huddersfield. As Temporary Contemporary moves into its second year of programming, in parallel to the offer in Queensgate Market, arts organisations from the region have temporarily moved into vacant units of the nearby 'Piazza' shopping centre. This collaborative effort to occupy vacant retail spaces and embrace Temporary Contemporary as a concept, has led to proposals for a Public Art Plan for Huddersfield, and to include it as part of the planning for the future 'cultural heart' of Huddersfield. The growing visibility of Temporary Contemporary as part of a broad portfolio of mixed cultural ecologies is contributing to a change in mindset about the ways in which place-based making can be an opportunity to activate space with all kinds of creative activity. 
${ }^{1}$ For further details about the ROTOR programme and its research see Swindells, S., \& Powell, A. (Eds.) (2014). "What Is to Be Done?": Cultural Leadership and Public Engagement in Art and Design Education. Newcastle upon Tyne: Cambridge Scholars Publishing and Powell, A., \& Swindells, S. (2015). 'ROTOR Transciplinary dialogue and debate: A Public Engagement Case Study'. Procedia-Social and Behavioral Sciences, $184,79-86$

https://doi.org/10.1016/j.sbspro.2015.05.056.

2 Speakers included: Simon Armitage, Dr Anna Souto, We Are Public, Patrick Fox, Lee Corner and Phil Wood.

${ }^{3}$ Holden, J. (2015) 'The Ecology of Culture

A Report commissioned by the Arts and

Humanities Research Council's Cultural Value

Project.' Arts and Humanities Research Council. The full report can be found at:

ahrc.ukri.org/documents/project-reports-andreviews/the-ecology-of-culture/

[accessed 6 February 2020].
4 ibid

5 The project is documented here:

https://incertainplaces.org/

${ }^{6}$ Guerney, K (2015) The Art of Public Space: Curating and Re-imagining the Ephemeral City. London, New York and Shanghai:

Palgrave Macmillan.

7 Powell, R. J. (2004) People Making Places: Imagination in the Public Realm (Art Catalogue). London: Public Arts.

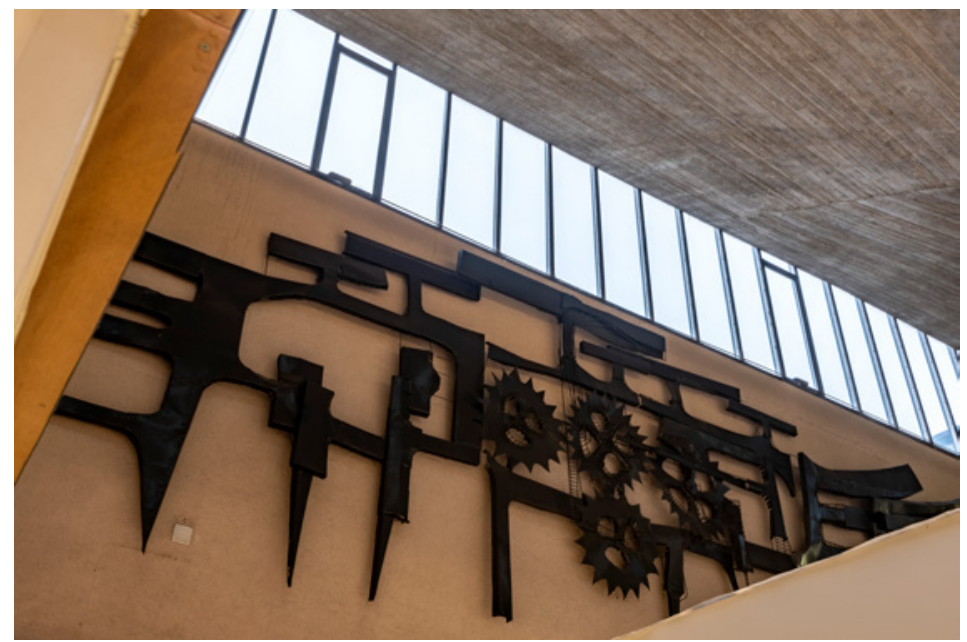

Queensgate Indoor Market, Huddersfield. Laura Mateescu, 2020. 


\section{Chapter One}

Action Research and Place-based making

Dr Rowan Bailey 


\section{Putting Space into Action Through Art}

In 2015-2016, I collaborated with the artist film-maker Huw Wahl on his project Action Space Film. ${ }^{1}$ The documentary focused on the 1970 s radical art movement Action Space, founded by artisteducators Ken and Mary Turner in 1968. Bringing together artists, performers, dancers, painters and musicians, the movement sought to produce cultural democratic spaces for art, education and creative play. Action Space became renowned for using large inflatable sculptures to create interventions in spaces outside of the gallery system.

Ken Turner's book Crashing Culture: 1954 to 2016 is an artist notebook which covers the terrain of his practice, from the inception of Action Space, through to his paintings and philosophical sojourns into continental philosophy, alongside contemporary reflections on performance art and the building of the inflatable for Wahl's film project. In the book he reflects on space as a sculptural performative act:

One is moving through a "thick space" and the thickness is defined by the people in that space. By thick, I mean the way through is as if one has to carve through, sculpturally making space, a decisive cut, or thrust: as a kind of action in solid matter liken to an object. To me that is exactly what performance is like. It has to seem like this to be able to rise to a level of awareness that in itself resembles the semblance of making something real. Making it happen is of an action, but this action is more than making something move. It is as if the space itself moves; moves apart, away to one side, is constructed, forming another shape, another form, being restructured and reconstituted as another substance. ${ }^{2}$

To coincide with the launch of Wahl's film, the School of Art, Design and Architecture hosted a symposium at the University of Huddersfield on 30 September 2016, entitled 'Putting Space into Action'. ${ }^{3}$ The event sought to explore how space is put into action through art. The papers presented provided instances of artists and art projects that have occupied vacant buildings, public spaces, small towns and even televisual media. For example, Dawna Schuld (Texas A\&M University) discussed the work of the sculptor and conceptual artist Maria Nordman through the theme of 'happenstance', which she suggested was deployed by the artist as an aesthetic device operating at 'the conscious and literal threshold between public and private space'. ${ }^{4}$ Ana Torok (Courtauld Institute of Art) examined P.S.1 


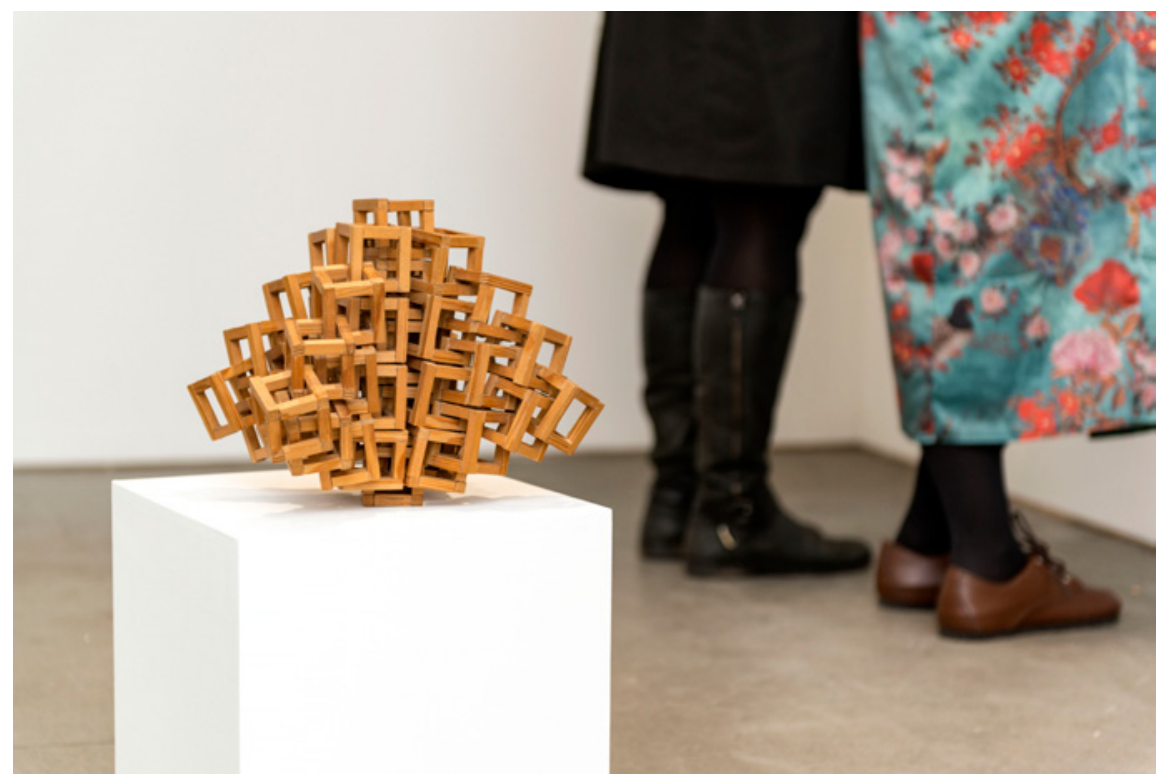

[Top] Joe Hancock,

Rosary, 1991.

[Right] Simon Woolham, Performing Paper, 2014.

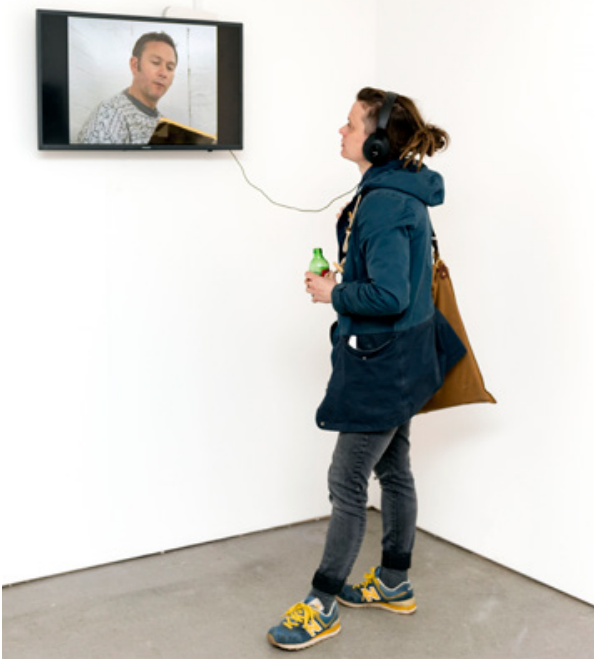


and the work of the Institute for Art and Urban Resources (IAUR) in 1970s Queens, New York, with a particular focus on the launch of the exhibition Rooms which featured seventy-eight artists who 'used the building as physical and conceptual material for their site-specific interventions'. This exhibition created a space for creative exchange rather than economic ends. Anna-Maria Kanta (University College London) examined the German mixed-media artist Ferdinand Kriwet's broadcast installations TV-LIVE and considered the transference from the public space of installation into mediations of the TV set. Elizabetta Rattalino (University of St. Andrews) considered the work of the Italian artist Maria Lai, who in 1981, staged a local community collaborative performance in a remote village in Sardinia. Legarsi all Montagna (Connecting to the Mountain) was the outcome of many years of social engagement by the artist with local inhabitants in the area. Other speakers included artists experimenting inside the frames of different locations and environments. Rose Butler and Becky Shaw (Sheffield Hallam University) presented their project Utopia (2016), a collaboration with Kings College London and Somerset House, which investigated the exchanges between artistic researchers and nursing and midwifery practitioners in the context of a medical ward simulation centre, and Boris Oicherman and Laura Steenberge (Stanford University) accounted for their sound and musical play experiments in the public spaces of Stanford University. ${ }^{5}$

All of these investigations into the activation of space through artistic and creative activity resonate with Turner's account of how space moves, is moved, constructed, given shape and form by performative interventions. Bodies, objects, activities, atmospheres sculpturally make space in concert and sometimes in discord with each other. The ideas presented at 'Putting Space into Action' and the conversations arising from this symposium have continued to preoccupy my thinking about the ways in which art and cultural activities enliven spaces in different ways, and in retrospect, these fascinating projects, many of which hail from the 1970s and early 1980s, seem to exemplify the scope and potential of what Temporary Contemporary has been trying to enact since it was first launched in 2018.

Both 'action' and 'space', as understood by Action Space and the artistic examples presented above, provide opportunities to make sense of two terms currently in use by Temporary Contemporary as an initiative: 'live action research' and 'place-based making'. They have served as underlying principles for the collaborations we have sought to develop between the Arts \& Creative Development Team at Kirklees Council, creative practitioners, 
community groups and cultural organisations within the region. Some of the exhibitions featured in the Market Gallery as part of the first year of Temporary Contemporary's programme resonate with these principles and modes of approach, in and through the works developed and displayed within the exhibition environment. In order to explain how 'action research' and 'placebased making' may be understood in this context, it is important to explain where these terms come from, why they are important, and how they have played a role in shaping some of the curatorial intentions for projects at the Market Gallery, Queensgate Market, Huddersfield.

\section{Action Research}

Action Research is often understood in research contexts familiar to the social sciences. It was first coined as a term by Kurt Lewin, a Professor in Social Psychology at Massachusetts Institute of Technology (MIT) in the 1940s. Lewin was primarily interested in seeking out practical solutions to issues of social isolation, segregation and division with minority groups in America. In his 1946 publication 'Action Research and Minority Problems', which featured in the Journal of Social Issues, he explains the difficulties of 'intergroup relations' between workers in Connecticut, of their lived experiences and perceptions of economic and social discrimination. He suggests that the social research needed to address the issues faced by different groups in a real world context requires 'comparative research on the conditions and effects of various forms of social action, and research leading to social action. Research that produces nothing but books will not suffice'. ${ }^{6}$ For Lewin, 'intergroup relations' need an integrated approach; an amalgamation of different research specialisms from psychology, sociology and cultural anthropology in order to really explore problems of stereotyping and attitude in all spheres of our lives: experiences in childhood, adolescence, housing, legal structures within communities, status and economic discrimination, social relations in families, clubs, friendship groups, schools, the school system, neighbourhoods, communities, the locale in which we live, the region around us, the national picture and the international climate. In this respect, action research is part of the complex entanglements of real world settings and as a set of methods, techniques and approaches, it seeks to improve problems or issues through participatory action. This is not about proposing a change and expecting people to readily accept it and its implementation. Rather, action research works to identify the lived experiences of a problem, to find ways to experiment, seek out approaches to support the 


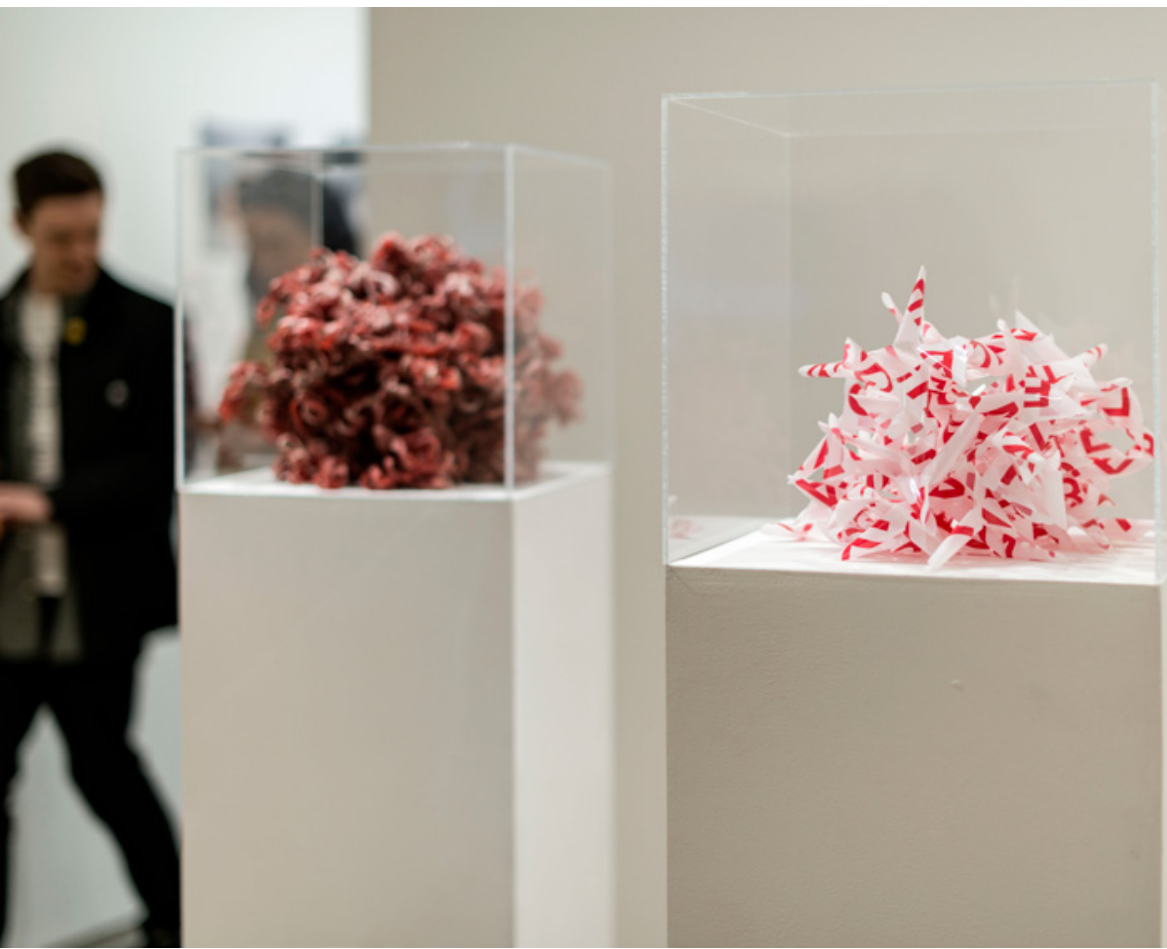


possibility of enacting change, to improvise with others, to create spaces for sharing, communicating and understanding experiences. To do this, Lewin suggests we have to be out in the field and not in the controlled settings of a laboratory-like environment. We need to develop a more intimate understanding of the contexts we are in and how human behaviours are both situated by and informed by these surroundings. Our environment is made up of a force field of energies which can impede or facilitate progress towards certain goals or objectives. Therefore, when we think about action research and what it can do, we must consider how it is part of a process of working towards thinking about how to stimulate change with others; how to bring about shifts in ways of thinking and doing, in organisations, in communities and in the social actions of people in different groups, at different times and in different contexts.

\section{Place-based making out in the field}

This consideration of the field - of the locale within which action research may be enacted - is linked to the complexities of intergroup relations in place-based making. Lewin's understanding of action research, in the context of social science and as part of a 'tool-kit' of techniques, methods, approaches for the professional practitioner 'out in the field' undertaking research with specific groups (organisations, communities, cultures), perhaps gives a clue as to what Temporary Contemporary might appear to be doing as a live action research project and how its own unique approach to being out in the field is aligned to visual cultural practices in the context of place-based making. These practices are as much about sociocultural processes between many interests and needs as they are creative and artistic processes in and of themselves.

Temporary Contemporary began as an initiative concerned with vacant spaces in Queensgate Indoor Market in the centre of Huddersfield. The town of Huddersfield is situated in the North of England with a population of around 160,000. The town, and the wider Kirklees region, have many positive attributes, including historic buildings, a rich textile heritage history, and an international reputation for music. ${ }^{7}$ However, $13 \%$ of residents hold no qualifications, and in the 2015 and 2019 Indices of Multiple Deprivation, published by the Government, Kirklees was identified as one of the most deprived districts in England for both income and employment summary measures. ${ }^{8}$ Many of Huddersfield's fine buildings, relating to its industrial past as a centre for textile production, are vacant. It is experiencing, like 
much of the United Kingdom, a change in the ways consumers use the high street, exacerbated by the credit crunch and austerity policies. Kirklees Council identified in 2016 that cultural production may be one of the ways to sustain economic benefits and prosperity in Huddersfield (Culture Kirklees, 2016).9 Temporary Contemporary, as a partnership project with the Arts \& Creative Development Team at Kirklees Council, sought to consider how vacant spaces, as a result of a declining high street, might be 're-activated' in ways that would bring different cultural practices into visibility and to create conditions of opportunity for communities and groups to share in thinking collectively about culture, cultural activity and new ways of experiencing and making places. Our project has worked to generate, argue for and reflect on a mixed cultural ecology, by combining research, art, craft, music, 'greening', public meeting spaces, food, drink and opportunities for young people, entrepreneurs, artisans and retailers. By embracing a diverse spectrum of emergent values (social, aesthetic, educational, ecological) it has helped to generate, in collaboration, a vibrant cultural offer. This has involved us thinking about Huddersfield as a place of assemblages shaped out of an existing cultural infrastructure, policies and communities, many of which are rooted in the historic locale of Huddersfield, but which continue to develop organically over time in a mixed and growing ecology of different producers and users. ${ }^{10}$

This activity has evolved out of the research exhibitions we held in the Market Gallery in our first year of programming. We were preoccupied with the very idea of place-based making and how creative and artistic practices, as productions of visual culture, can present new ways of seeing and understanding local contexts and to consider how we might put space into action through cultural activity. From out of these exhibitions we were able to present a different mode of approach to place-based making. For example, by using creative artistic methods, such as photographic montage, existing perceptions and ways of thinking about our surroundings were challenged. By mapping urban spaces we were able to seek out what is often invisible to our habituated perceptions of place. By re-imagining historic and landmark buildings and monuments in the locale, with the use of new technologies, we were able to speculate on the possible futures of Huddersfield town. 


\section{Curatorial Action Research: rethinking place}

The final section of this chapter considers six of the exhibitions in the Market Gallery that rethought place through underling research and in the situated context of Queensgate Market. Place, Space, Action (6-14 April 2018), the inaugural exhibition at the Market Gallery was a group show featuring 22 artists and designers (academic staff from the Department of Art and Communication in the School of Art, Design and Architecture). They were tasked with exploring the themes 'place', 'space' and 'action' and a range of media such as painting, illustration, photography, digital design, sculpture and video work featured on display. The exhibition presented stories, experiences and imaginary interactions, including engagement with the architectural structure of the market itself, the internal space of histories and memories attached to place, dialogues with different external stimuli, including urban landscapes and urban sprawls, architectural interiors and the intimacies of thinking in studio environments. The exhibition served as an example of curatorial action research prompting audiences to reflect on visual cultural activity live inside the context of the market. As the first exhibition launch of the Temporary Contemporary initiative, Place, Space, Action aimed to be a prompt for our times and for the creative opportunities in front of us. The ethos of the show is reflected in the open call for artworks in the exhibition:

ACTION: To initiate, to be swift and prompt, to spur, to swing, to plan, to effect change, to transform.

The activity of rethinking place through curatorial action continued throughout the first year exhibition programme of Temporary Contemporary, but was particularly apparent in some examples. Uncanny Valley (7-21 December 2018) was an exhibition of photographic images taken at the Gleadless Valley estate, Sheffield. Gleadless Valley is a post-WWII Sheffield housing development. Whilst estates designed by the same architectural practice have been critically acclaimed and redeveloped, Gleadless Valley on the periphery of the city, has not. Still without regeneration, it has been described as the 'city's worst area to live.'.1 The exhibition showcased photographic montages produced by Nick Deakin, using his own images and those of photographers Richard Mulhearn and James O'Hara. The compositions repeat the lyrical features of the estate (the hand rails, television aerials, windows, balconies, satellite dishes) and reinterpret them as a 'reality of fictions'. These new fictions make the estate's aesthetic potential tangible in ways that move beyond preconceived ideas and assumptions about estate 
Build Your Own...
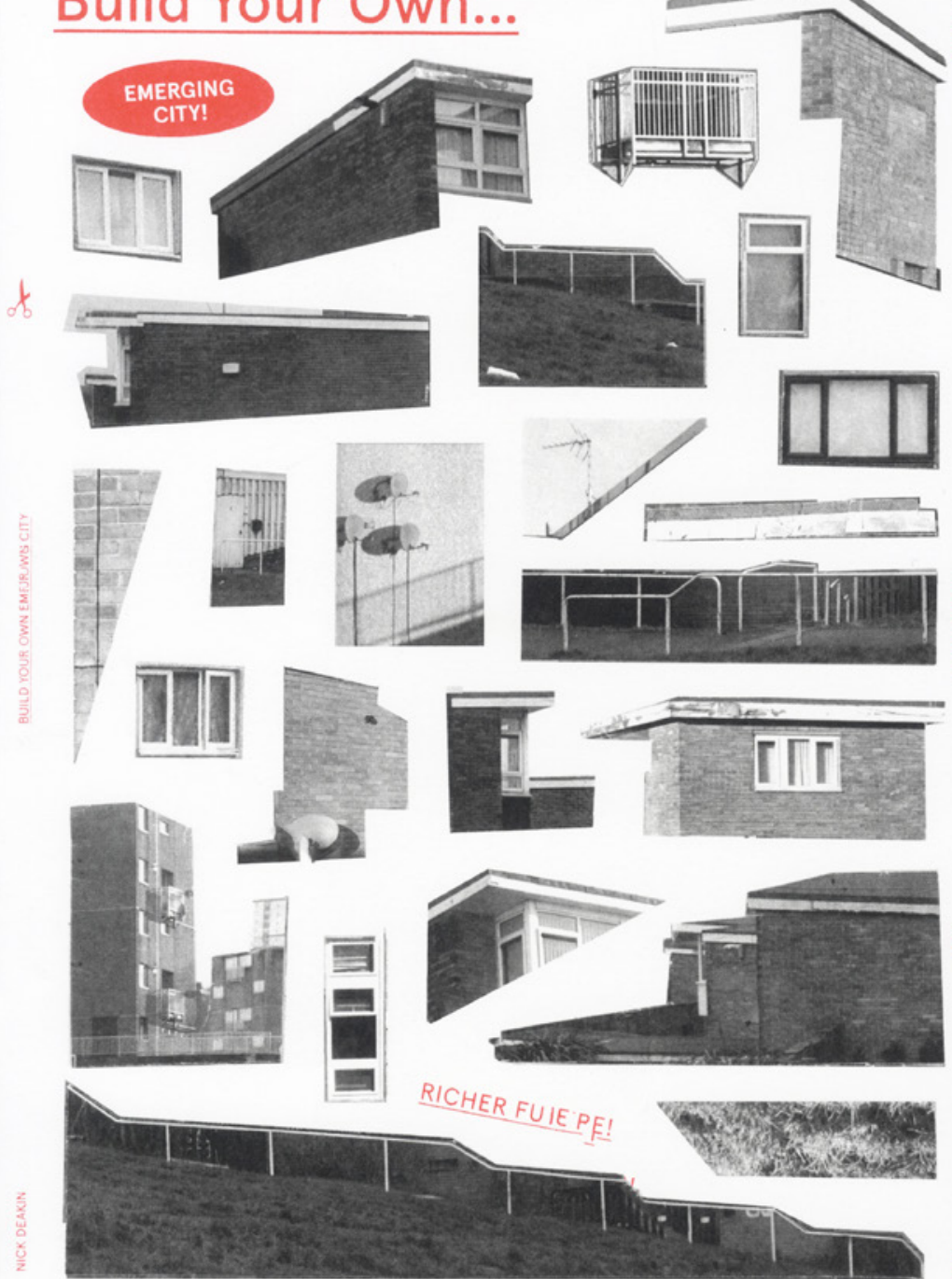
living. The exhibition was accompanied by a limited edition artists' book.

Temporary Tactical Urbanism (13 March-6 April 2019) was conceived to address the questions: what do the terms 'temporary', 'tactical', 'do it yourself', and 'guerrilla urbanism' mean? How do these terms differ? Who benefits from approaches to urban intervention? What do these words mean in the context of the United Kingdom, following the 2008 financial crisis, and specifically in Huddersfield? The research underpinning this exhibition was developed by a team of postgraduate students at the University of Huddersfield, led by Dr loanni Delsante, Reader in Urban Design in the School of Art, Design and Architecture. The content of the exhibition included a range of visual materials developed through literature reviews, field trips, design workshops, research symposia and conferences. It examined specific case studies and tactics. By looking at precedents (such as Bologna, Rotterdam and Seville) the exhibition showcased an opportunity for further conversations about bottom-up transformations in Huddersfield town centre.

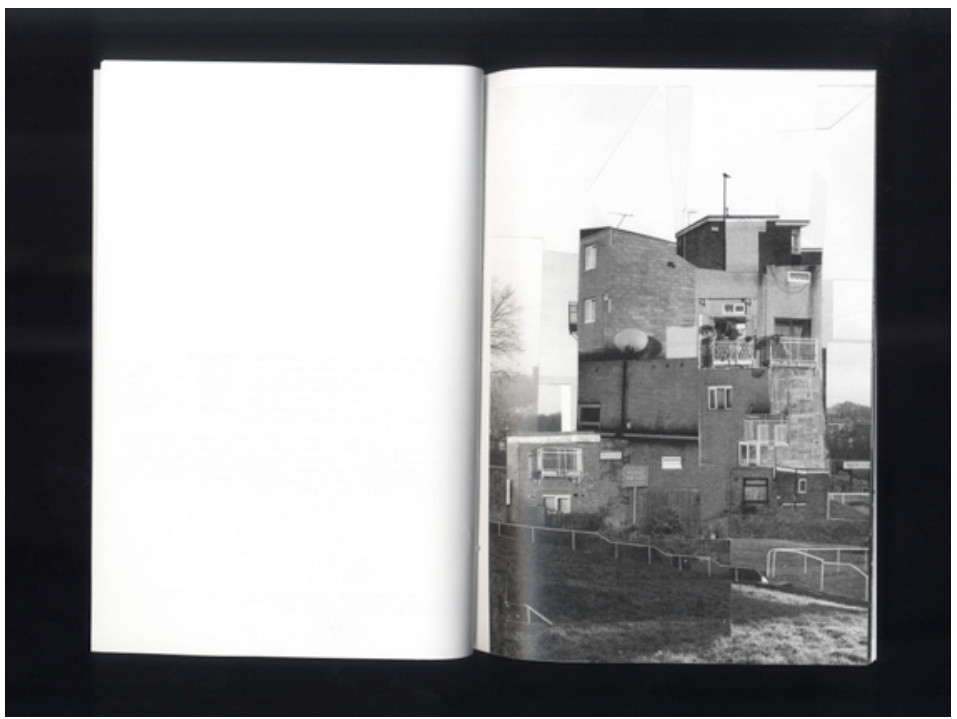




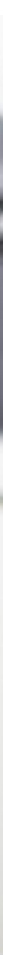

What's this dull town to me? (13 March-6 April 2019) used psychogeographic methods to explore changes to Britain's high streets. Psychogeography encourages attention to the emotional and cerebral responses to exterior environments. Andrew Taylor and Katrina Whitehead's research focused on Huddersfield, with the aim of 're-viewing the subtle spatial codes and signals that surround us' in order to 're-connect the liminal retail spaces with the town's people to collectively discover a way to create a new and novel vision of place.'.12 The exhibition extended existing relationships the curators had developed with augmented reality (AR) and software companies, SilverboxIT and PCT. ${ }^{13}$ The result was a 'beta test' presentation in the Market Gallery that used AR to reveal archival imagery hidden within contemporary photography and an AR heritage walk. Both practitioners used material from a range of archives to render visible Huddersfield's past as a centre for textile production and to reflect on historical imagery of the high street. 
The Temporary Tactical Urbanism team comprised

Dr loanni Delsante, with Yreilyn Cartagena, Tabassum Ahmed, Eduardo Baldauf and Li Yue (Lucian).

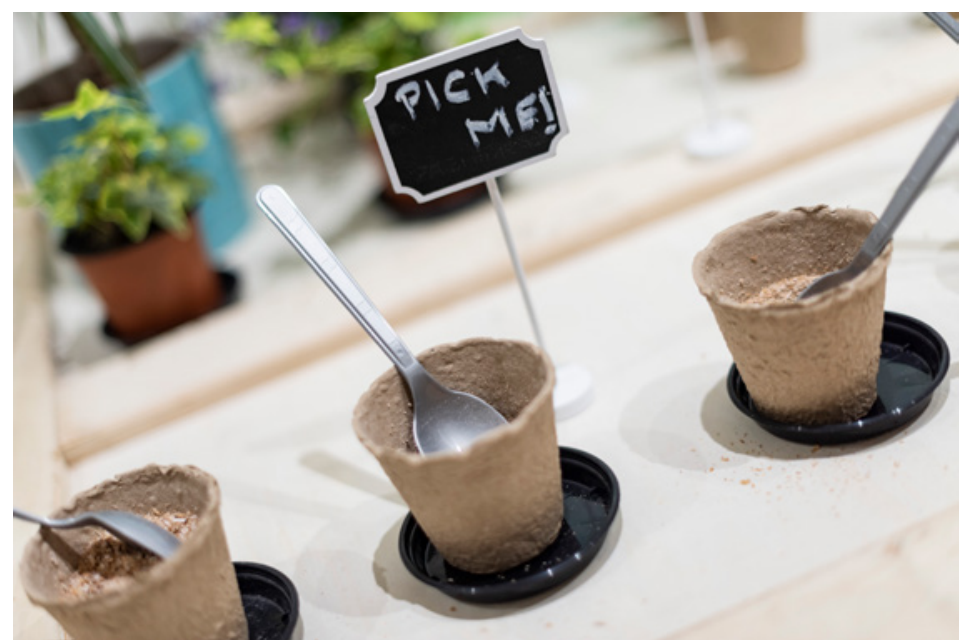

[Above \& right] Seed installation, design by Tabassum Ahmed and Eduardo Baldauf, set up by Temporary Tactical Urbanism. 


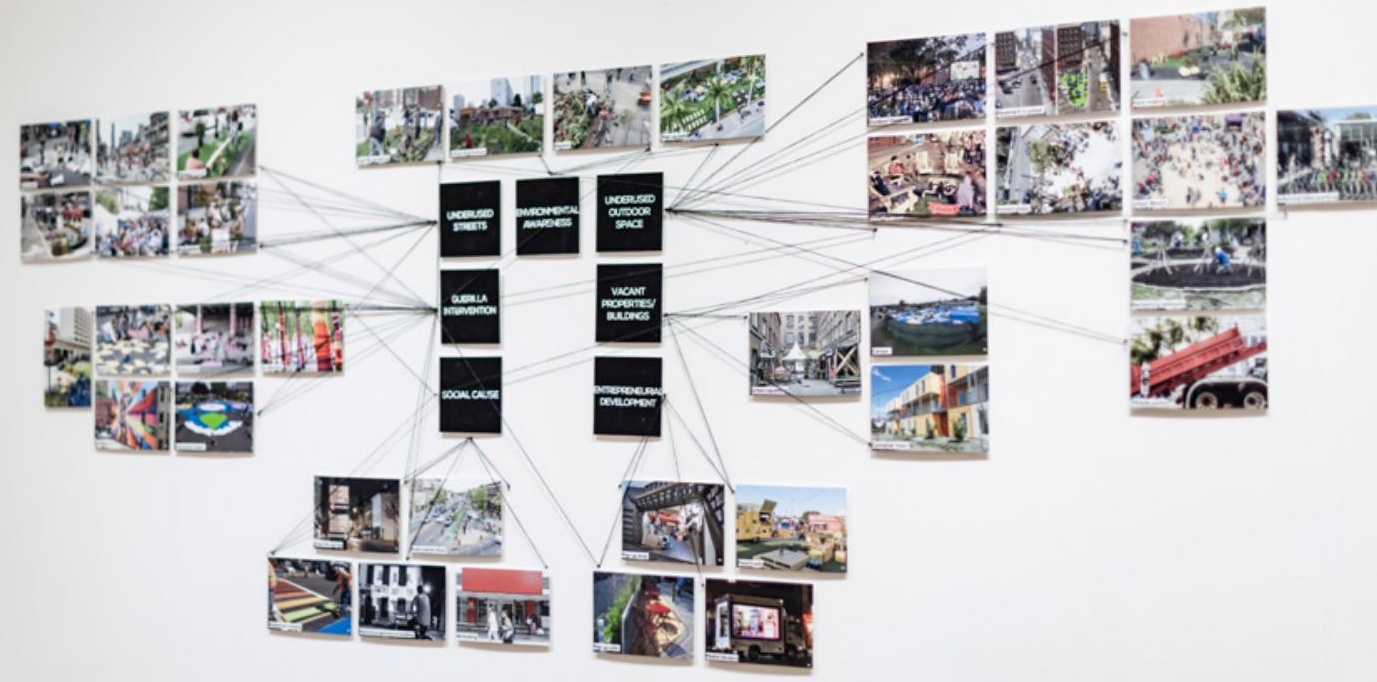

Installation of actions curated and set up by Tabassum Ahmed.

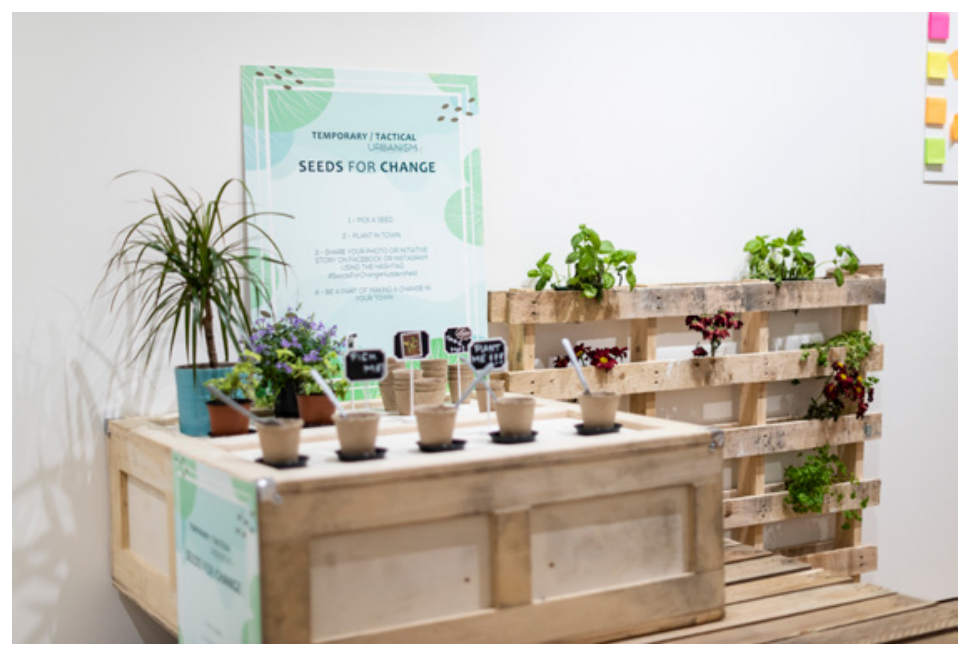


Nic Clear and Hyun Jun Park selected and scanned three iconic sites in Huddersfield: Castle Hill, Queensgate Market and the Railway Station for their exhibition Synthetic Spaces (31 January4 March 2019). The information produced by the scans is highly technical and yet the images themselves evoke a much more speculative response to these historic sites.

When used in combination with other techniques, the scans facilitate both an extremely precise mapping of the spaces as well as an opportunity to develop narratives around the potentiality of these buildings as part of Huddersfield's historic and cultural infrastructure. By manipulating 'point-cloud' data Clear and Park created synthetic spatial models that exist between the virtual and the actual and to combine the 'measured, the 'experienced' and even the 'practiced' in a way that no other form of spatial mapping is capable of. In this respect, Clear and Park manipulated the scan data to re-imagine familiar sites in Huddersfield in unique ways.

In addition to this, the group show Situating Practices, curated by doctoral student Claire Booth and funded by the University Graduate School Researcher Environment Development Fund, brought together the work of postgraduate research students Susan Carron Clarke, Adrian Evans, Laura Harris, Caitlin Kiely, Julia Mckinlay, Beth Morgan and Chrisitan Skovagaard Peterson. The exhibitors were from different disciplines and sought to explore the boundaries between social science and creative practice approaches to research. In this respect, engagement with the places and spaces of research across disciplines presented an opportunity to also explore the boundaries inside and outside of the Market Gallery environment. As Booth explains in her analysis of the exhibition process: 'Situating research practices within the indoor market made visible tensions between the curated inside and the non-curated outside, and the delimitation of space between instrumental and non-instrumental values'. The exhibition was reviewed by Dr Louise Atkinson, co-director of Curator Space and independent artist researcher. ${ }^{14}$

These six examples show how art, design and architectural practices can play a role in presenting new ways of seeing and understanding place and local contexts. In this respect space is indeed activated by these forms of visual cultural experimentation. This is an engagement with challenging existing perceptions of place, by using a range of creative methods, technologies, techniques and visual narratives, and to communicate these alternatives to different audiences. In this sense our preoccupation with the very idea of place-based 

used as productions of visual culture.

${ }_{1}^{1}$ This collaboration was supported by a grant from the Henry Moore Foundation.

2 Turner, K., (2016) Crashing Culture 1954-2016 Artist Notebook Performance Artist and Painter, California, US: CreateSpace Independent Publishing Platform, p.33

${ }^{3}$ For further details of the symposium Putting Space into Action see https://research.hud.ac.uk/ institutes-centres/ceada/ourprojects/psia/

${ }^{4}$ For an account of some of Schuld's ideas as presented at the symposium see Schuld, D. (2018) Minimal Conditions: Light, Space, and Subjectivity, California: University of California Press.

${ }^{5}$ For details of the papers presented at the symposium Putting Space into Action, see after research.hud.ac.uk/institutes-centres/ceada/ ourprojects/psia/\#!\#papers

${ }^{6}$ See: Lewin, K. (Nov 1945), 'Action Research and Minority Problems' Journal of Social Issues, https://doi.org/10.1111/j.1540-4560.1946. tb02295.x

${ }^{7}$ Huddersfield Contemporary Music Festival, established in 1978 has featured major international figures of experimental and avant-garde music.
${ }^{8}$ See: www.gov.uk/government/statistics/ english-indices-of-deprivation-2019 [accessed 11 May 2020]

${ }^{9}$ See after: www.kirklees.gov.uk/beta/arts-helpand-advice/pdf/culture-kirklees-our-vision.pdf

10 See Bailey, R, et al (2019) 'Cultural Ecology and Cultural Critique', Arts 8(4) 166 special edition Reconsidering the State(s) of Criticism. MPI - https://doi.org/10.3390/arts8040166

11 The Star (2008) quoted in research.hud. ac.uk/art-design/temporarycontemporary/ marketgallery/deakin/ [accessed 6 February 2020].

12 Taylor and Whitehead (2019) research.hud. ac.uk/art-design/temporarycontemporary/ marketgallery/andrew-katrina/ [accessed 6 February 2020]

13 To find out more information about the companies that supported the project see: ptc.com/en and silverboxit.uk/

${ }^{14}$ For further details of the exhibition Situating Practices see the forthcoming publication Claire Booth-Kurpnieks and Louise Atkinson, 'Situating Practices: An Ecological Approach to Exhibition Making', RUUKKU- Studies in Artistic Research, Vol.14. Special issue on Ecologies of Practice. 


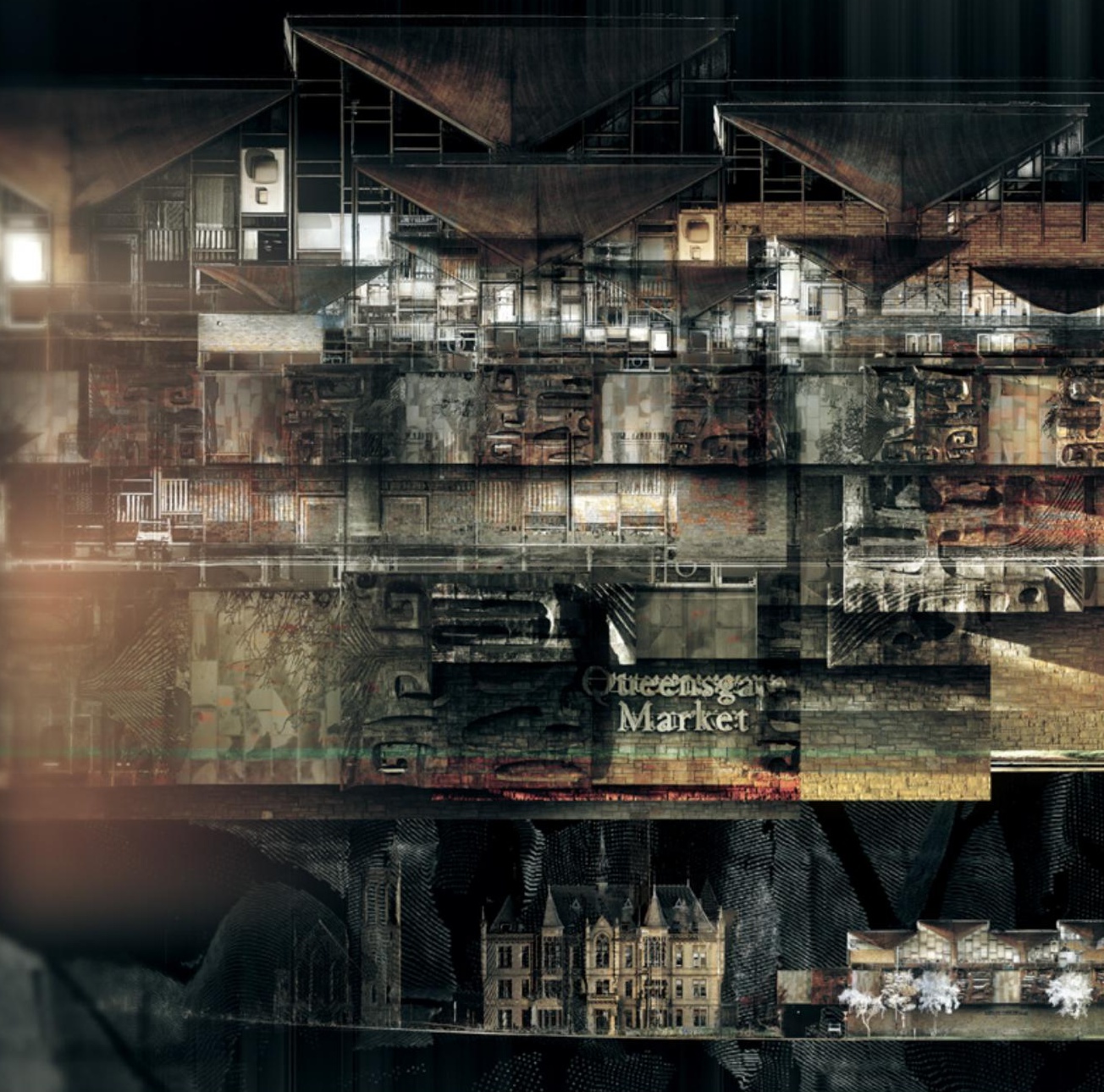

Synthetic Spaces

31 January - 4 March 2019

Professor Nic Clear and Hyun Jun Park 


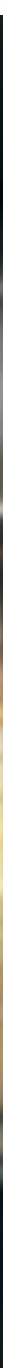



Landscape as Archive (2018) by Catilin Kiely.

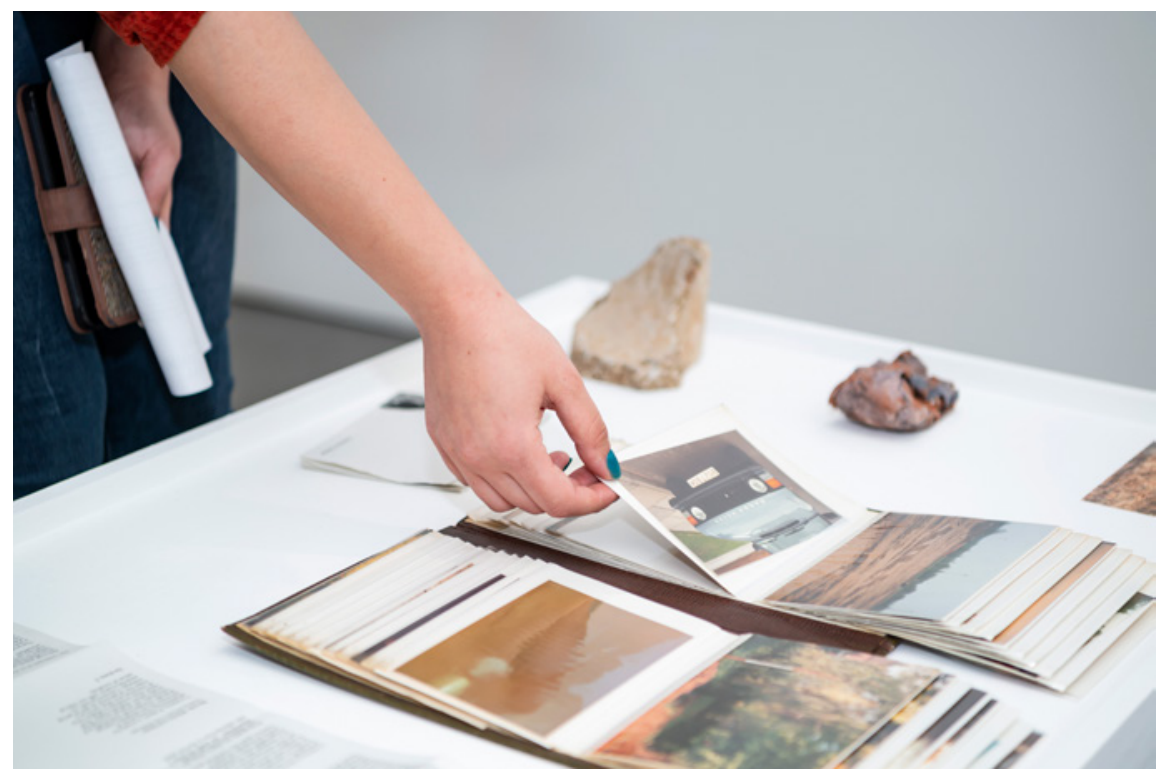




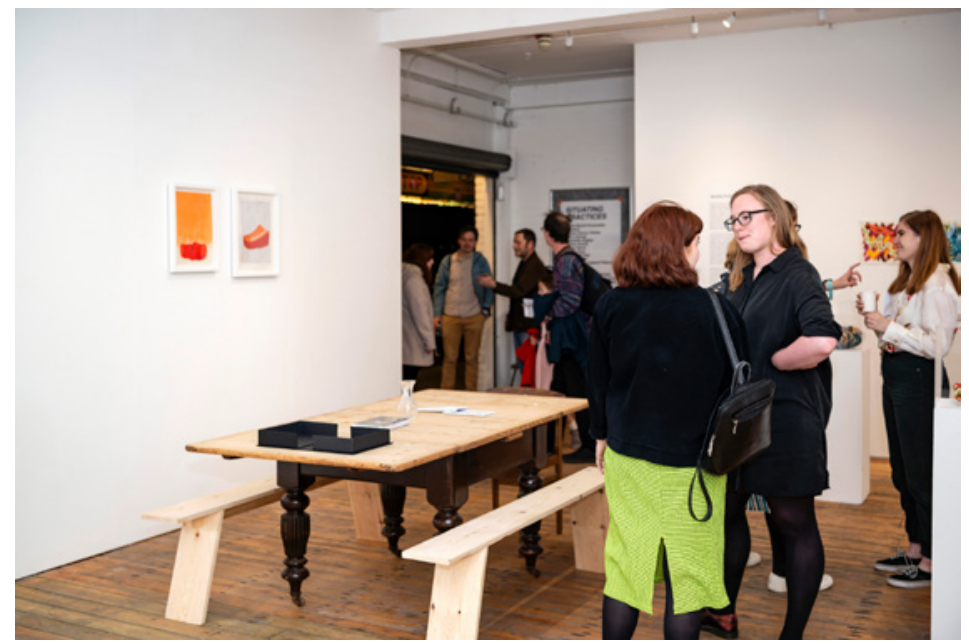

[Above] Situating Practices private view.

[Below] Situating Practices exhibition featuring The girl with the Paua Shell Eyes (2019) by Susan Carron Clarke.

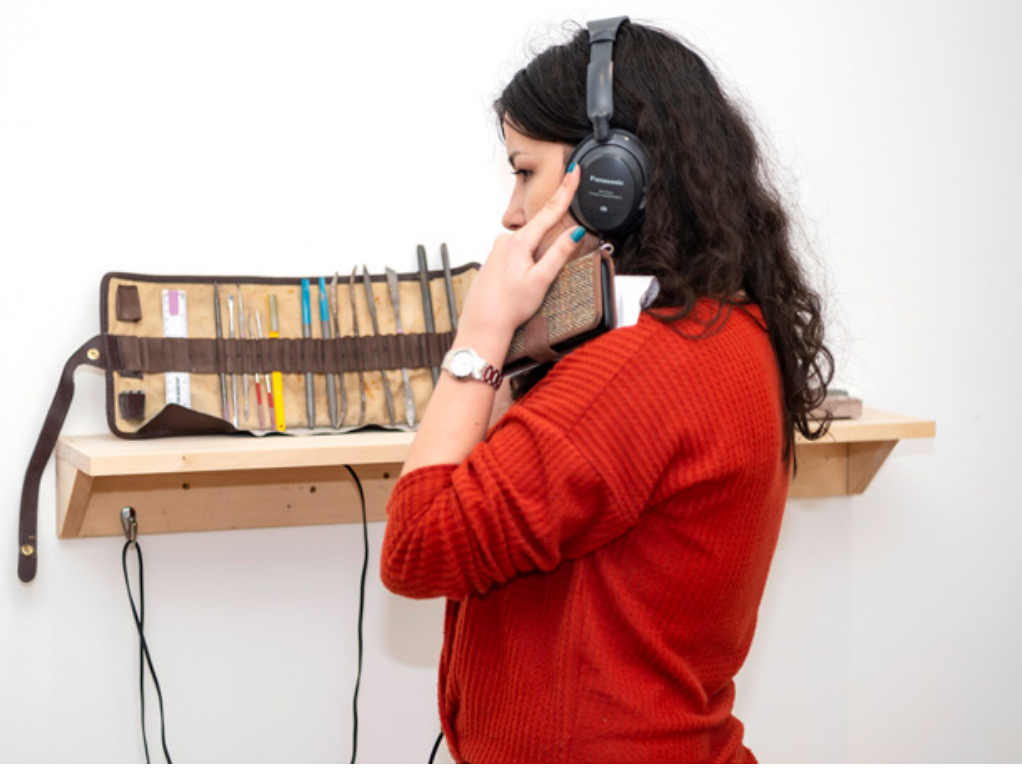




\section{Chapter Two}

\section{Mixed Cultural Ecologies}

\section{By Professor Donal Fitzpatrick}


The concept of the Temporary Contemporary initiative proposed to Kirklees Council was driven by a reconsideration of place as an expression of time. More specifically, a reconsideration of place as both an expression of the present moment and custodian of the legacy of its former use. Issues of place have dominated 20th-century cultural theory. The issue of place was also on our minds specifically because of the challenges for cultural workers in surviving in an unaffordable spatial environment. Temporary Contemporary, then, was driven by reconsideration of modern towns and cities as 'cellular' cultural ecological structures understood in their unique configurations as 'contemporary', 'temporary' and as part of an ecosystem and a system of legacies.

The site that the council proposed for this project was the extraordinary architectural edifice presently housing Queensgate Indoor Market in Huddersfield. The experience of this vibrant building presented an exemplar of constructed space layered by time and transformed by the many incarnations and disparate activities housed over its lifetime. The final proposal generated between the School of Art, Design and Architecture and Kirklees Council was a new contribution to this complex building and the cultural history of the town.

A key value espoused by the joint proposal was to respect the existing activities housed within the building and to work with these activities inside a new temporal envelope that would aid and abet the plural diversity and cultural ecology of the Queensgate Market site and the town of Huddersfield. This chapter will consider the terms cultural and mixed ecology through a discussion of five exhibitions from the Market Gallery programme. The exhibitions by Ryan Durrant, Richard Mulhearn, Jade Lord, Emma Rigby and Lizzie Harrison, Nicola Perren and Charlotte Goldthorpe exemplify 'ecology' in a broad sense.

\section{Cultural Ecology}

The term 'Cultural Ecology' was originally derived from 1950s anthropological theory ${ }^{1}$ and has now extended to the creative economy with the application of an ecological approaches to explain cultural developments. ${ }^{2}$ By utilising the biological tool box of ecological thinking we were able to identify the importance of interdependence and interrelation between cultural forms of production and how they adapt and transform each other. Considering the relations between existing and latent cultural resources and their roles in the growth and generation of new forms of aesthetic, social and economic production were the 

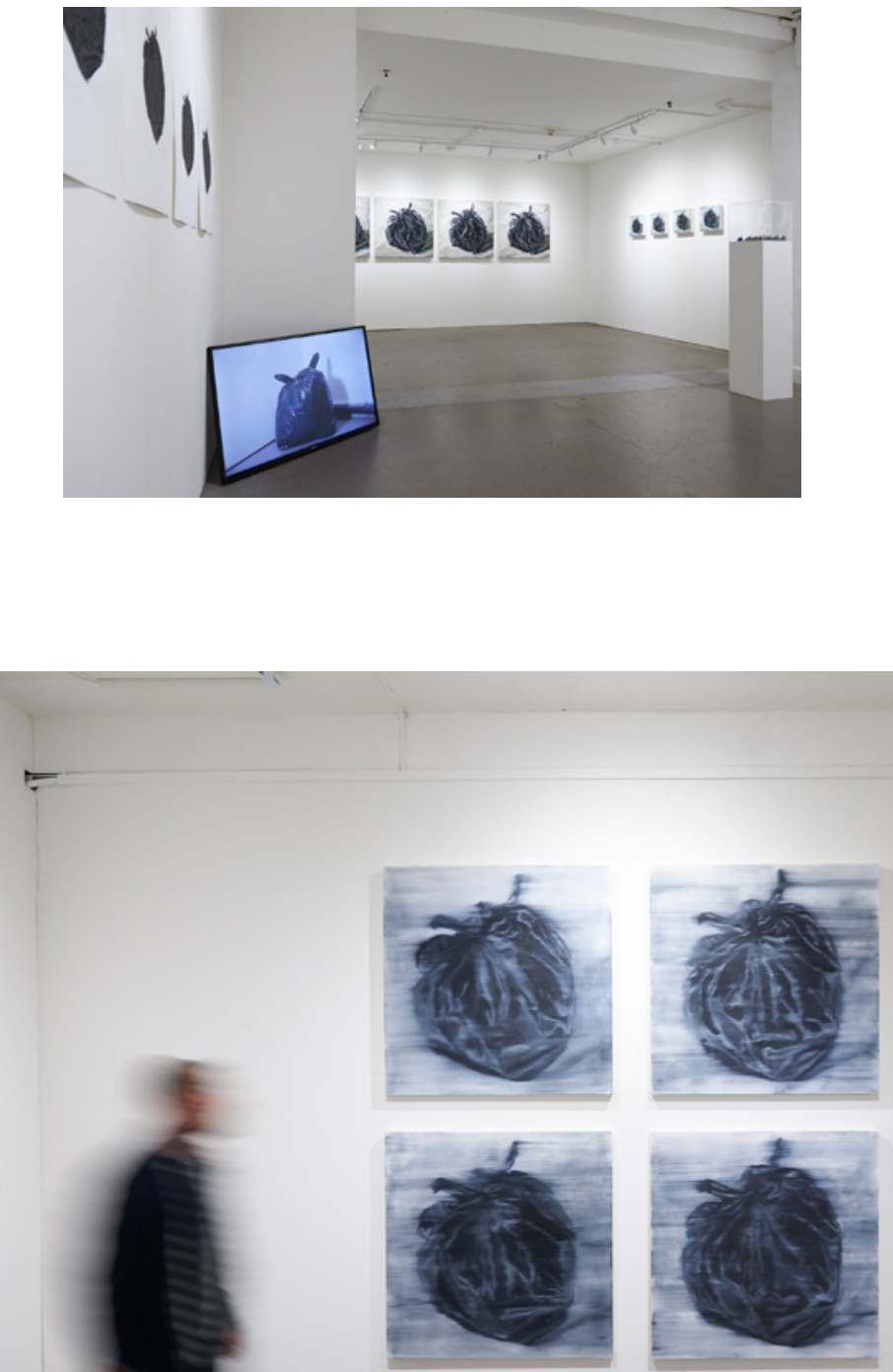
key goals of Temporary Contemporary. The operating principles were to investigate, for example, the intergroup relations between the School of Art, Design and Architecture, Kirklees Council, commercial traders, property owners, transport hubs, the town library, art gallery and performative music venues. These existing tangible and intangible assets represented a cultural ecosystem capable of expansive growth. By naming and measuring these cultural agencies and their entanglement within an immersive mesh of complex social relationships a new model of porous cultural production emerged. This new model thrived as an extended mixed ecology within a dynamic cultural space opened up by the rejection of the binary divisions of art and non-art, culture and nature.

\section{Exhibitions in the Ecosystem}

Operationally the Market Gallery created a series of thematic group exhibitions that exposed visual work that would have otherwise gone unseen. As a quintessential 'white cube' gallery it has helped to render visible arts and culture research in the town. The multiple strands of the programme in Queensgate Market presented opportunities for showcasing music and performance practices from other Schools within the University of Huddersfield. The interdisciplinary nature of so many of the artworks shown in the first year of Temporary Contemporary's programme reflected the partnership between the School of Art, Design and Architecture, the town and Council, and demonstrated a plethora of creative and cultural research practices.

In Ryan Durrant's solo exhibition Black Bag the black bin liner was examined as a key icon of contemporary human malfeasance towards the environment. The ubiquitous black bag, synonymous with the repetition and reproduction of waste, was explored as a container of unseen content, a masked image of human forgetting and the site of our greatest fantasy, what Timothy Morton names as our imaginary concept of 'away'. ${ }^{3}$ The black bag is a receptacle of the unwanted, discarded, disused, transformed into a toxic veil, a poisonous fantasy and ecological threat to our survival. In Durrant's artworks this image of the black bag becomes an emblem of both our mythical flight from responsibility and our contemporary fantasy of an elsewhere, an 'away' to where we can consign our unwanted excess with impunity.

Similarly, Richard Mulhearn's installation Flood (7-21 December 2018) had a direct link to an expanded notion of 'ecology' that is nonetheless rooted in the natural world. The title refers 
to sudden changes in environments and their impact on conventional behaviours, and also to the experience of viewing a sequence (flood) of images that come together to create narratives. Mulhearn's photographs create a tension between the conscious and the unconscious and create the conditions for 'unreadable' moments to emerge. There is an uncertainty within the world of the image and in the experience of looking at images, the strategies of sequencing deployed in this installation generated arbitrary and porous photographic forms. Mulhearn's work equally resonates with this book's discussion of ecology as it does with questions of looking and representation, the topic of Chapter 3.

In The Laundry Pile by Jade Lord, Emma Rigby and Lizzie Harrison, the implications of laundry in contemporary culture are examined. The impact of 21 st-century technologies in the form of household laundry machines and the development of synthetic fibres have contributed both to an expansion in the volume of garments owned and the frequency of washing cycles. The average increase to 284 washing cycles and 260 drying cycles per domestic UK household is detailed and the implications of clothes washing examined in the context of environmental impact. The implications for garment design through an identification of the environmental impact of the leaching of artificial dyes and the generation of microfibre pollution, as well as the increase in water and energy consumption, were explored in the exhibition. More subtly the socio-historical implications of the changes were tracked via the cultural narratives of collective activities and social interactions with a call for more sustainable practices.

In a similar vein, this lost sense of community was explored in Nicola Perren's exhibition Quilting Together. In these works, the implications of the professional and amateur environment of creative industries was explored. The identification of creative quilting as a form of collective enterprise was pursued through the evaluation of the Meltham Quilting Bee. This project brought together the amateur and the professional in the generation of a quilt and art object that incorporated the enormous social and historical resonance of textile and garment production in Kirklees. Of significance was the implication of this project for the expansion of craft practices in cultural ecology as a form of social making.

The 'social ecology' of networks and interactions, and the cultural ecology of disciplinary negotiations were both in evidence in the Making Material Memories (15 April-3 May 2019) exhibition 


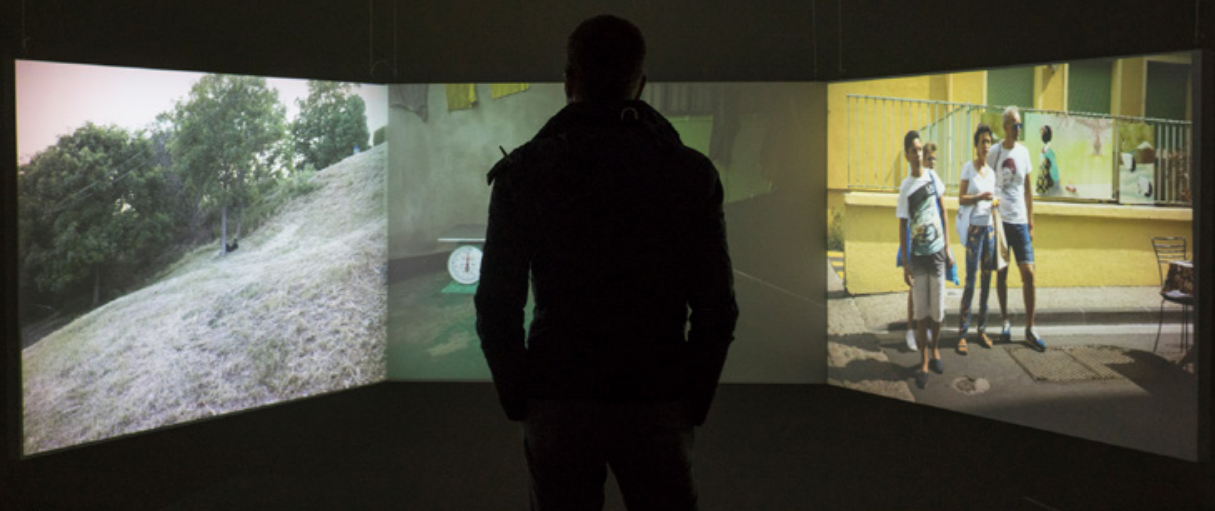

Flood

Richard Mulhearn

7 - 21 December 


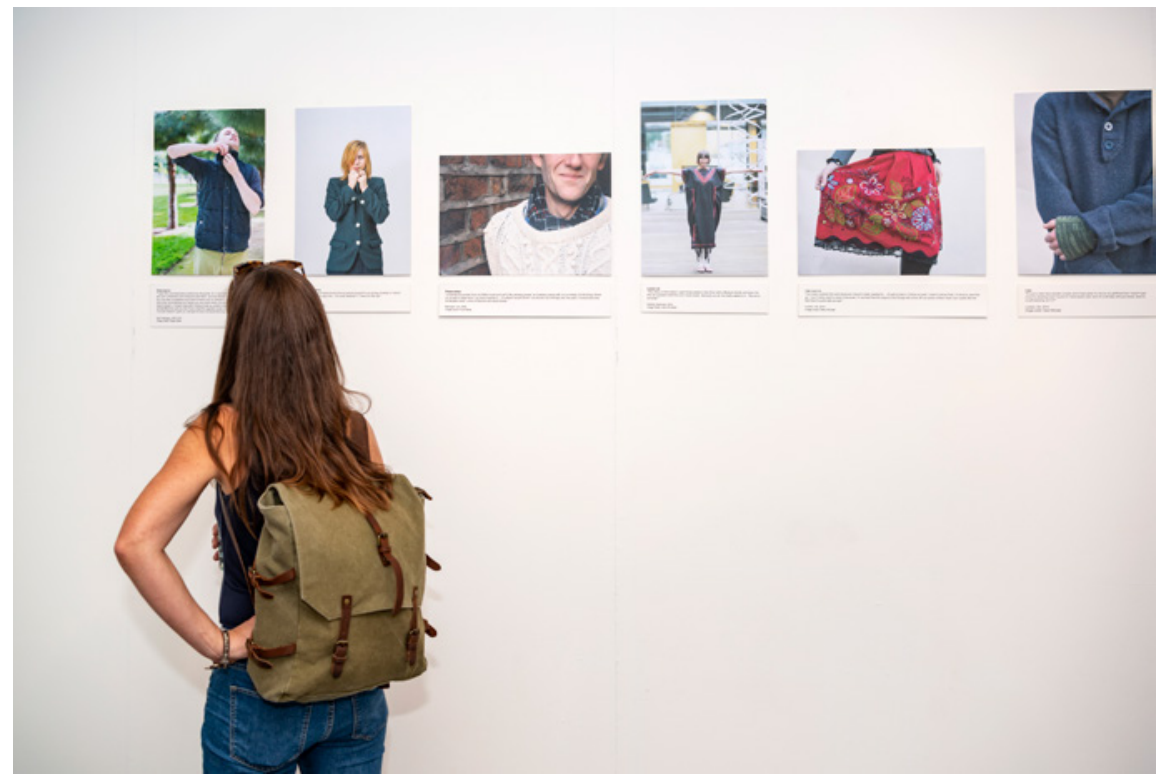

The Laundry Pile

24 June - 13 July 2019

Jade Lord, Emma Rigby

and Lizzie Harrison

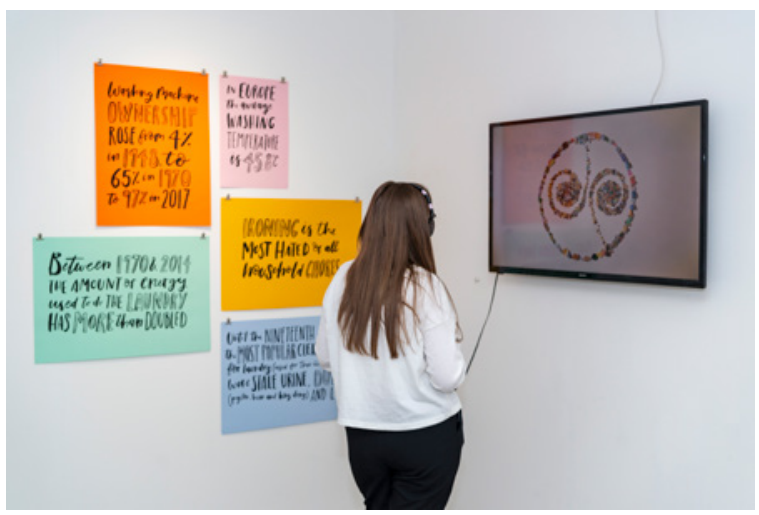



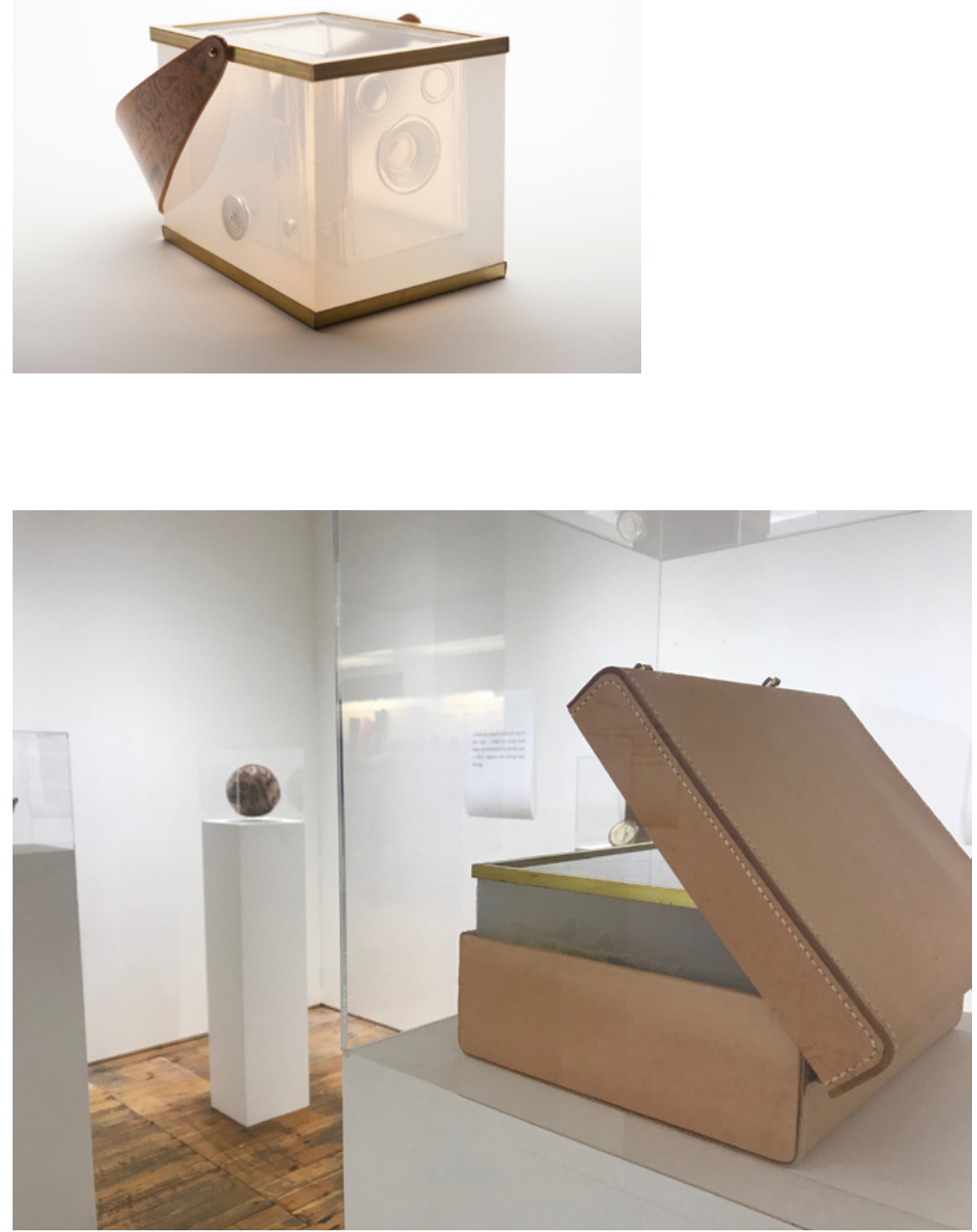


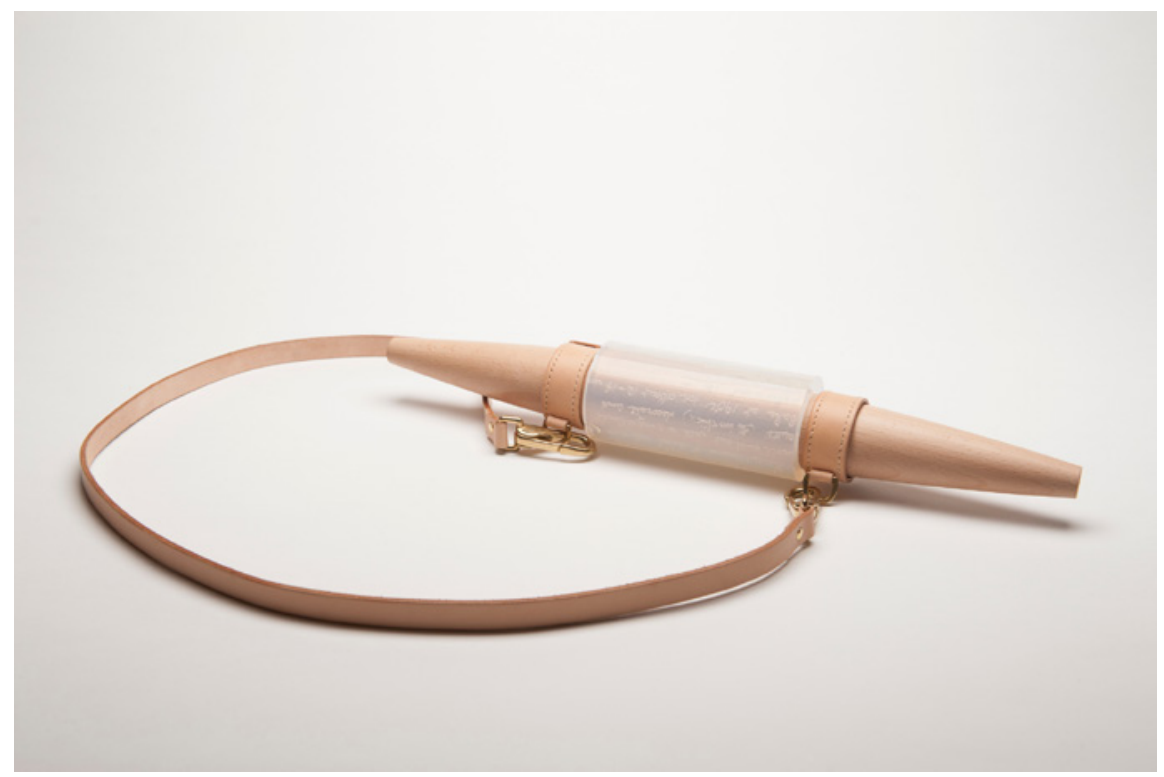

by Charlotte Goldthorpe. The show put on display the outcomes of her research, bringing together craft and storytelling in nine pieces. In 2015, Goldthorpe began to collect donated stories at her 'Lost Love Cafés'. The narratives documented relationships from the care of parental love to the fleeting passions of brief encounters. Goldthorpe processed elements from the gathered stories into bespoke craft artefacts. The narratives dictated the choices of materials, techniques, forms and processes. These included leather working, silicone casting, brass soldering, forging, wood and metal turning. Goldthorpe developed new processes - often in collaboration with skilled craft practitioners - to realise the finished works. Throughout the research process, friendships have developed between participants and craftspeople, allowing new stories and memories to be made. The show exemplified the notion of participation, partnership, collaboration, storytelling and rootedness that the Temporary Contemporary initiative offers as part of the solution for creating vibrant spaces through art and culture in UK towns. 


\section{The cellular organism}

The collaborative partnerships generated by the focus on the Queensgate Market site identified significant cultural opportunities. In taking an ecological approach Temporary Contemporary was able to produce multiple symbiotic benefits to all parties within an expanded cultural ecosystem. Time was a key element, impressed upon the local vendors and stall holders that our initiative would work within their existing spatial and temporal activities, that the title of the initiative meant that the existence of our project within any one existing place was indeed temporal, that if the project was not supporting the growth of the cultural ecology of the building it would cease to exist and move on.

The subsequent identification of abandoned or underused spaces within the building and the development of flexible times for the delivery of creative events were central to establishing the parameters of the project and crucial to building trust with our collaborative partners. The proposition of Temporary Contemporary was predicated on this open approach and the expectation of change and further development. It is important to stress that the model developed was not based on the specificity of any one space but on an understanding of the complexity of the concept 'place' as a stratified cultural construction of space and time. A new cultural paradigm conceived of as a cellular organism of great mobility and agency, adapting and inhabiting different spatial theatres, emerged as an exciting opportunity for urban transformation. This approach allowed for sensitive micro shifts in culture to be captured and named within the town and for the recognition of the complex interplay of factors that generate the locus of place and the subsequent integration of culture with daily lived experience.

${ }^{1}$ Steward, J., (1955, reprinted 1972)
The Theory of Cultural Change. Champaign, IL:
University of Illinois Press.
${ }^{3}$ Morton, T., (2013) Hyperobjects: Philosophy and Ecology after the End of the World. Minneapolis: The University of Minnesota Press.

\footnotetext{
${ }^{2}$ Holden, J. (2015) The Ecology of Culture

A Report commissioned by the Arts and

Humanities Research Council's Cultural Value

Project.'Arts and Humanities Research Council.

The full report can be found at:

ahrc.ukri.org/documents/project-reports-

andreviews/the-ecology-of-culture/

[accessed 6 February 2020].
} 


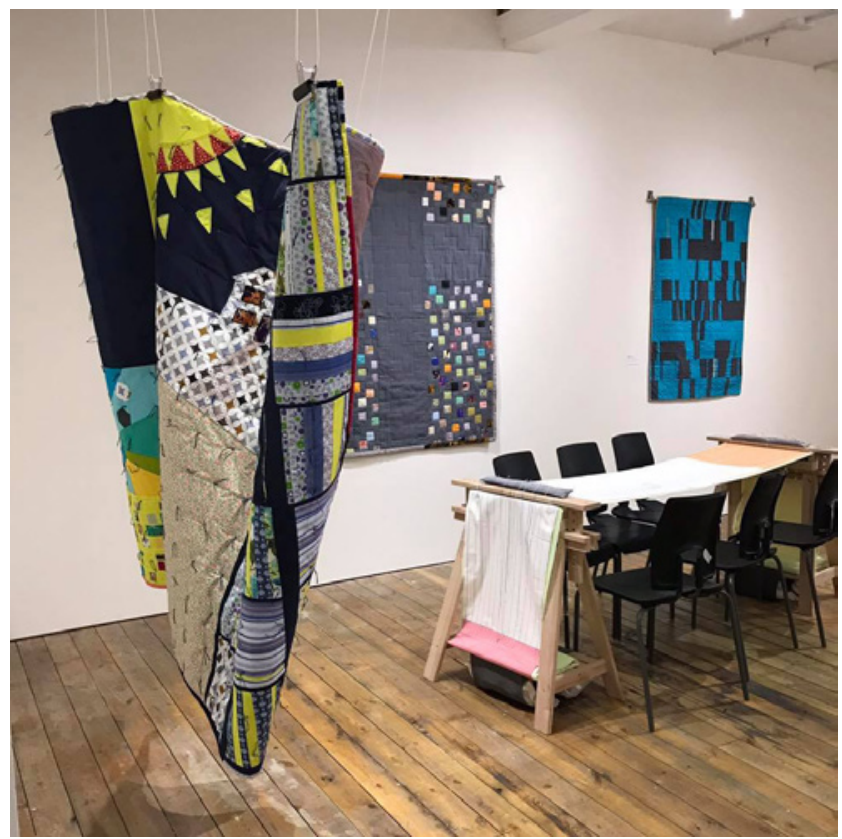



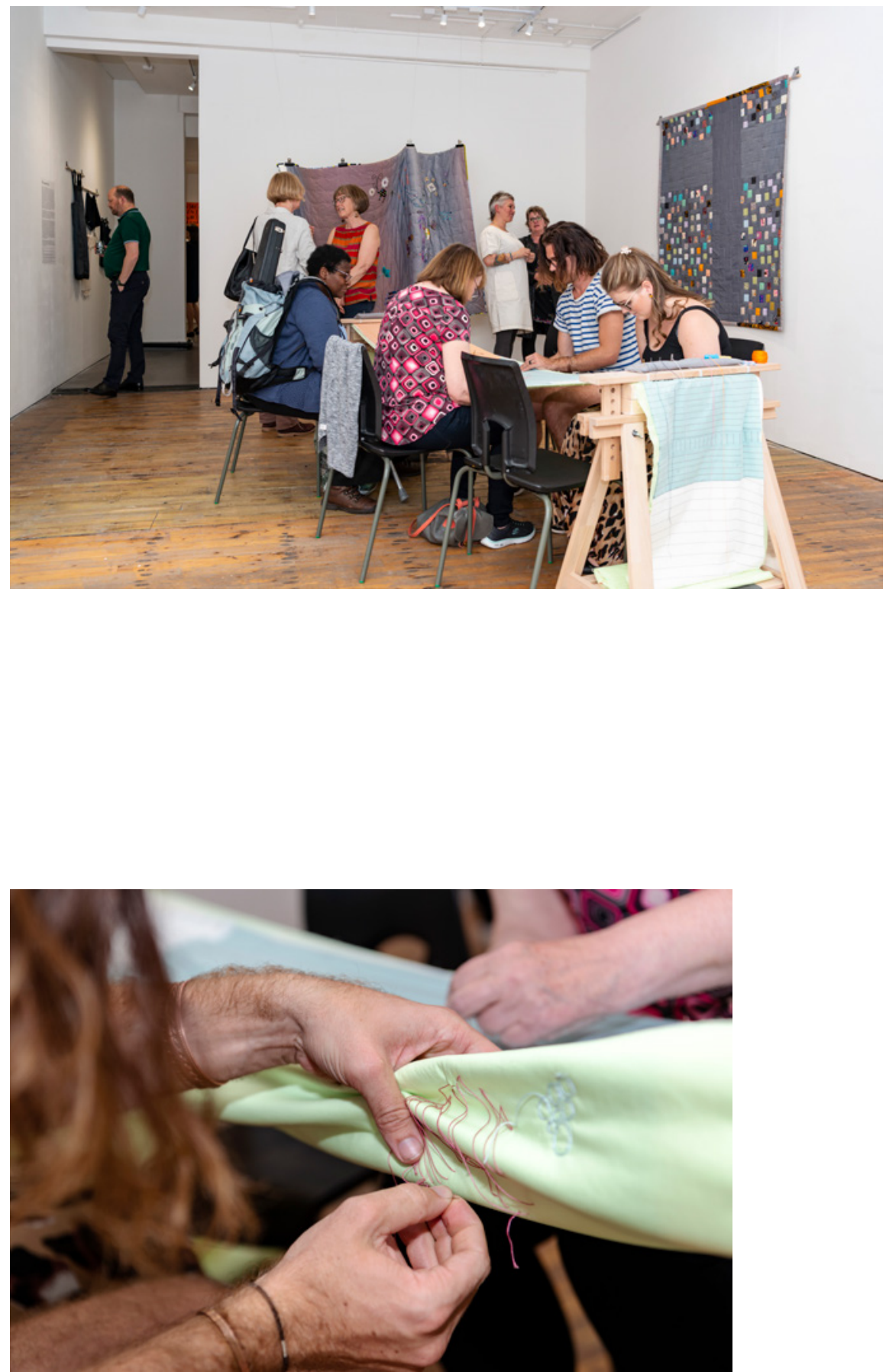


\section{Chapter Three}

\section{Looking is Contingent on the Apparatus of Viewing}

By Dr Anna Powell

\& Dr Linda Jean Pittwood 

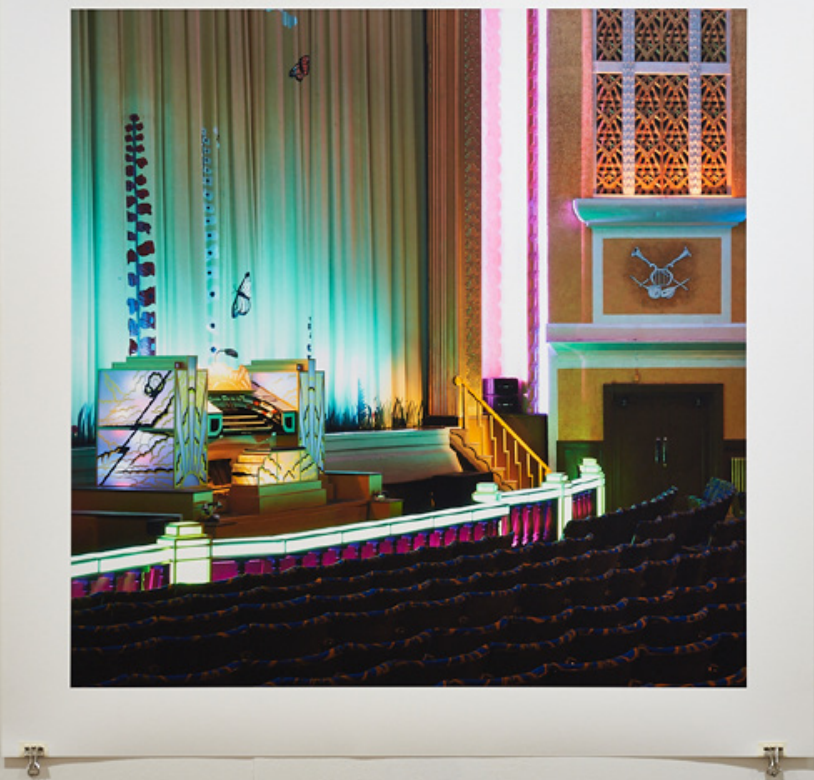

This chapter takes as its departure point the notion, articulated in a book by Dr Alison J. Carr, artist and curator of the Temporary Contemporary Market Gallery exhibition Showgirl Manifesto (11-27 October 2018), that 'looking is contingent on the apparatus of viewing. ${ }^{1}$ This evocative idea resonates with the cultural state of post-structural postmodernity (put forward by 20th century thinkers such as Michel Foucault, Jacques Derrida, Jacques Lacan and Judith Butler). Which is to say, put very simply, the theory that everything exists and can be understood only in relation to context, and that all is understood in, with and through its relationship to a person's (viewer's) existing knowledge and experience. But it is also a practical idea. To be able to see, objects must be made visible. To see a showgirl requires that we have access to that world. To see a photograph of a showgirl the image must be conceived, produced, printed, hung on a wall, displayed in a gallery designed for that purpose, and visitors must be invited in to receive it. It is at this point - this temporal and spatial moment of display - that the knowledges and experiences of the visitor become part of the apparatus of viewing. 
The exhibition programme within the Temporary Contemporary initiative does more than simply exhibit artworks (not that this is ever a simple endeavour). The exhibition programme is part of the wider Temporary Contemporary mission, achieved through its partnership with Kirklees Council, to articulate complex relationships, promote creativity and engage communities. These practices are achieved through each artwork, each exhibition, the exhibition programme itself, the Market Gallery's situation within the market, other related events and the existence of all of these parts relating to and negotiating with each other in the ecosystem. The ecosystem and its constituent parts contribute to the apparatus of viewing.

There is also a legacy of relationships to consider as part of this ecosystem (and part of the apparatus). The evolution of Temporary Contemporary has, in part, grown out of the legacy of the ROTOR programme. ROTOR was a five-year partnership programme of exhibitions that took place in Huddersfield Art Gallery, led by the University of Huddersfield, Kirklees Council and the gallery and supported by Arts Council England. ROTOR's main concern at the outset was to ask questions about, and provide a platform for exploring the ways in which people might access and engage with the arts. ROTOR aimed to invite viewers to make an engaged and real connection with the works it exhibited by embedding engagement into exhibition content and embracing the challenges of what it means to effectively engage with a viewer.

Through its exhibitions, Temporary Contemporary reflects a similar concern for enabling and supporting opportunities for making, showing and, importantly, for encountering arts and culture. This chapter reflects on the relationship between 'looking', 'understanding' and the apparatuses that affect and enable these activities by focussing on six exhibitions in the first year of the Market Gallery programme. Some of these exhibitions represented categories of persons, or memorialised individuals, others made visible the complex role of memory in articulating our own lived experiences. They questioned both representation and audience as part of the apparatus of looking, asking how the politics of looking, memory and memorial play their parts in constructing our understanding of the world.

\section{Representation and the politics of looking}

The exhibition Showgirl Manifesto (11-27 October 2018) included works by Alison J. Carr, Chloe Nightingale, Isabella Streffen, 


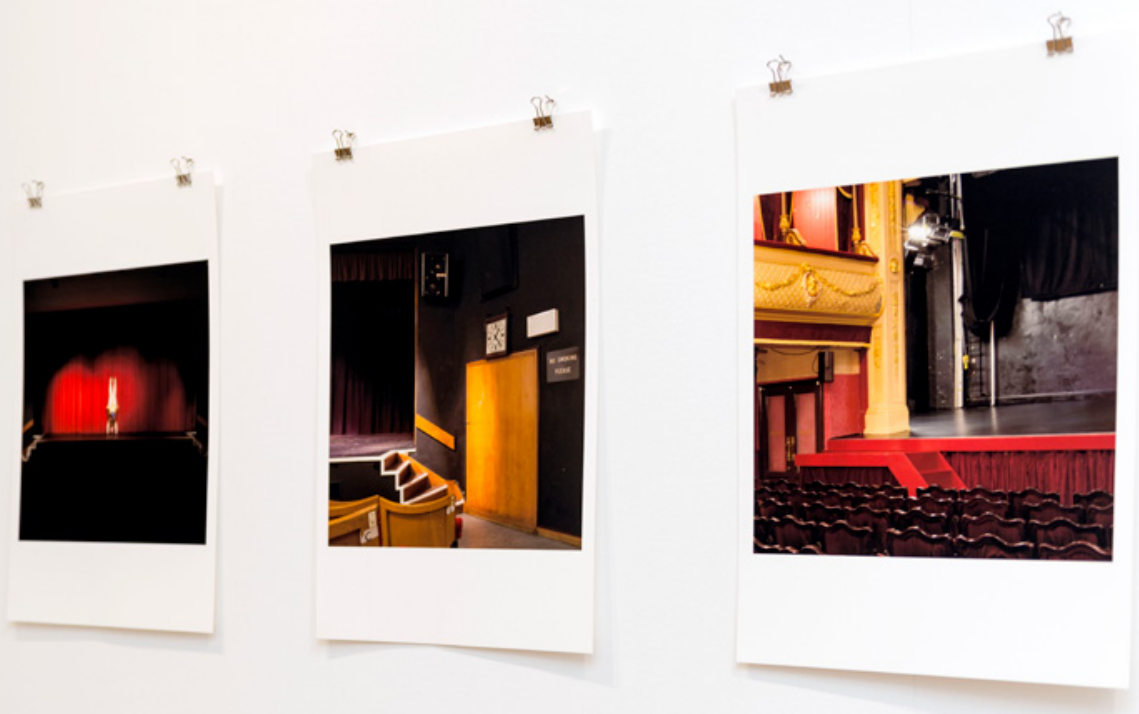

[Above] Left: Manifesto Alison J Carr Middle: Ascending A Staircase, Library Theatre, Sheffield, 1934 Alison J Carr Right: Ascending A Staircase, City Varieties, Leeds, 1865 Alison J Carr.

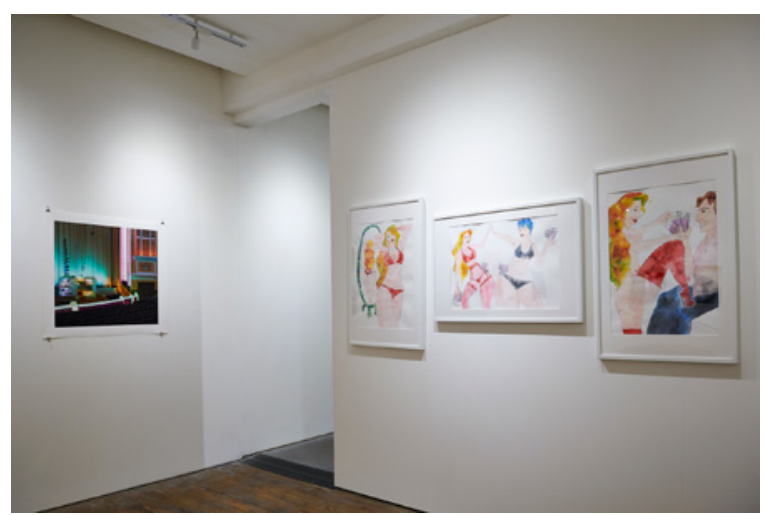

[Left] Right: Working in Heels, 2018, A1 Line drawings with Brusho pigment, Alice Finch. 
Alice Finch, Sophie Lisa Beresford, Sharon Kivland, Julie Cook, Lucy Halstead, Laura Gonzalez, Nwando Ebizie and Britten Leigh. These were curated responses to the ideas set out in Alison J. Carr's book entitled Viewing Pleasure and Being a Showgirl, How do I Look? In the book, Carr addresses themes of representation and looking through an exploration of the experiences of showgirls, asserting, as in the framing of this chapter that "looking is contingent on the apparatuses of viewing', and observing that the digital technologies of contemporary life often act as supplements to 'the liveness of performance encounters. ${ }^{2}$ Contextualising these ideas in relation to feminist theory and referencing contemporary and historical works and performances, the book concludes with Carr's 'Showgirl Manifesto'; the main inspiration behind the Temporary Contemporary exhibition at the Market Gallery. Raising questions about what it means to look and to be looked at, and about the relationship between women and consumerism, it investigated showgirl activity in its collection of photography and print works through, amongst others, the themes of empowerment and activism, enjoyment and femininity, performativity and authorship, and collectivism and individuality. The exhibition's critical engagement with ideas around looking and their historical provenance within theories of 'the gaze', necessitated an intentional degree of self-awareness in the exhibition's audience, who became simultaneously a participant in these discussions while remaining an observer of the images on show. This critical engagement underpins the complex nature of what it means to be a viewer.

The politics of looking, and critical engagement with looking and representation, was a topic foregrounded in the exhibition Photography and Lived Experience (14-21 June 2019), which showcased the work of five postgraduate photographers in the School of Art, Design and Architecture: Alex Beldea, Thomas Duffield, Tim Brown, Sam Welburn and Simon Weldon. The exhibition was preceded by a symposium on the subject of lived experience in the research, practice and reception of photography with a keynote address by Dr Benedict Burbridge (the University of Sussex). 'The gaze' in the exhibition Photography and Lived Experience was turned firmly towards photographic processes and outcomes, asking questions such as: how does photography enable us to see beyond the limits of our own experiences (as an apparatus of viewing)? And how is photography materially and constantly changing the reality of lived experience? 
Alex Beldea, Thomas Duffield, Tim Brown,

Sam Welburn and Simon Weldon.

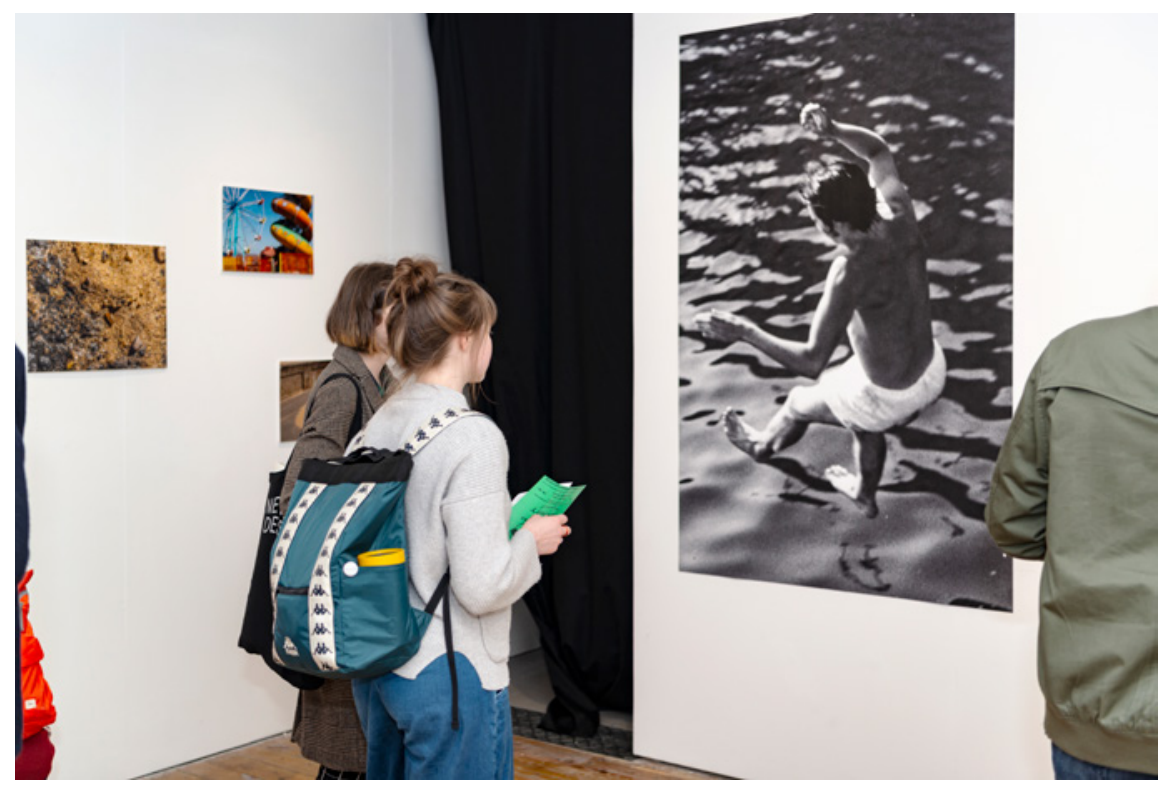



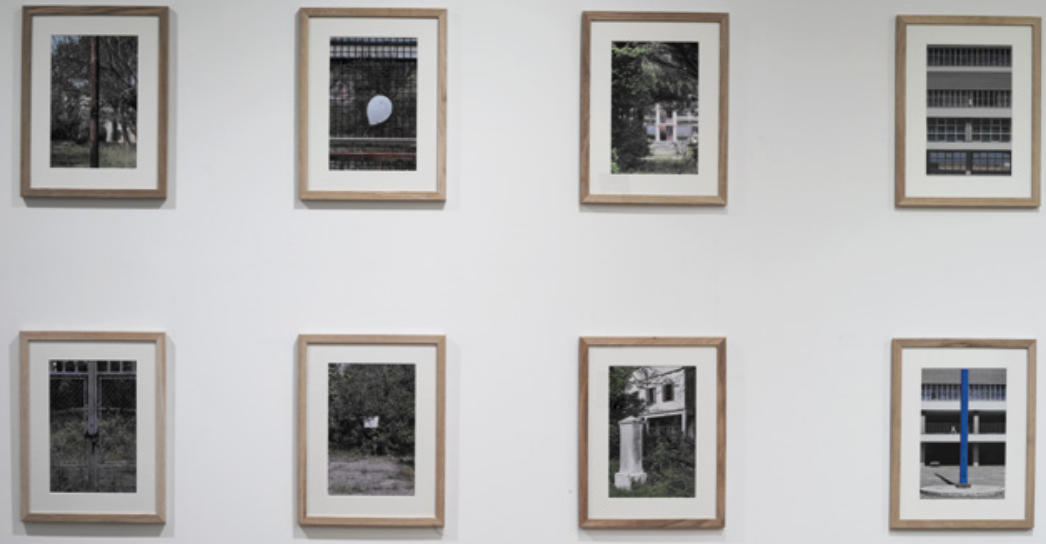
Alex Beldea, Thomas Duffield, Tim Brown,

Sam Welburn and Simon Weldon.
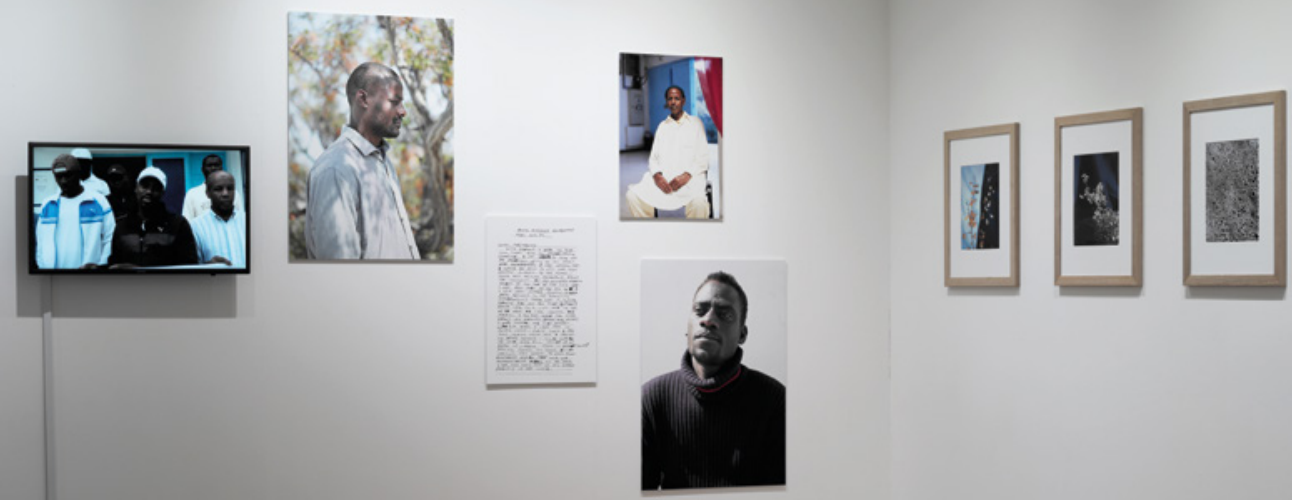
Beldea's work explored the plight of 32 male refugees from a range of African countries, who spent eight years stranded in Tunisia waiting for international relocation, using photographs, interviews, letters and video. The 32 fled to Tunisia when war broke out in Libya in 2011, a small group within the many tens of thousands that fled the conflict. Their fate lies with the Tunisian government, which continues to refuse to initiate proper asylum procedures. Complementary but historic, Brown's images represented the early stages of an investigation into colonie vacanze (children's summer camps) operating during the years of Mussolini's Fascist regime in 1930s-40s Italy and the difficult heritage they represent as both neglected and repurposed architectural sites. These summer camps generated for social betterment were designed to indoctrinate youth into the ideologies of Italian Fascism. Today, many of these architectural structures lie derelict and empty and are a haunt for urban explorers, photographers, graffiti and vandals, whilst others have been repurposed by private property developers for contemporary forms of cultural tourism.

In contrast, Duffield, Welburn and Weldon apply their photographic lens to the UK context in three separate projects. In Unturned Stones, Duffield explored the complex and dynamic nature of his own family life, questioning what discourses are produced through the multitude of photographs a family often produces. Welburn examined the passing of the traditional seaside holiday town, capturing the "rhythms" of the seaside industry and specifically the fate and "lost and fading culture" of the Northern English seaside. Weldon's work is a personal journal responding to his father's own collection of photographic material "in a pursuit of answers and resolution" following his father's death. Together, the five artists explored the breadth of photography's potential to examine, document and memorialise lives, to tell intimate stories of people affected by macro political decisions and shifts, but also to speak to how photography practice and photographic objects can interrupt our memories, making it harder to live with particular 'truths'.

\section{Reconstructed memories}

Garry Clarkson's Empire of Memory (14-21 June 2019) addressed ideas around looking, through image-based manifestations of memory. His exhibition asked questions about how we know and to some extent construct - our past and present through visual representations. It addressed the possibilities of memory on both a macro and micro scale; presenting contemporary 


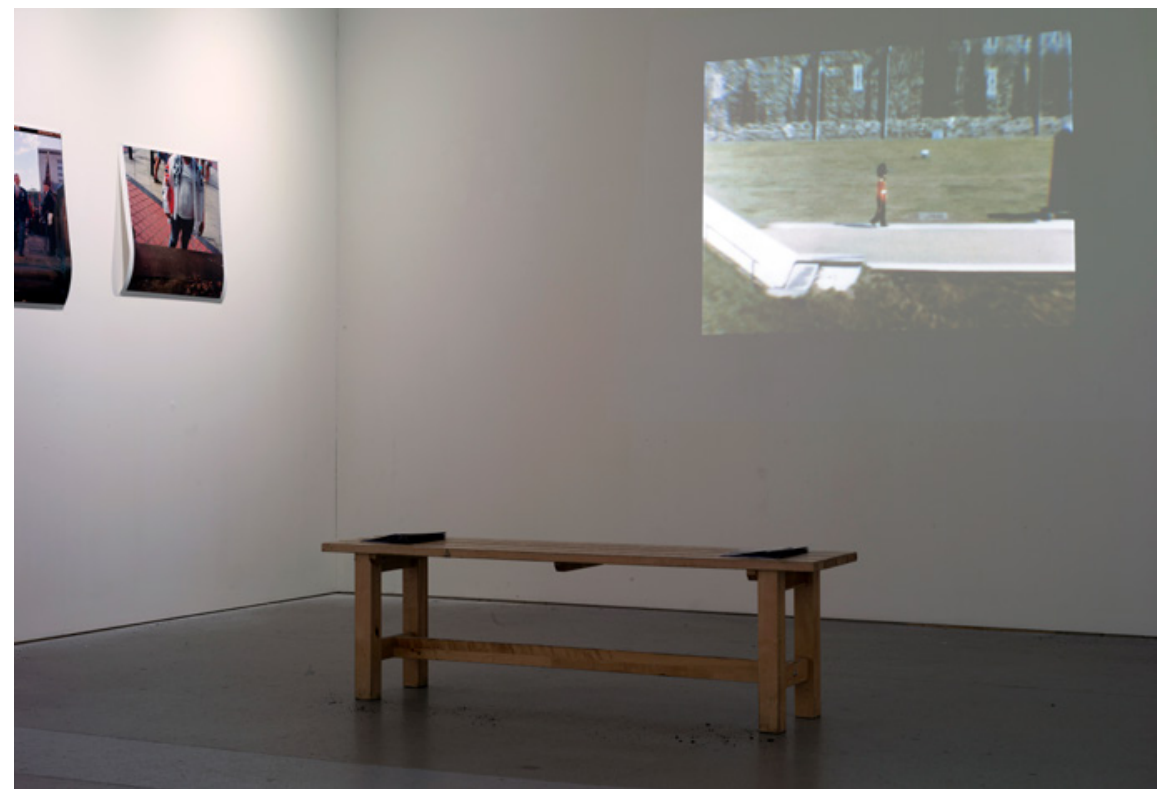

Empire of Memory

10 - 26 January 2019

Garry Clarkson

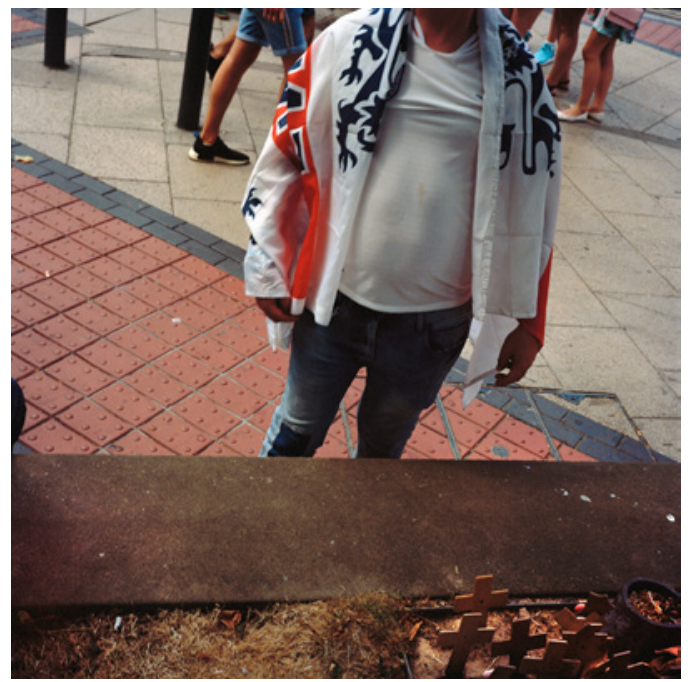


photographs alongside archive material, family albums and public records. The exhibition examined different manifestations of collective and individual memory, and the ways in which remembering and forgetting exist in a complex relationship with conflict and with healing. Empire of Memory connected with its viewer not only through its subject matter, which presented images that were narratively fragmented and yet somehow familiar and relatable, but also through the ways in which it asked the viewer to consider and question the processes behind the making of images. This purposeful transparency; a breaking of the 'fourth wall' of sorts, aimed to prompt debate about how war and conflict are represented in the media and through personal visual narratives. It had the further effect of inviting audiences to consider the reliability of images, and in particular, the reliability of the photograph as a tool for recording events from the past; that is, the past that is made up of personal memories and feelings.

Dr Liam Devlin's exhibition entitled Bigfoot in West Belfast followed the postgraduate research symposium Photography and Lived Experience. Devlin's work reflects on his early life growing up with the conflict in Northern Ireland in the 1970s and 1980s. The exhibition foregrounded the significance of personal experiences and collective imagination in how we remember the past, and their relationship to media representations of historical events. Its video montage and wall text intertwined the aesthetics of photojournalism - the documentary evidence of the past upon which we so often base our understanding of past events - with more subjective and imaginative interpretations (magic realism) of a remembered past. In doing so it asked viewers to question what they see, and to critically re-engage with authoritative representations of history and reality. Both Clarkson's and

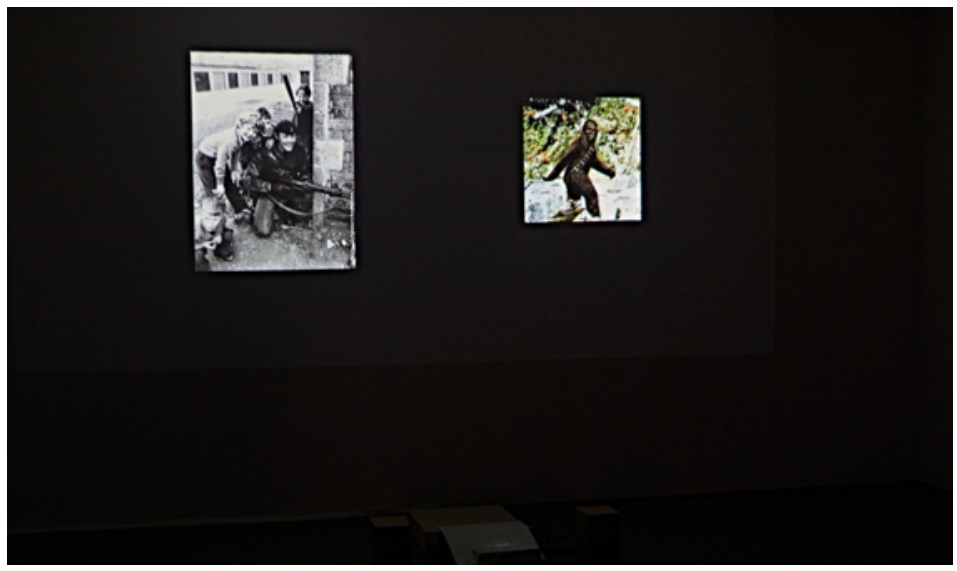



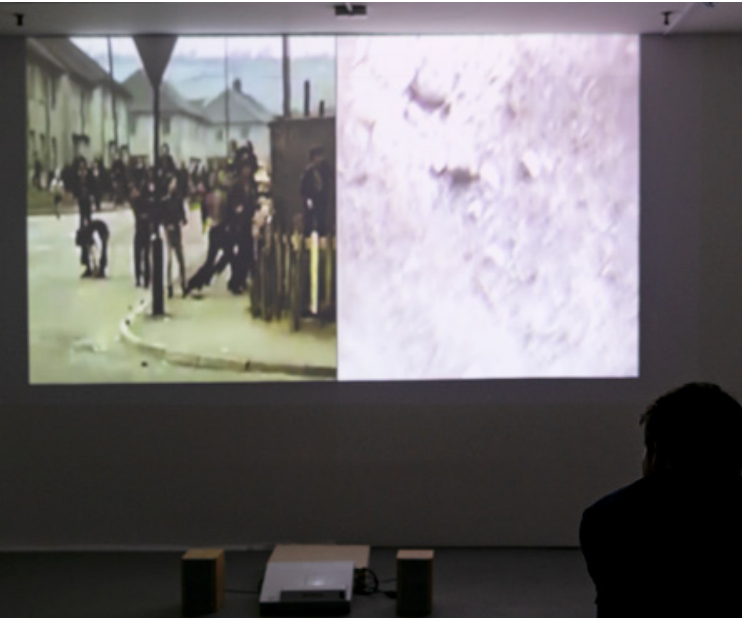

Bigfoot in West Belfast

14 - 21 June 2019

Dr Liam Devlin 
Dr Stella Baraklianou
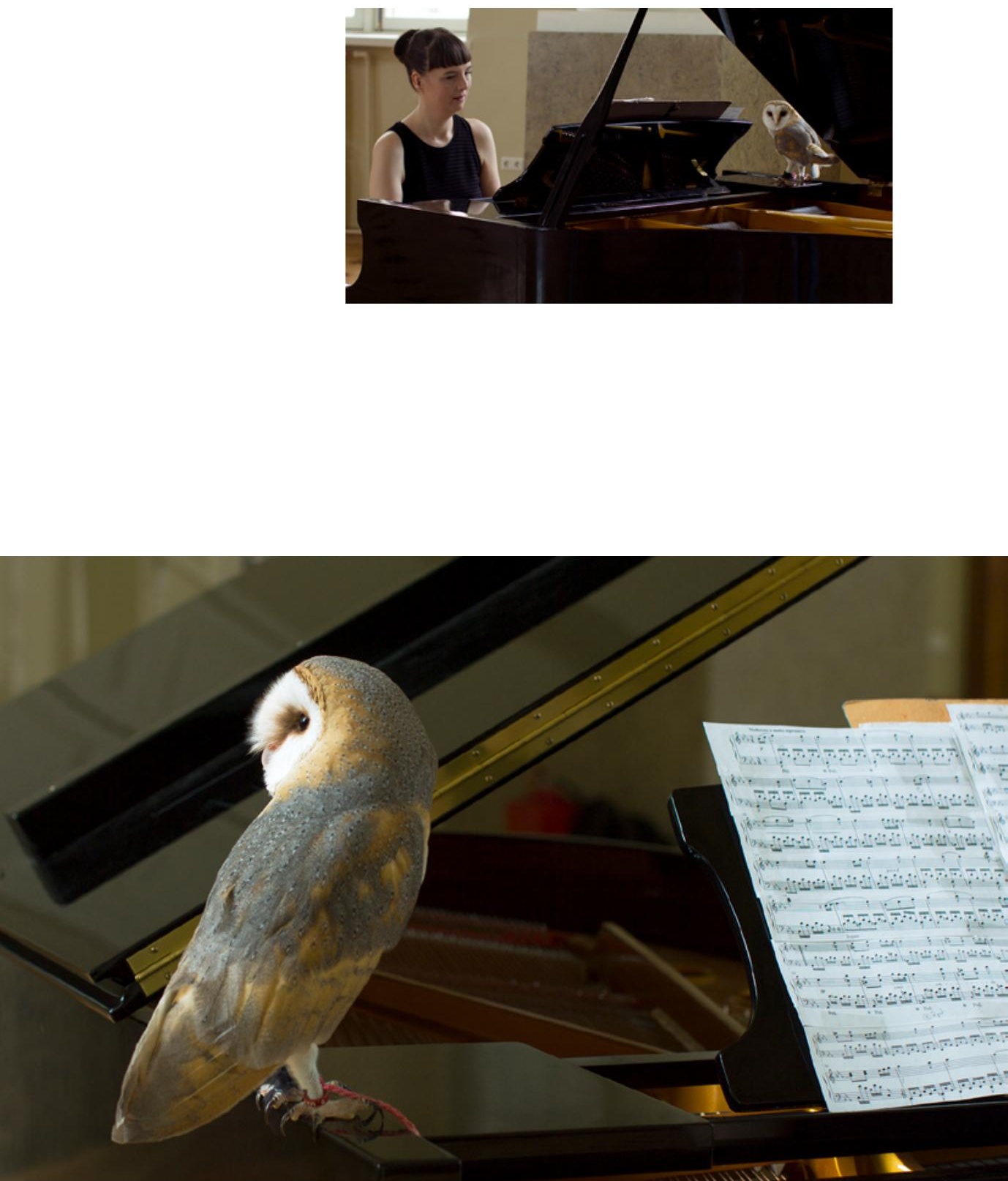
Devlin's approaches to looking resonated closely with Temporary Contemporary's concern for questioning the wider role of gallery and exhibition in curating visual representations of events, ideas, stories and memories.

\section{Memorialisation and monuments}

Dr Stella Baraklianou's Nocturne exhibition (15 April-3 May 2019) addressed representation and audience through its reflections on moments of encounter, and through its intentionally confused temporality which asked audiences to consider when they are looking, as well what they are looking at. Showcasing experimental film and writings which were the outcome of Baraklianou's residency at St Petersburg in June 2018-May 2019, Nocturne was a collaborative work with musician Katelyn Clark, whose sound and performance work can be observed throughout the film. Based around the life and work of piano composer John Field (b Dublin 1782-Moscow 1837), the exhibition, with its immersive, floor to ceiling projections, asked questions about instances where diverse practices convene - from music composition to performance, from writing to photography - interrogating meaning at this moment of encounter, and questioning the processes of translation as practices that are transmuted across media. It further addressed the subject of convergence through the ambiguous sense of time it presented, with its projected image of Moscow station in apparent broad daylight, when in fact the images were filmed at the break of dawn during the 'white nights' of Russian summertime; the night-long luminosity which is the result of its high latitude. The figure of the owl in the film - the nocturnal creature awake and disoriented in the light-flooded music room - heightens this sense of temporal uncertainty. In her questioning of the ways in which blurring and slippage occurs at the intersection of practices, Baraklianou used the organism as a metaphor, as can be seen in the exhibition extract below, in which she describes the musical score and painting:

Let's begin with a square; not any square but a small, black, square, just a black rectangle. Appearing inside this perfect square the figures of musical notes, forming eventually a musical score. It is an invisible score, one of unfinished streaks of black on black, with brush strokes so thick it resembles some kind of trembling, living organism breathing in the depths of blackness. 
Dr Dale Holmes' exhibition entitled A Proposal for a Monument for Carl Einstein (10-26 January 2019) consisted of painting, text fragments and sculptural monuments, and asked viewers to contemplate the uncertainty surrounding the graveside orations by Carl Einstein for Rosa Luxemburg. A further exploration of the role of memory as a mode of seeing and knowing, Holmes' exhibition took 'the memorial' as its central idea, asking viewers to question why it is that certain historical events are recorded and recounted while others are left to slip away, and the significance of this for our relationship with the past, present and future. As part of his exhibition, Holmes collaborated with John Robin Bold, Jorge Boehringer and The Fucks to present what he described as a series of sonic interventions, which included a solo performance, a group Situation and a composed, as he describes it, 'dis-coordinated' ensemble entitled The Fibrous Body (for Carl, Rosa, and Karl). These responses to his exhibition fittingly echoed the values embodied in the research underpinning the show; an in-depth international project culminating in a publication whose innovative approach to history-(re)writing presents a rethinking of the relevance of historical 'facts' for today's reader, drawing attention to the precariousness of memory and giving a voice to those rendered voiceless by the canon. These sonic interventions were exercises in public engagement not merely to attract audiences to the exhibition but rather, in the spirit of Temporary Contemporary, they harnessed the power of dialogue - one of the key narratives within Holmes' work - to provide a space for genuine interaction with the artist, the works and the ideas behind them.

Harold Bloom's statements that history as we know it is 'identical with the literary Art of Memory', and that 'Memory is always an art, even when it works involuntarily" 3 might be seen to resonate throughout all of these exhibitions. Each of them presented provocations around representation and audience, and intentionally encouraged its viewers to ask questions about what and how we view, represent, and remember our world; our reality. The exhibitions and Temporary Contemporary ask us and help us to consider more deeply the event of looking, and the multiple apparatuses that constitute the experiences of looking. 
A proposal for a monument for Carl Einstein, to be sited at the location of his suicide in LestelleBetharram, Pyrenées, France.

This work is proposed as a monument to the memory of the German Jewish Intellectual Carl Einstein. Einstein was one of many prominent figures who were forced into exile by the rise of fascism and the eventual cementing of the Nazi Party's power during the Weimar period into the early 1930 . Einstein was the first and most incisive critic of Cubism and with his close friend Daniel-Henry Kahnweiller brought the work of Pablo Picasso and Georges Braque to prominence. During the Spanish Civil War, he fought against the Fascists as a member of the anarcho-syndicalist Durruti Column. Trapped in southern France on 5 July 1940, rather than be captured by the Nazis, Einstein took his life by jumping from a bridge.

\section{A proposal for a monument for Carl Einstein, to be sited at the location of his hermitage on Calle Einstein, Maspalomas, Gran Canaria, Spain.}

This work is proposed as a monument to the memory of the German Jewish Intellectual Carl Einstein. Einstein was one of many prominent figures who were forced into exile by the rise of fascism and the eventual cementing of the Nazi Party's power during the Weimar period into the early 1930 . Einstein was the first and most incisive critic of Cubism and with his close friend Daniel-Henry Kahnweiller brought the work of Pablo Picasso and Georges Braque to prominence. During the Spanish Civil War, he fought against the Fascists as a member of the anarcho-syndicalist Durruti Column. Trapped in southern France on 5 July 1940 , rather than be captured by the Nazis, Einstein faked his own suicide and escaped over the border into Spain, eventually making it to the island of Gran Canaria where he lived a long quiet life walking in the hills, writing poetry and fiction under a pen name and sunbathing naked in the sand dunes.

He passed away peacefully on 23 August 1972 . 


\section{Chapter Four}

The Exhibition in Art, Design and Architecture

By Professor Nic Clear 


\section{Designing Curation: The Exhibition in Art, Design and Architecture}

Throughout my career I have used exhibitions to develop my research, my teaching and to support the works of colleagues and external collaborators. I approach exhibitions not as a rarefied opportunity to display work, though it can be that, but as a practical and effective means to generate, develop, assess and disseminate ideas and practices. Exhibitions come in many shapes and sizes offering various degrees of opportunity, but an exhibition of any kind offers the possibility to engage with a piece of work, a space and an audience. Exhibitions are a way of supporting practice, but they can also be a form of practice in their own right. In this text I will contextualise my own exhibition practice and show how it is part of wider set of aspirations that critically engage with research within the School of Art Design and Architecture and the development of cultural practices in the town of Huddersfield.

\section{The Exhibition as a Site of Privilege}

The privileging of the exhibition as an exclusive means of display principally dates back to the academic traditions of 18th and 19th century Paris, when selected works were chosen for the Paris Salon to represent officially sanctioned neo-classical culture of the Ecole des Beaux Arts. ${ }^{1}$ The role of the Salon exhibition was to perpetuate models and values of type, connoisseurship and academic elitism. While the Salon reinforced norms of received taste, this was increasingly opposed by independent exhibitions, such as the Salon des Refusés, which resisted the mainstream pronouncements on what was good and worthy, though they still tended to adopt many of the same formal tropes of presentation. ${ }^{2}$ At the beginning of the 20th century, particularly in reaction to the horrors of World War I, this sense of opposition was further heightened by more radical elements rejecting the values of the ancient regime altogether and transformed the exhibition through lampooning its format and structures. Many of these exhibitions have subsequently become iconic within the avantgarde canon. The second half of the 20th century saw the rise of an institutionalised model of art practice where the role of the gallery became akin to a secular place of worship, pandering to an expanding consumer culture, but once again privileged the dominant values of the haute bourgeoise. The typological model for the gallery space, the 'White Cube', ${ }^{3}$ developed an ascetic context within which the supposedly neutral surroundings allowed for an unfettered contemplation of the art object, or in some cases the absence of the art object. 


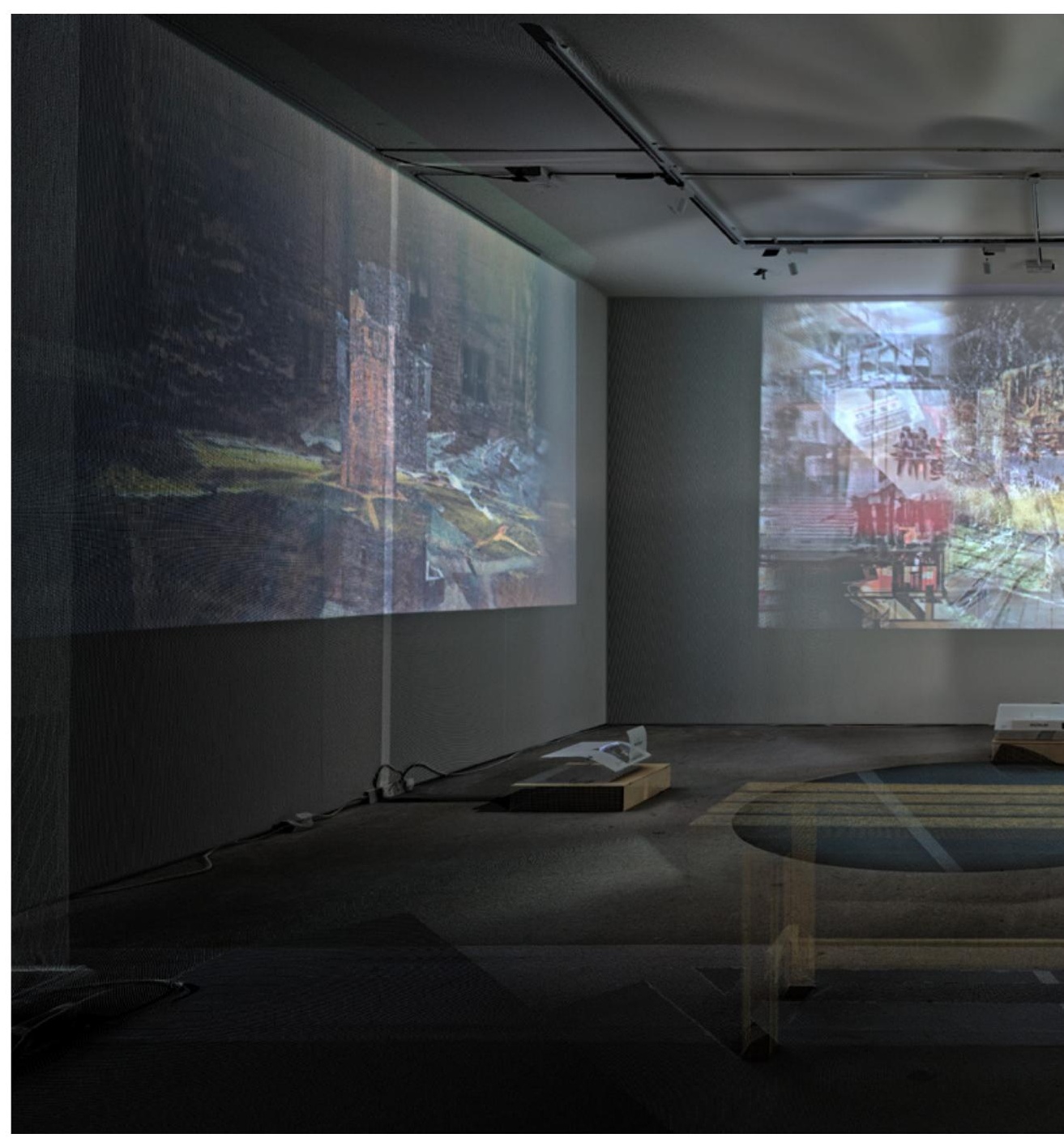

Synthetic Spaces

31 January- 4 March 2019

Professor Nic Clear and Hyun Jun Park 


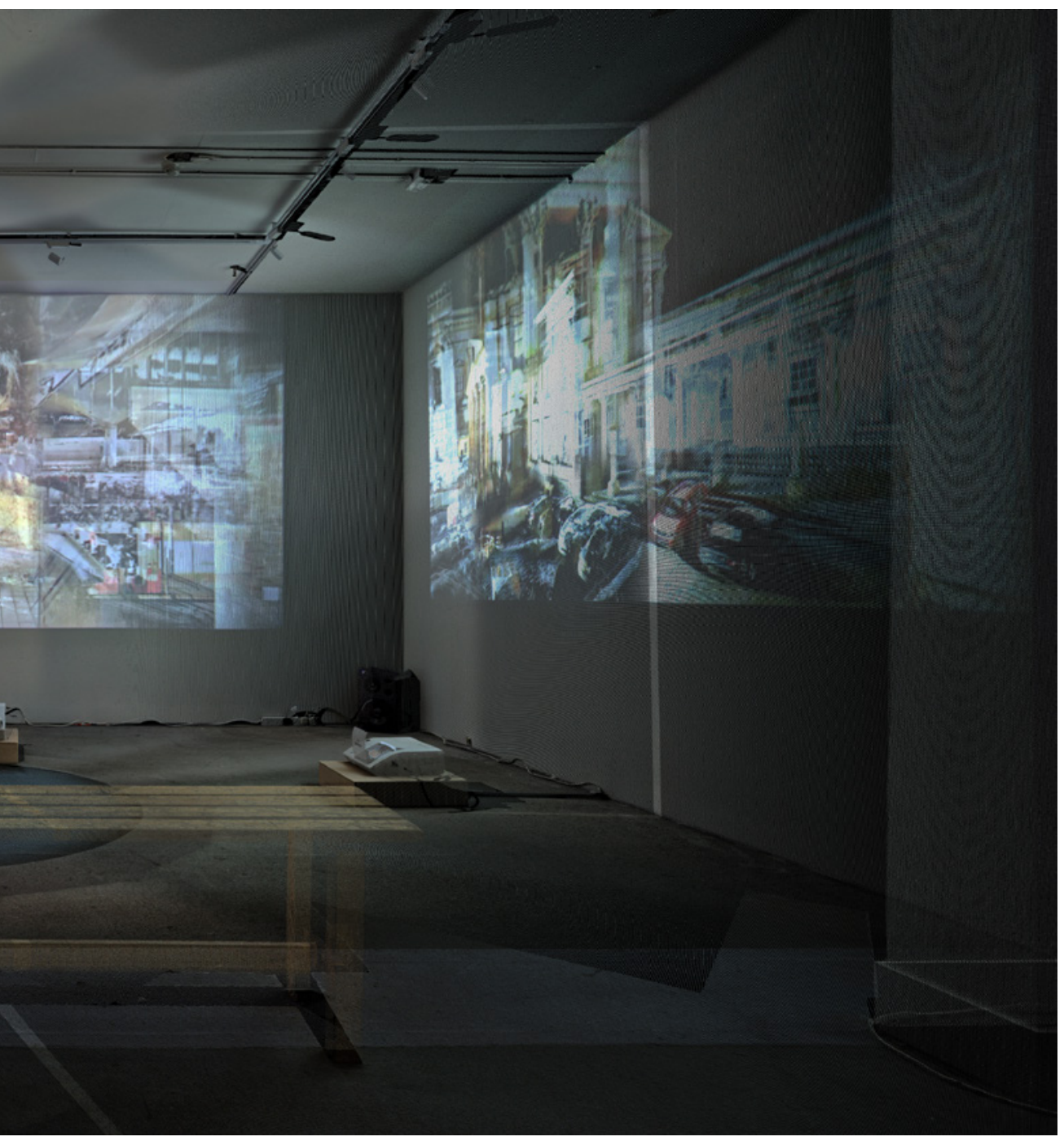


The elitist model of the gallery should be understood alongside its other principle contemporary function, the gallery as a place of economic exchange. The American art critic and gallerist Dave Hickey has argued that art should not receive public subsidy for this reason, and in his disdain for an institutionalised art culture, argues that the vested interests that maintain the hegemonic view of art culture has led to sterility and a lack of risk taking. Another common tendency that fixes the elitist model of art practice is the way that galleries are created as the vanity projects of rich individuals, or status symbols of culturally rapacious organisations that set up foundations, so-called 'hubrispace', and commission 'starchitects' to design object galleries every bit as rarefied as the work on display.

\section{The Exhibition and its Social Function}

The consideration of the exhibition as a format in its own right has been part of art practice since Dada and Surrealism, and further developed through Conceptual art. ${ }^{6}$ These tendencies helped to lay bare the formulaic vectors of art as commodity, exploding the conception that the exhibition is an innocent participant in the dissemination of art practice, and reframing it as one of art's legitimating structures. While the conceptual strategy of negating the honorific status of the exhibition through parody or opposition has itself been recuperated as part of the contemporary spectacle, ${ }^{7}$ opportunities to develop ideas and practices outside of the corporate art complex are still an important part of creative activity.

Not all galleries are constrained by the straightjackets of elitism and commerce, many do challenge commercial stereotypes and construct models of gallery practice that are anti-elitist, inclusive, not principally concerned with commerce, and eschew the mythology of the gallery as a place for 'high-seriousness'. These spaces help to promote the idea that exhibitions can have a wider social function, while producing work that is meaningful and engaging to a wider set of audiences. ${ }^{8}$

I first became involved in galleries as a year-out architectural student when I found regular employment as an art technician to supplement earnings as a freelance architectural designer. I enjoyed the work, more than architectural drafting, as it could be intellectually stimulating, physically engaging and posed challenges of working creatively with others. As a result of my experience as a technician I have been using exhibitions as an integral part of my practice, as both a teacher and designer, 
and given that one of my principal architectural interests has been to engage with concepts of spatial practice through the construction, design and realisation of projects, the design of exhibitions gives an opportunity to directly engage with this. Through my experiences I began to view the exhibition less as an end in-itself, but as a tactic in the creation, development and dissemination of ideas and an opportunity to meet and collaborate with existing practitioners and to find ways to create new connections within a wider constituency of practices.

Since my arrival at the University of Huddersfield in January 2018 I have been actively involved with the Temporary Contemporary initiative, both in terms of my own practice, as a researcher and teacher, but also as the Head of the Department of Architecture \& 3D who sees the opportunities afforded by Temporary Contemporary for both staff and students to display work and engage with the local community. Exhibitions should work at many levels, the role of the gallery and the exhibition in a context such as Huddersfield can educate and entertain and hopefully contribute to a vibrant cultural base.

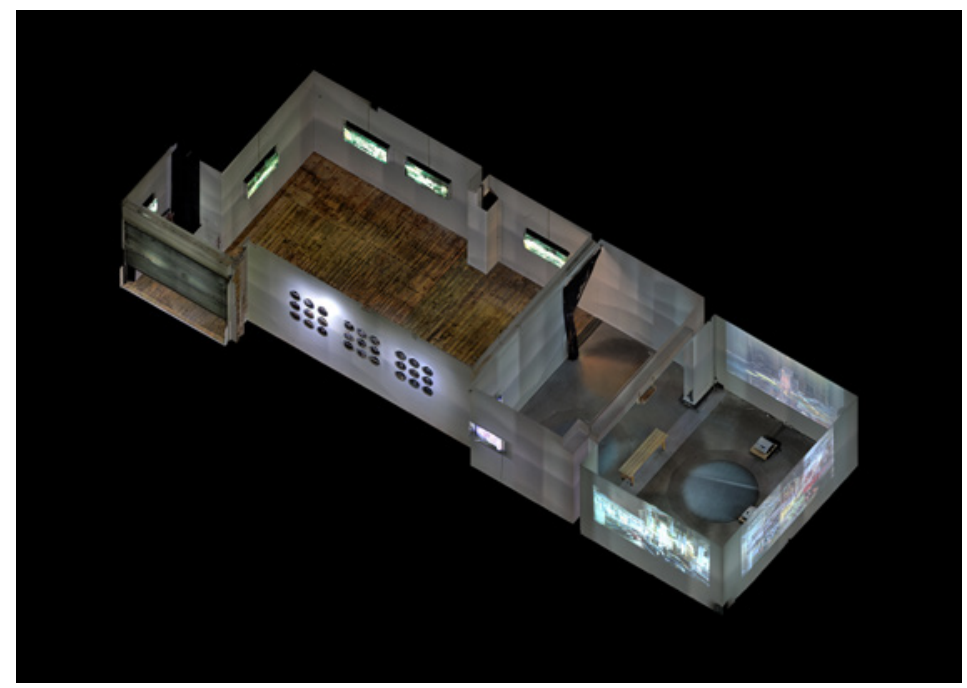



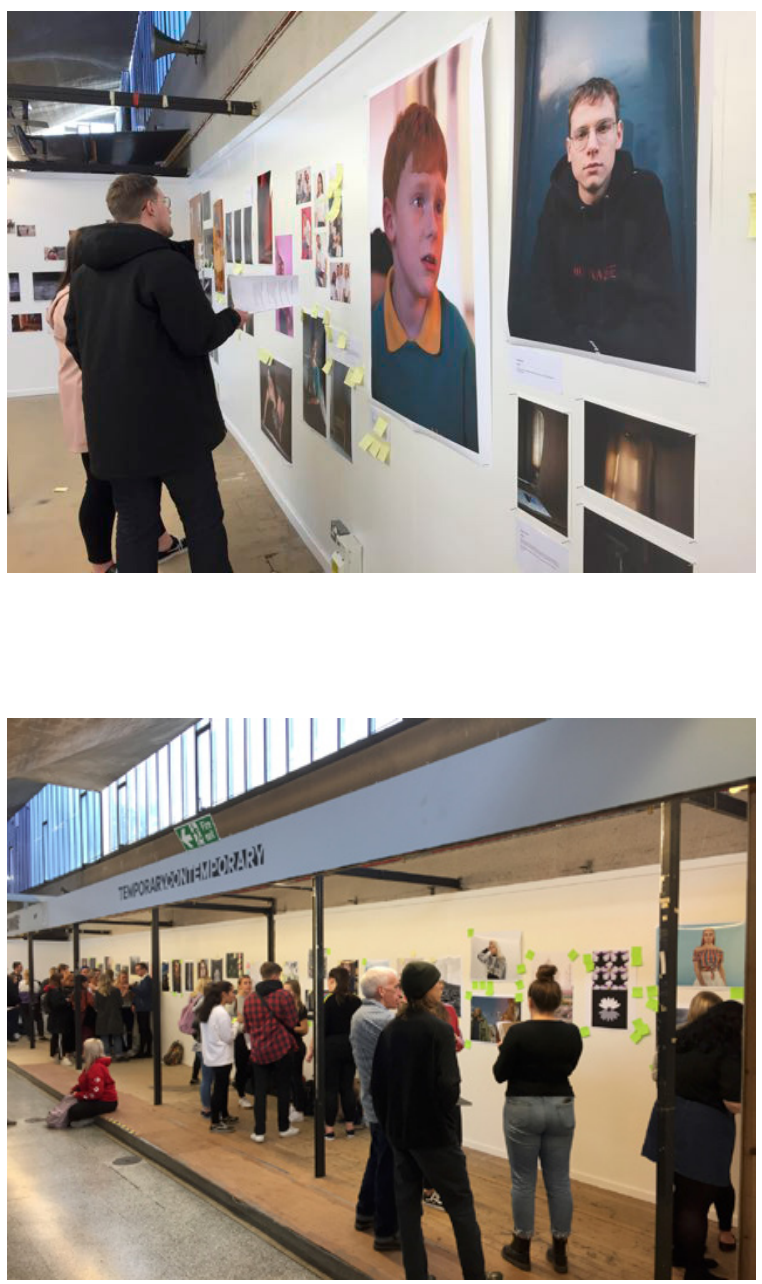

Undergraduate student work from BA (hons) Photography on display in the Market Hardware space. 


\section{The Exhibition in Teaching and Research}

Throughout my teaching career I have used exhibitions as part of my teaching practice; exhibitions can be a powerful tool to enable students to engage with the impact that their work can have beyond the institution. There are four principle areas where exhibitions can prove to be of great importance in supporting student development:

1. To give students a deadline that emulates real world practice.

2. To enable students to understand the importance of 'framing' their work for external audiences.

3. To disseminate the work outside the narrow confines of the immediate academic context within which it was produced.

4. To encourage learners to see themselves as participants in culture rather than observers, especially as social media channels now play such a big part in the dissemination of the work. Through this process learners can develop important skills of curating their own real-world and online spaces.

The Market Hardware space showcasing student works as part of Temporary Contemporary interventions in Queensgate Indoor Market, has been used by a variety of student groups for a range of activities from a pop-up gallery to a space for peer-to-peer critical feedback ('crits'). This diverse group of students from year 1 undergraduate to Masters students have been engaged at different times and in different ways and the feedback from students around the actuality of seeing work in a public space has been overwhelmingly positive.

Much of the research that I have produced over the last 20 years has been developed through the use of exhibitions as an integral part of my practice. Many of these have been self-initiated and the exhibition itself is considered as part of a wider design practice. During this period I have also produced a number of commercial exhibitions. The role of the exhibition is often to set deadlines, forcing me to produce work. It also gives me an opportunity to receive feedback on work and will often provide opportunities for future outlets of my work. Exhibitions are machines for making work.

In the last five years I have set-up, organised, designed and installed over 30 exhibitions, nationally and internationally, but I do not consider myself a curator in any traditional sense. 
The term curator comes with specific associations and implications, and the role that I take does not just consider the themes of the show and selecting the works, but thinking, in Lefebvre's terms, about the production of the space of the exhibition: the conceived, perceived and practiced. ${ }^{9}$ It would perhaps be more accurate to say I design exhibitions, but hopefully that design constitutes considerably more than the spatial layout and the visual forms, which can also incorporate graphic material such as posters and signage. While all exhibitions are designed, and the spatial organisation of any exhibition constitutes a conscious aesthetic intervention within a gallery space, I also design the concepts and often the content as well. Whereas curation and design are usually considered separate activities, my practice consciously integrates the syntactical structures of how the artefacts are assembled and presented, alongside the semantic relations between works and between the works and the audience.

\section{The Exhibition as Case Study}

The series of exhibitions that form the Synthetic Spaces project serve as an example of how an exhibition can be used as a way to expand practice through the creation of new content, both in terms of the visual works and accompanying written texts. Also, how an exhibition can facilitate establishing the development and dissemination of a body of work leading to an integrated portfolio of research activity.

The project started with an opportunity to exhibit in the Market Gallery, the invitation was made at the beginning of December 2018 with the show scheduled to open at the end of January 2019. My colleague Hyun Jun Park and I had been working with 3D laser scanning images for some time and rather than exhibiting scans that we had already produced, as was expected, it was decided to create new work based on ideas that we had been discussing and specifically locating the work within Huddersfield and featuring three of its iconic landmarks: Castle Hill, the Railway Station and Queensgate Market itself.

3D scanning is a technology that offers powerful ways of capturing and representing space through the creation of evocative point-cloud models, though it is currently used principally as a tool for surveying. Synthetic Spaces was an opportunity to develop a scanning project with a more narrative focus, through the creation of an immersive video installation and a series of graphic pieces utilising complex layered compositions. 


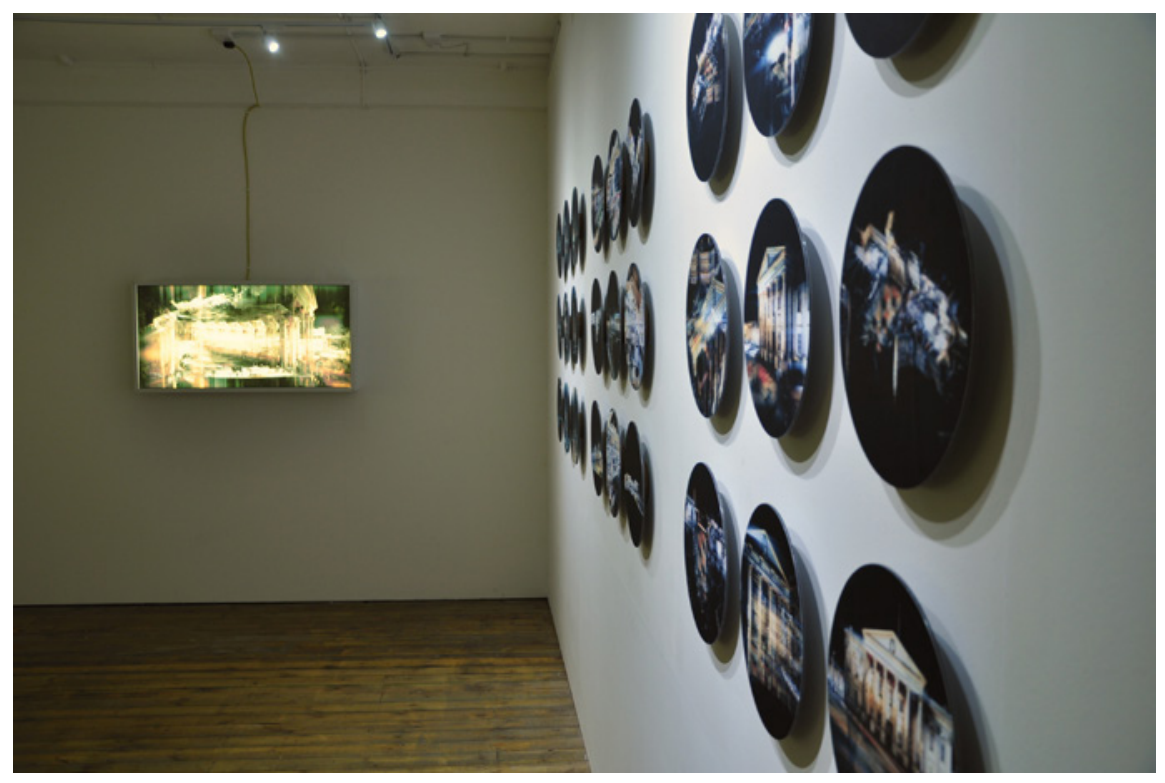

Synthetic Spaces

31 January- 4 March 2019

Professor Nic Clear and Hyun Jun Park 
The fact that none of the scan data existed at the time the exhibition was initiated meant that the task of creating the works was principally based on what we felt was required for the exhibition itself. An initial layout was developed using one space of the gallery as the projection area and the other space to install the graphic pieces. We initially used conventional photography to develop an overall idea of what we wanted in the show, and then created a timeline of what we would have to do to produce those works in time for the exhibition. The design of the work considered the access we had to each site as well as the time it would take to capture and process the scan data, which would determine the final resolution of the works. Once the parameters of what was to be exhibited were fixed, the production of the work was quite systematic. The scans were undertaken, test images were produced to develop the exact look and feel of the work, including the production of a series of composite images for each site that were created to produce clear ideas for the animation sequences. Once complete the stills and animated sequences were rendered off, the videos were edited and graded and a soundtrack for the sequence was composed which reinforced the themes of how our perceptions of spaces are composed of shifting layers which seem to operate through highly subjective conceptions of time.

One of the animation tests developed from footage of the interior of Queensgate Market was so successful that it was decided that this could function as a stand-alone piece and the only decision that had to be made was exactly how to display it. The final layout and organisation of the show was decided only when we came to install the works prior to the opening, with several works not selected, though worked up version of those pieces have been used in subsequent exhibitions.

During the exhibition we submitted some of the graphic work to the CSESC 5+2 Biennial Exhibition of Environmental Art and Design in Yunnan Arts University, these were accepted for the exhibition and won the Excellent Project Award in the Comprehensive Design Award Section. A visitor to the Market Gallery from the Auckland University of Technology in New Zealand, who we were due to visit as part of a research exchange in June 2019, asked us if we would be interested in putting the show on as part of our trip, and we were obviously delighted. The show had to be slightly modified and was accompanied by a public lecture and scanning workshop. We also decided to make additional works that gave more general information about Huddersfield's location and contextualising the project. 
Hyun Jun and I were also due to curate a show in October 2019 as part of the Shanghai Urban Space Art Season where we had been given quite a large space. We had already agreed a group show titled 'Sensorium', but redesigned the space to incorporate a reworked version of Synthetic Spaces. In both Auckland and Shanghai, rather than the immersive video installation, the films that we had made for the original show were exhibited as three video triptychs.

The work produced for the Synthetic Spaces exhibition has also been the catalyst for a number of lecture presentations and written works, including a keynote lecture at Leeds School of Architecture's symposium on film and architecture 'Scene and Sequence: On Cinematic Urbanisms', a version of which was also presented at a symposium in Huddersfield on perspective. We also submitted a paper to the annual RIBA Research Matters Conference at the University of Nottingham alongside the public lecture in Auckland. Most recently a more formal version of these ideas has been accepted for the IASTE conference in September 2020. Four of the composite images have also been on display in Huddersfield town centre.

In just under 12 months an essentially impromptu body of work has been the subject of four exhibitions (three of which were international), four lectures with another refereed conference presentations and paper to come.

\section{Exhibitions: a conclusion}

Exhibitions can often feel intimidating as there is pressure for many practitioners to think that such a context should only be used for 'finished' work. For 'professional' artists and designers the necessity of making work for commercial purposes does mean that the exhibition can potentially make or break implications. As part of an academic context this imperative is less pressing; the nature of research encourages speculation and allows for mistakes and reversals in a way that work produced in a commercial context may not. Also, as educators if we are encouraging our students to be ambitious and take risks then we have a duty to be ambitious and take risks as well. Finally, as part of a University whose fortunes are bound up with the town in which it is located, the School of Art Design and Architecture has a further incentive to contribute to the cultural life and identity of Huddersfield and be an integral part of its future. 
1 Crow, T (1987): Painters and Public Life

in 18th Century Paris, New Haven - London:

Yale University Press.

${ }^{2}$ Clark, TJ. (1986) Image of the People:

Gustave Courbet and the 1848 Revolution.

London: Thames and Hudson.

${ }^{3}$ O'Doherty, B (1982) Inside the White Cube: The Ideology of the Gallery Space, Santa Monica -

San Francisco: The Lapis Press

${ }^{4}$ Hickey, D. (2009) The Invisible Dragon:

Essays on Beauty. Chicago: University of

Chicago Press.

5 Day, J (2007) Hubrispace: Personal Museums and the Architectures of Self-Deification,

in Davis, M., Bertrand Monk, D. 'Evil Paradises:

Dreamworlds of Neoliberalism', London-New

York: The Free Press.
${ }^{6}$ Crimp, D. (1993) On the Museum's Ruins, Cambridge-London: MIT Press.

7 Canjeurs, P., Debord, G. (1960) Preliminaries Toward Defining a Unitary Revolutionary Program, in Knabb, K. (ed) (1981) 'Situationist International Anthology', San Francisco: Bureau of Public Secrets.

8 Willats, S. (1986) Audience and Intervention, London: Coracle.

${ }^{9}$ Lefebvre, L. (1991), The Production of Space, (trans Nicholson-Smith, D.), Oxford: Basil Blackwell. 


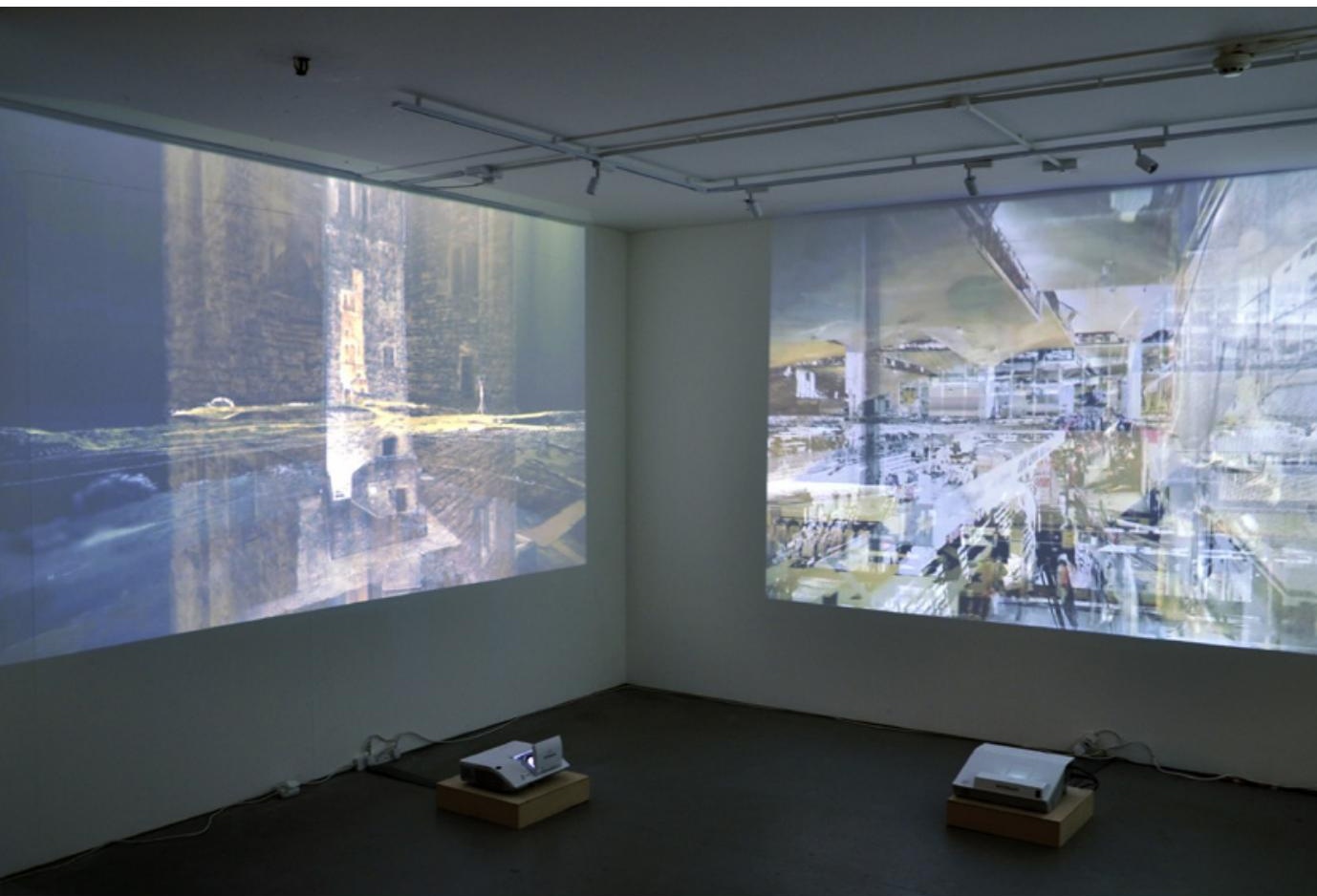

Synthetic Spaces

31 January- 4 March 2019

Professor Nic Clear and Hyun Jun Park 


\section{Conclusion}


The chapters of this book reflect on the exhibitions that took place in the first year of the Market Gallery Temporary Contemporary exhibition programme. Using the case studies of the individual exhibitions, and reflecting on the wider initiative, the contributors have argued that art, design and architecture can play a unique role in presenting new ways of seeing and understanding place and local contexts. The contributors have considered how cities and towns can be conceptualised as 'cellular organisms' in which exhibitions can intervene in a thriving 'mixed cultural ecology' and where artists can investigate the ecology itself. Moreover, this book has been an opportunity to argue for attention to be made to the contexts and apparatuses that facilitate and affect viewing and representations of people's lives through visual culture. It has also continuously reflected on the role of exhibitions for practitioners and educators in art, design and architecture. The final thoughts of this book relate to how Temporary Contemporary continues to iterate in Huddersfield, supporting the conditions for creative and cultural activity, and creating democratic cultural activity produced by and for 'non-exclusive audiences.' ${ }^{\text {. }}$

The organic development of Temporary Contemporary as an initiative that embraces a mixed cultural ecology is now manifest in the expansion of the project from underneath the mushroom columns of Queensgate Market to other spaces in Huddersfield. This includes the Piazza: a 50-year old shopping centre opposite the market and adjacent to Huddersfield Art Gallery and Library. The empty shop units within the Piazza are now being used by a broad range of arts and cultural producers, services and activities. A sense of collective ownership over the means of arts and cultural production is reflected in the curation of a shared programme of activities promoted through the Temporary Contemporary platform. At the same time, each collaborator within the initiative retains their own identity and visibility, using marketing and promotion platforms relevant to their respective projects. This willingness to participate in developing a broad portfolio of cultural activities shows a receptivity to fostering interrelations between different groups and interests, often with the aim of facilitating further opportunities for self-actuated and collective change.

Being able to share ownership of Temporary Contemporary as a mixed cultural ecology reflects the ethos of ongoing social relations of participation and exchange. Kirklees Council has indicated that Temporary Contemporary's model of working in partnership has contributed to plans for a 'cultural heart' in the town, geographically and ethically rooted in Temporary Contemporary's activities to date. In impacting the thinking of the council, the public and provide a unique space for artists and cultural producers to share their work has created change 
that goes far beyond the usual temporality of exhibition production, and its insights will continue to be refracted and shared. The other main beneficiaries are the creatives and arts organisations who have come together at the 'happenings' accompanying the exhibition programme, as well as the organisations currently occupying the Piazza. In a region where creatives are spread across a large semi-rural geography with fewer opportunities to congregate, this is incredibly valuable.

\section{'Non-exclusive Audiences'}

The artist Thomas Hirschhorn is known for producing temporary structures to reconfigure notions of 'public space' in and through the production of distinct sculptural forms. His 'direct sculptures', 'altars', 'kiosks' and 'monuments' turn public spaces into sculptural interventions. These structures emphasise a field of possibilities and redistributed power relations. For example, Hirschhorn's reconsideration of the monument as a platform where site and audience are given form through installations, collaborative events and activities, produces a different kind of space situated outside of the museum or gallery environment. ${ }^{2}$ This is part of Hirschhorn's underlying motivations to bridge links between art and philosophy, and in particular, to bring a force-field of interactions into play by staging interfaces and interferences between different sources of influence.

One of his more recent monument projects, supported by the Dia Art Foundation, was located in a public housing district of the Bronx, New York City, USA, entitled Forest Houses. ${ }^{3}$ As a dedication to the Italian Marxist Antonio Gramsci, whose writings on hegemony have come to play a significant role in theorisations of popular culture, the project allowed for a public to engage in the ideas of the 'organic intellectual', a term used by Gramsci in his Prison Notebooks. ${ }^{4}$ This term orchestrates around the differentiation between 'intellectuals' as social agents and the functionary technical, administrative and bureaucratic capacities of specialists, the organisers of industry. Whereas the 'traditional intellectual' is focused on received histories of the past, and sees their position in culture as autonomous from the economic structure of society, the 'organic intellectual' is caught up in a struggle for hegemony - the manufacturing of consent through emergent subaltern groups and new identity formations. In his respect, Gramsci's ideal is a confluence between high and popular culture. 
Hirschhorn's commitment to working with what he calls 'nonexclusive audiences' stems from his consideration of the role of art in culture. Spectrum of Evaluation, first formulated in 2008, includes a diagram which situates potential power relations between different audiences, artists and institutions within a field of possibilities. The spectrum presents the art world's professions - 'traditional intellectuals' if you like - the 'institution-director, art critic, curator, gallerist, art historian, collector, art-professor'. ${ }^{6}$ The artist is a second dynamic, evaluated by the work they produce, but also by the 'experts' of the art world. But, coming out of the work is a third dynamic, which Hirschhorn names 'the other', who has the potential to send back evaluation to the artist. The 'non-exclusive audience' is, for Hirschhorn, made up of 'primary spectators' - or 'organic intellectuals' - creating a set of viewpoints or positions, which the curator Yasmil Raymond indicates is 'produced from the ideology of assessment and appraisal that conditions the development of art from a subaltern group, formed by individuals excluded from the art world. This does not exclude artists, academics, professionals, but qualifies it'. 7 The exchange between the 'subaltern group' and the field of 'art professionals' is enabled by Hirschhorn's projects. As he indicates in his discussion of the Spectrum of Evaluation:

I want to exclude nothing. But as an artist, I think I must determine the dynamic, the line of force, or the DIRECTION OF IMPACT. ${ }^{8}$

In this respect, we can learn much from Hirschhorn's projects, especially in relation to what artistic and cultural research can do when it moves beyond the walls of the gallery environment to be formed and informed by non-exclusive participants.

The collaborative focus of Temporary Contemporary has led to an organic expansion of the project with contributions from a range of arts and cultural practitioners and organisations. For example, in 2019, the Piazza shopping centre opened some of its vacant units for a range of activities, including artisan pop ups, exhibitions by emerging and mid-career artists and cultural practitioners, and students seeking to develop opportunities to design and curate in the public realm. Temporary Contemporary's monthly late night 'happenings' have expanded into this wider network of cultural activity with a shared programme of events. In this respect, Temporary Contemporary has evolved as a model of cultural activity that continues to iterate in the town. 


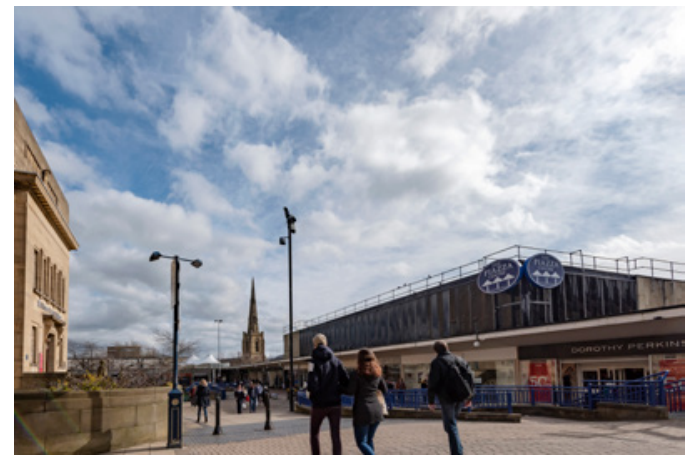

Exterior of the Piazza Shopping Centre.

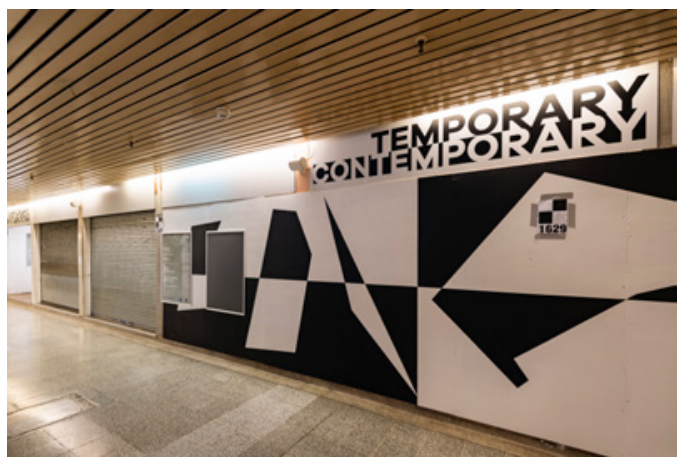

Exterior of the Market Gallery within Queensgate Market.

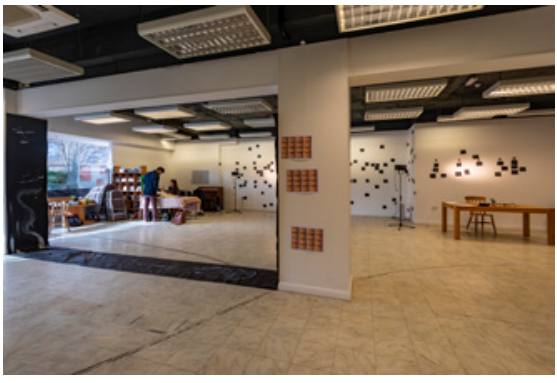

ame, Piazza Shopping Centre.

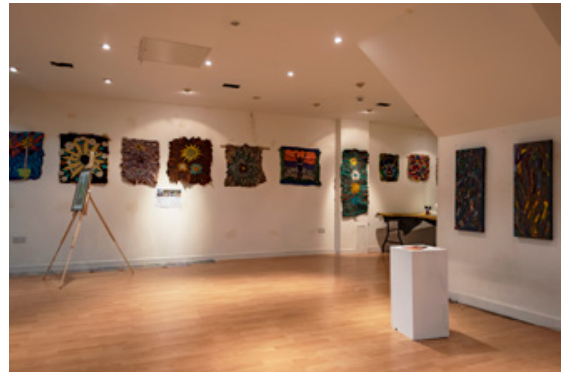

CollaborARTi, Piazza Shopping Centre. 


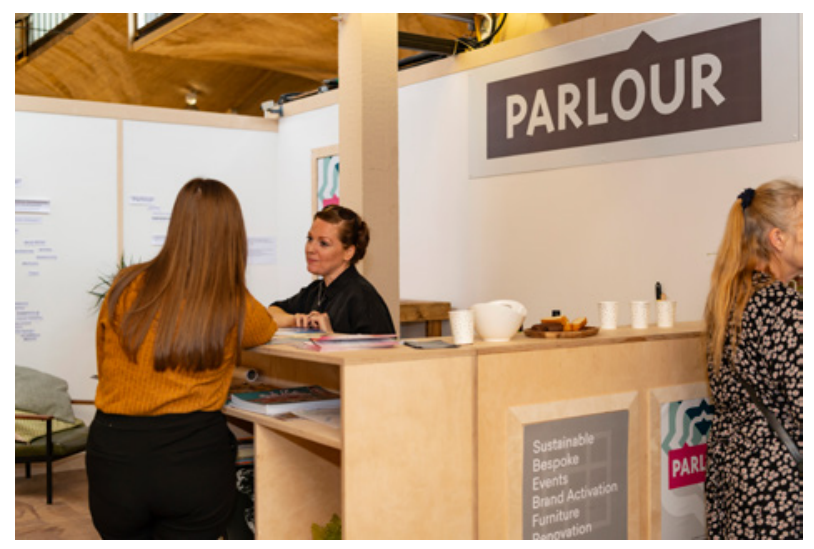

Parlour by Parley space. Image courtesy of Victoria McCorkell (pictured) and Laura Mateescu.

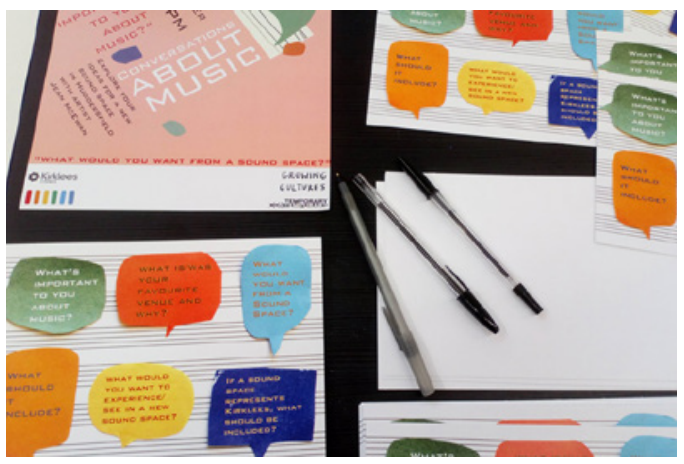

Image courtesy of Jean McEwan.

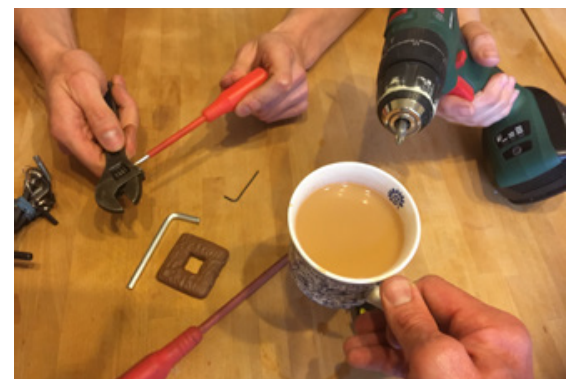

Image courtesy of Huddersfield Repair Café. 
But this activity is only made possible by the collaborators involved. It is with their contributions to this ecological network that the real potential of Temporary Contemporary becomes visible. These collaborators include: AME, Chol Theatre, CollaborARTi, Children's Art School, Culture Declares Emergency, Dark Horse, HOOT, Huddersfield Repair Café, Jean McEwan, Magic Rock, KWAS, Victoria McCorkell (Parlour by Parley), S2R (Support to Recovery), West Yorkshire Print Workshop and WOVEN in Kirklees.

Temporary Contemporary has opened up a force-field of possibilities for thinking about what might constitute a future cultural ecology in Huddersfield and what new democracies of experience may be generated from out of this network. This may include modes and avenues of access to culture in all of its forms. This pluralising potential is at the heart of public access to and engagement with Temporary Contemporary. Hirschhorn's ambitions to bridge links between traditional and organic intellectuals, between art professions and non exclusive audiences, tells us something about the necessity to withdraw from the dangerous regularity of situating culture over and above the cultural processes of production. Creative actions have the potential to take shape in the world to be shared with others.

One of the next challenges for the Temporary Contemporary collaborators is to speculate on the creative and cultural futures for Huddersfield and towns like it in the wake of the global COVID19 pandemic, as well as the role that art and culture should occupy in dismantling the systems of privilege and racism brought into the spotlight by the murder of George Floyd in Minneapolis, Minnesota, USA in May 2020, leading to widespread protests.

In 2020, Temporary Contemporary will host an event to celebrate the working practices and projects developed through the initiative and to explore with others how we might collectively evolve and grow. This also includes the launch of an indoor garden in the market, a symbol perhaps for a vibrant, living ecology connected in a mycelium network, where new spores of creative activity have the potential to pop up at any moment. We will continue to address how creative energies can transfer, entangle and produce their own unique forms by having access to the shared nutrients generated by this cultural ecology. 
1 This is a term deployed by the artist

Thomas Hirschhorn.

${ }^{2}$ See in particular, Hirschhorn, Lee and Foster (eds.). (2013) Critical Laboratory: The Writings of Thomas Hirschhorn. Cambridge, Massachusetts: MIT Press.

3 Buchloh, Brown, Kivland and Hoban (2015)

GramsciMonument. Dia Art Foundation and

London: Koenig Books.

4 Gramsci, A. (1998) Selections from the Prison

Notebooks. London: Lawrence and Wishart Ltd.

5 Urbinati, N., (2015) 'Know Yourself: Antonio

Gramsci and Liberation Today' in Buchloh,

Brown, Kivland and Hoban (2015) Gramsci

Monument. Dia Art Foundation and London:

Koenig Books.
6 Yasmil Raymond quoting Hirschhorn,

'Desegregating the Experience of Art: A User's Guide to Gramsci Monument', 16. Available at: www.sommerakademie.zpk.org/fileadmin/user upload/2016/PDFs/Reader_Yasmil_Raymond/ Raymond_Gramsci_Book_FINAL.pdf [accessed 7 February 2020]

7 ibid

8 Hirschhorn, T. (2009) Spectrum of Evaluation, Critical Laboratory, pp.80-81.

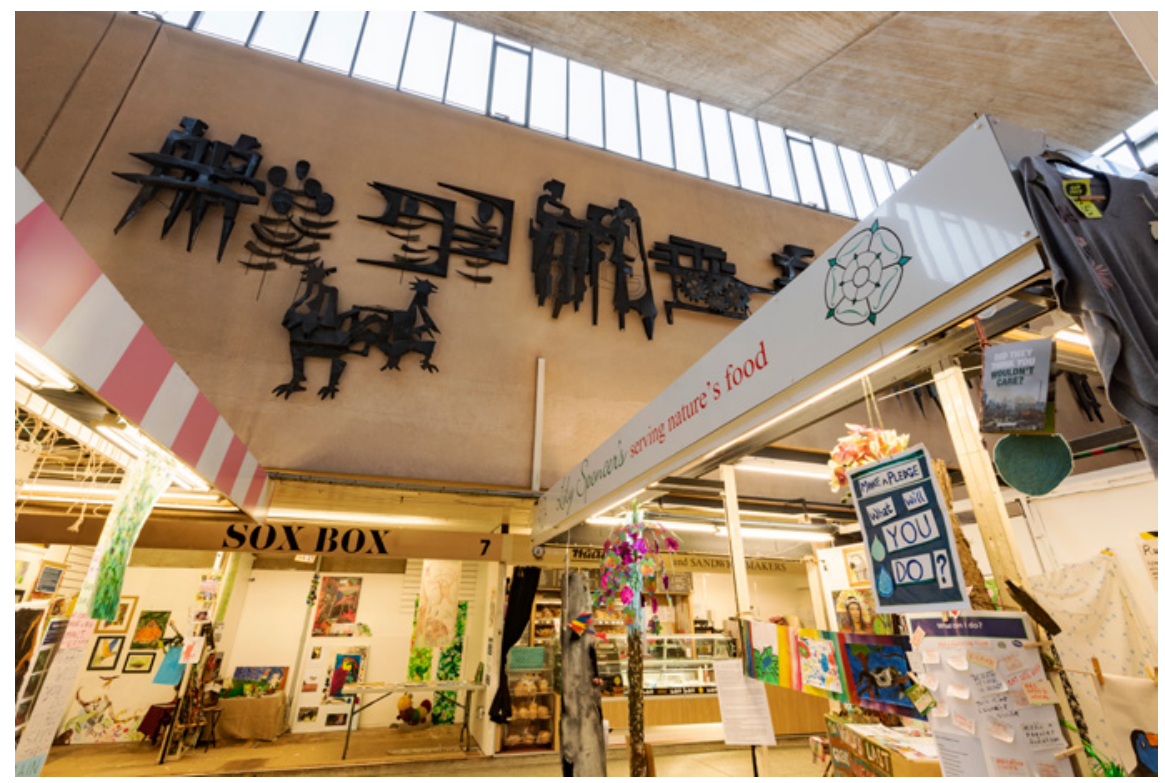

Queensgate Indoor Market, Huddersfield. Laura Mateescu, 2020. 

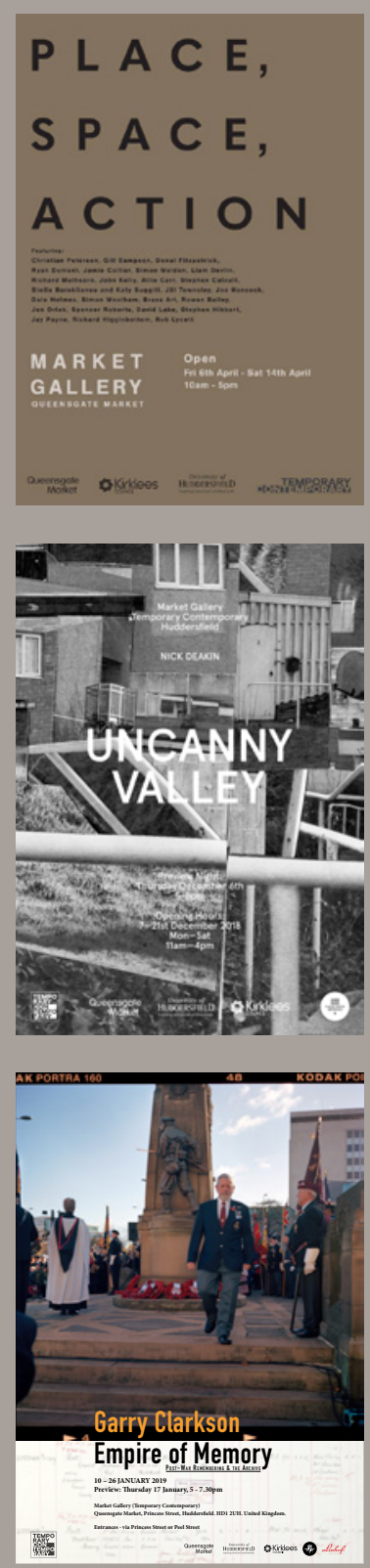
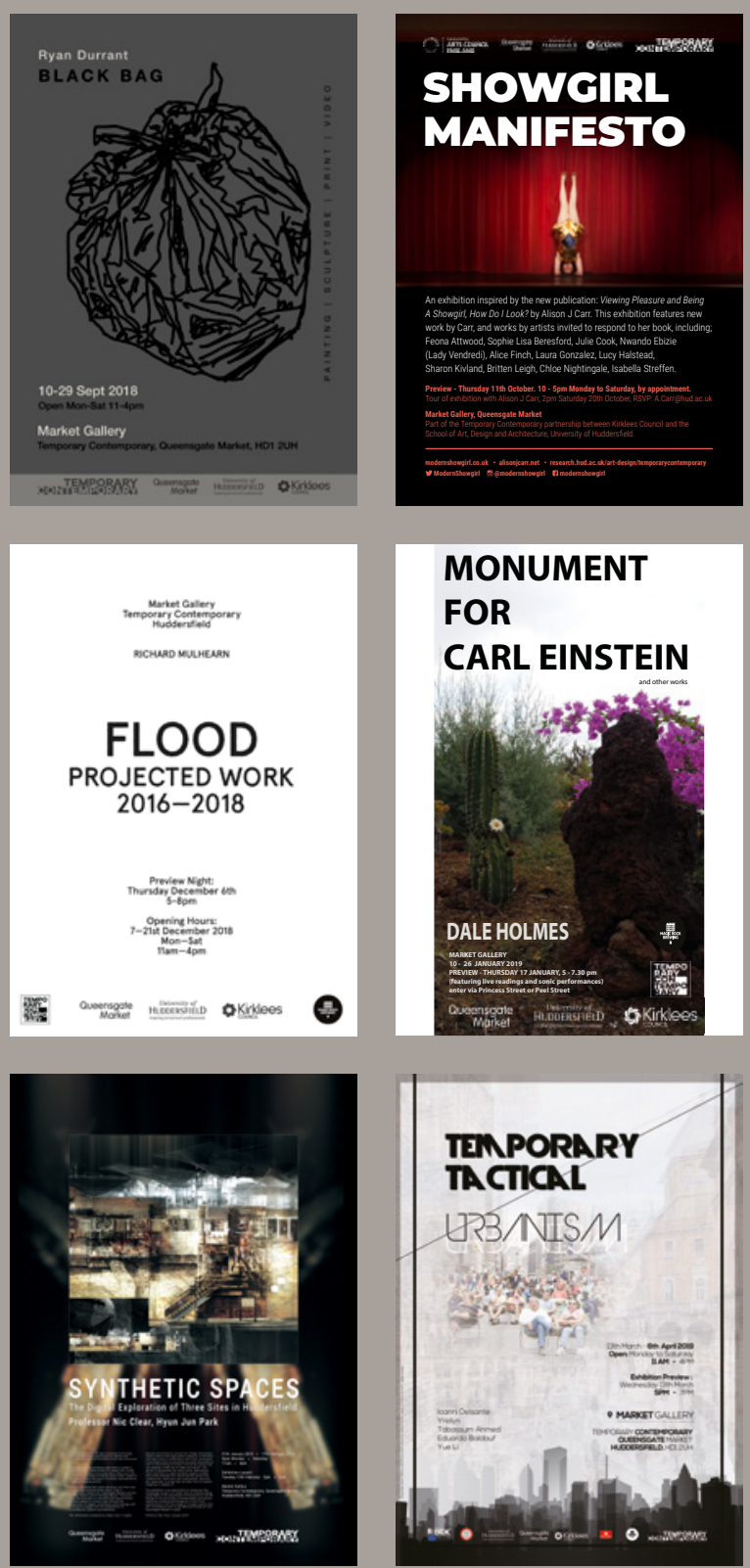

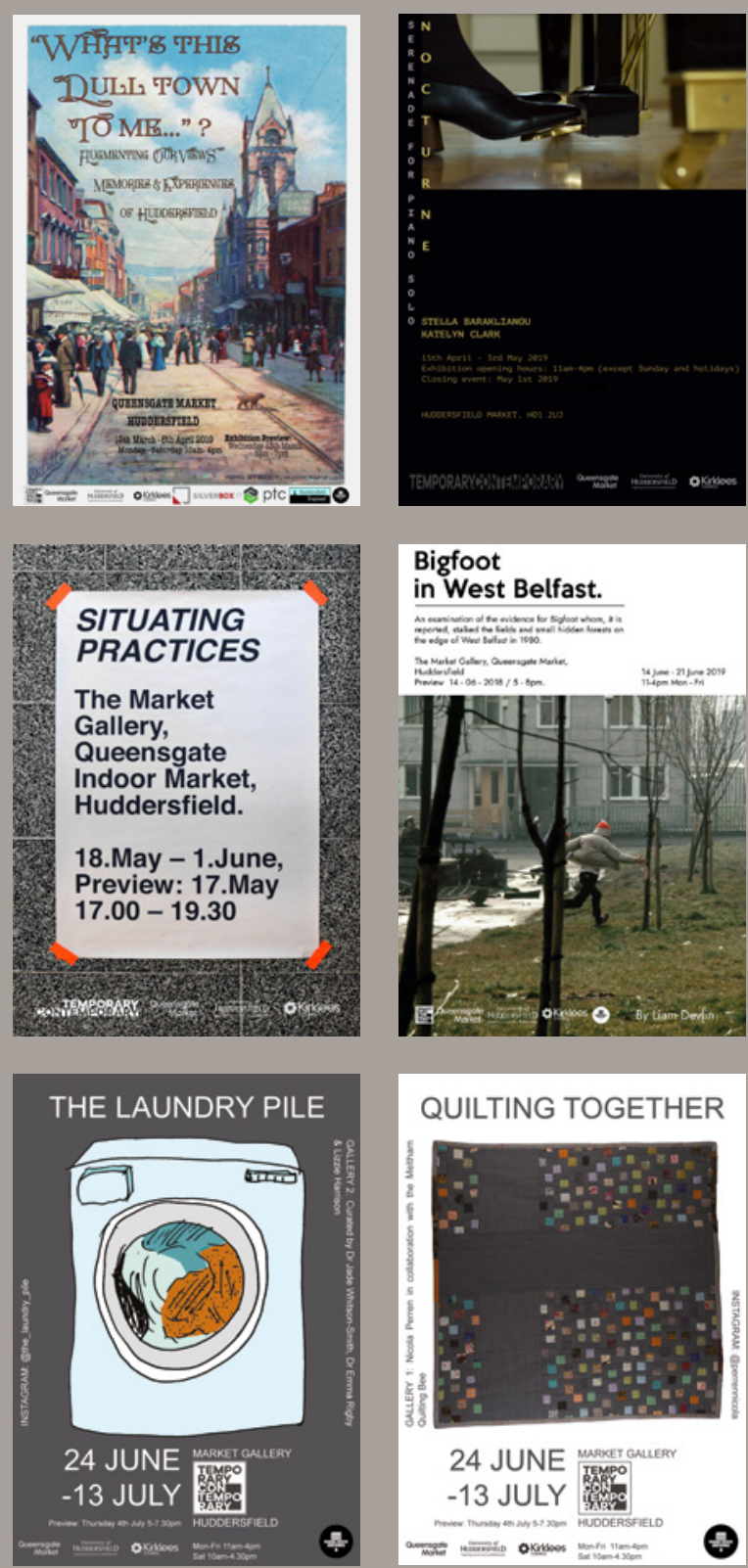
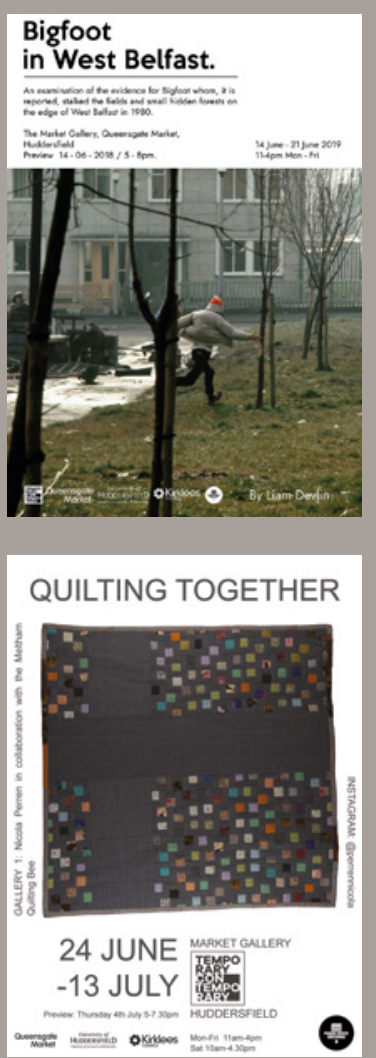

㩆

MAKING MATERIAL MEMORIES

CHARLOTTE GOLDTHORPE

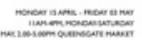
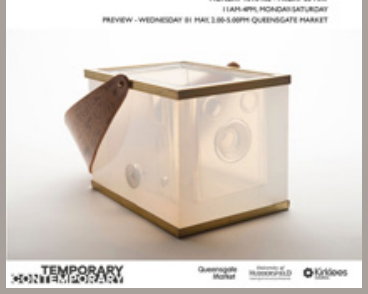

Photography \& Lived Experience.

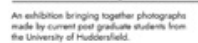

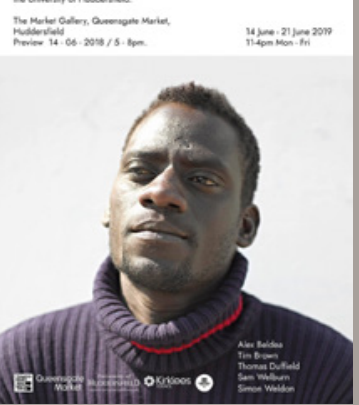

Temporary

Contemporary

Posters, 2018 - 2019 
Acknowledgements 
The School of Art, Design and Architecture, University of Huddersfield, on behalf of Temporary Contemporary, would like to thank all of the partners, advisors, stakeholders, artists, participants and audiences who have been involved in the first year of the initiative and are working with us into the next phase.

The Temporary Contemporary partners extend their grateful thanks to Queensgate Market, the Piazza Shopping Centre, and the retailers that occupy these locations and work alongside us, for their continued support.

\section{Core Partner}

Kirklees Council

Chief Executive Jacqui Gedman

Strategic Lead for Cultural Development Kath Davies

Chris Cotton Strategic Lead for Markets

Cultural Development Officer Robin Widdowson

Cultural Project Officer Anne Postlethwaite

\section{Advisors}

\section{Helen Pheby}

Helen Pheby PhD, Head of Curatorial Programme at Yorkshire Sculpture Park. Dr Pheby was Vice Chair of the Civic art gallery and theatre in Barnsley. She is currently the Chair of UP Projects, London; curatorial advisor to ArtRole in Iraqi Kurdistan and NIROX in South Africa; Cultural Fellow of York St John University and was an advisor to the Arts Council Collection Acquisition Committee in 2016-17.

\section{Derek Horton}

Derek Horton, artist, writer and teacher. Following an early career in school and community-based arts education and social activism, he established the innovative Contemporary Creative Practice BA course at Leeds Metropolitan University where he was Director of Research in The Leeds School of Contemporary Art and Graphic Design until 2008. He was subsequently Visiting Professor at The School of Art, Birmingham City University.

Natalie Walton and Alison Mclntyre

Natalie Walton and Alison Mclntyre, Directors of HATCH. Walton is an arts education project 
manager and consultant with over 15 years' experience of working with museums, galleries, festivals, touring exhibitions and national and local partnership programmes. Mclntyre is an artist and engagement specialist with over 15 years' experience of making and collaborating with communities on exhibitions, at festivals and with museums and galleries.

\section{Natalie Rudd}

Natalie Rudd, Senior Curator at Arts Council Collection, based at Longside Gallery in Yorkshire. Rudd was previously curator at University of Manchester and before that at Tate Liverpool. Her recent publications include: Paul de Monchaux: A Monograph (2019), Kaleidoscope: Colour \& Sequence in 1960s British Art (2017) and Tess Jaray (2017).

\section{Collaborating Organisations}

\section{PARLEY}

Huddersfield Repair Café

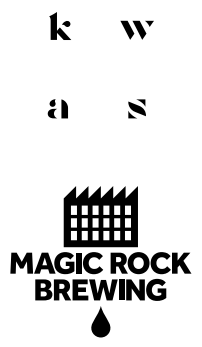

Parley create spaces, projects and events to encourage arts and cultural conversation, engagement, learning and development, including the Parlour space in Queensgate Market. Parley is led by Victoria McCorkell. www.byparley.co.uk

Huddersfield Repair Café convenes one Saturday per month. Volunteers fix electrical goods, computers, kids' toys, bikes and wooden items. The café is a sociable way to help reduce the amount of stuff we throw away, meet people, learn new skills, save money and reduce the climate impact of new stuff we all buy.

KWAS is an independent vegan wine bar and shop based in Huddersfield. The shop offers an adaptable art space, with regular gigs and tasting events.

Magic Rock Brewing is an English brewery established in Huddersfield in 2011. It now distributes its quality craft beer to over 25 countries around the world. 


\section{Piazza Collaborators}

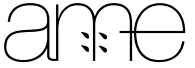

The Children's Art School

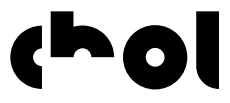

\section{CollaborARTi}
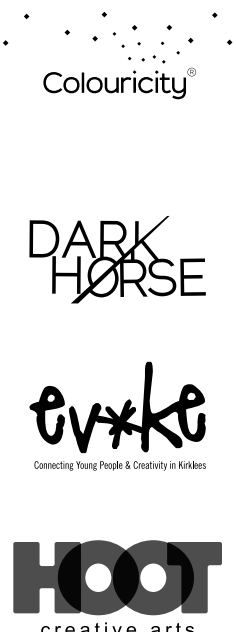

ame is an international creative hub that supports experimental music and art. They commission works from both emerging and established performers, composers and artists, frequently providing concerts, installations, educational projects and artists-in-residence programmes in Dai 大 Hall.

The Children's Art School is a charitable organisation which is committed to promoting the value of art education for children and young people.

Chol Theatre brings live story making experiences to people in their everyday places and spaces. Chol believe in the power of creating and sharing stories to make a difference in people's lives.

CollaborARTi offers artists a platform to progress through exhibitions, installations, interactive artist demonstrations, workshops and classes.

Colouricity are an organisation that consult on the use of colour to improve our mood, emotions, relationships, environment, general wellbeing and psyche through exhibitions, products and colour therapy sessions.

Dark Horse's mission is for people with learning disabilities to be given the equality of opportunity to train and work in the performing arts.

EvoKe is Kirklees' Cultural Education Partnership, providing opportunities for children and young people to benefit from the amazing creative and cultural offer across the borough.

The mission of Hoot is to normalise mental health, support personal growth and promote social change. It does this by creating opportunities for participants to work with professional artists, exploring identity, emotional wellbeing, purpose and meaning in a safe, expressive and welcoming environment. 


\section{wate \\ Kirklees Libraries.}

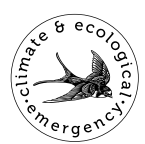

WYPW
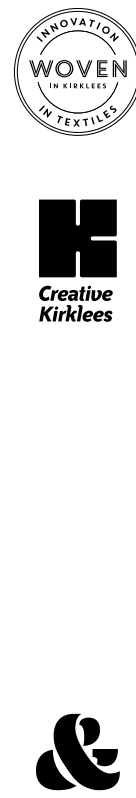

Huddersfield Library shares a venue with Huddersfield Art Gallery overlooking the Piazza Shopping Centre. They hold events for children, young people and their families.

Kirklees Culture Declares Emergency is a community group declaring a Climate and Ecological Emergency and taking action in response to it. They are aligned with the world wide movement Culture Declares Emergency, a growing community of creative practitioners and organisations concerned about the dire state of our living planet.

Established in 1984, West Yorkshire Print Workshop is the largest open access printmaking facility in Yorkshire. They support, nurture and promote creative talent through the joy of making prints.

Woven in Kirklees Textile Festival is a biennial festival celebrating the heritage and history of the textiles industry in the region alongside contemporary practice.

Creative Kirklees is an online guide to arts and creative events, news and opportunities in Kirklees. It is managed by the Creative Development Team in Kirklees Council.

\section{Photographer}

Extra special thanks to Laura Mateescu for photographing many of the Temporary Contemporary market gallery exhibitions and other events.

\section{Design}

A.N.D. Studio is a collaborative branding and graphic design studio based in Huddersfield. Founded by Aidan Nolan in 2010. 
